Aus der Klinik für Hämatologie und Medizinische Onkologie (Prof. Dr. med. L. Trümper)

der Medizinischen Fakultät der Universität Göttingen

\title{
Analyse von \\ Interleukin-10-Genvariationen bei \\ diffus großzelligen B-Zell-Lymphomen
}

\author{
INAUGURAL-DISSERTATION \\ zur Erlangung des Doktorgrades \\ der Medizinischen Fakultät der \\ Georg-August-Universität zu Göttingen
}

\author{
vorgelegt von \\ Julia Stächele \\ aus \\ Oberkirch
}

Göttingen 2015 
Dekan:

Referent:

Ko-Referent:

Datum der mündlichen Prüfung: $\quad$ 22. September 2016
Prof. Dr. Heyo K. Kroemer

Prof. Dr. Dieter Kube

Prof. Dr. Tim Beißbarth 
Hiermit erkläre ich, die Dissertation mit dem Titel "Analyse von Interleukin-10-Genvariationen bei diffus großzelligen BZell-Lymphomen" eigenständig angefertigt und keine anderen als die von mir angegebenen Quellen und Hilfsmittel verwendet zu haben.

Göttingen, den 11. Dezember $2015 \quad$ Julia Stächele 


\section{Inhaltsverzeichnis}

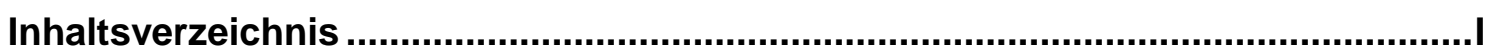

Abbildungsverzeichnis ...................................................................................

Tabellenverzeichnis ............................................................................................ IV

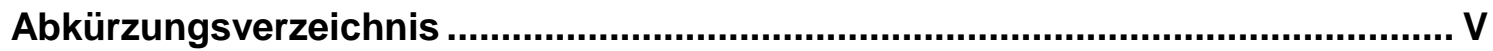

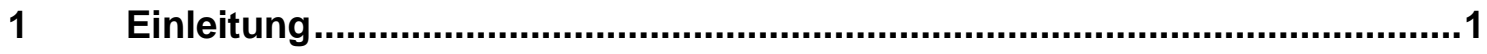

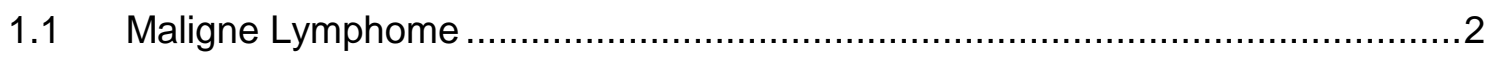

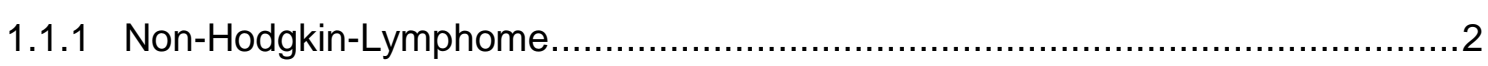

1.2 Das Zytokin Interleukin-10 .............................................................. 4

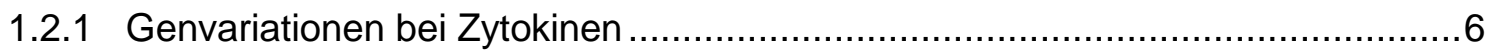

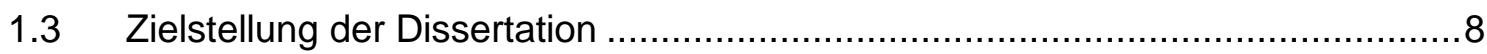

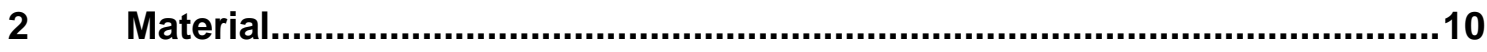

$2.1 \quad$ Biologisches Material........................................................................... 10

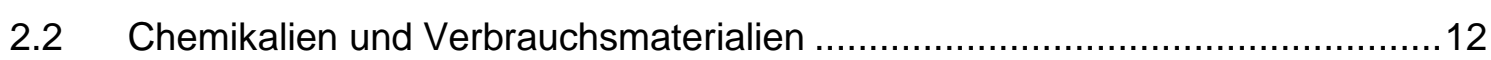

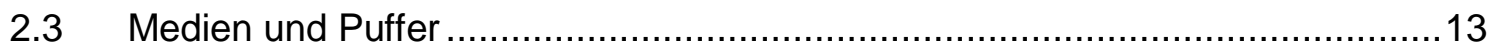

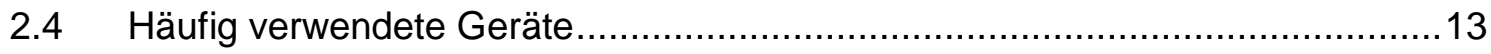

2.5 Gebrauchsfertige Reaktionssysteme ..................................................... 14

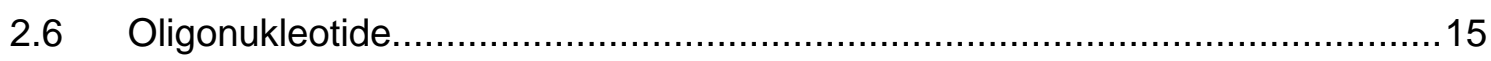

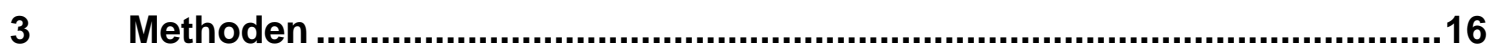

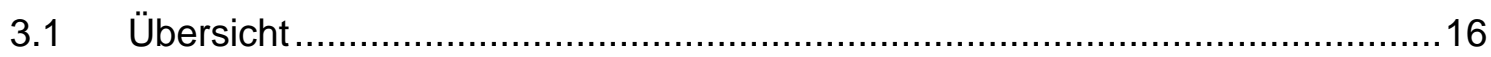

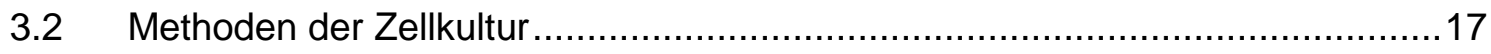

3.2.1 Auftauen und Kryokonservierung der Zellen .............................................. 17

3.2.2 Kultivierung der Zellen.................................................................. 17

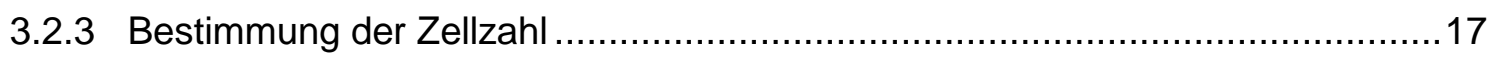

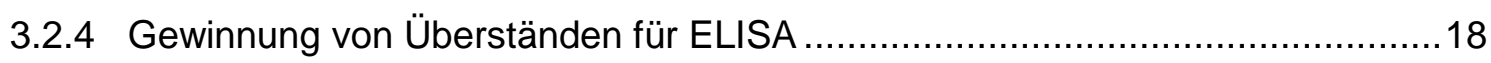

3.2.5 Vorbereitung der Zellen für die Isolation von RNA .................................... 18

3.3 Molekularbiologische Methoden ............................................................

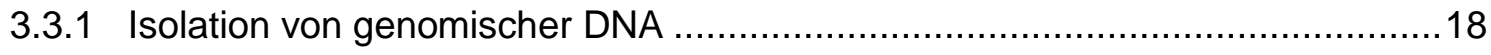

3.3.2 Isolation von RNA und reverse Transkription........................................... 19

3.3.3 Konzentrationsbestimmung von Nukleinsäuren ........................................ 19

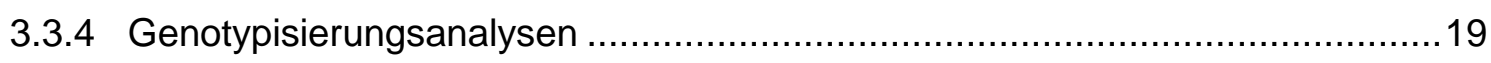

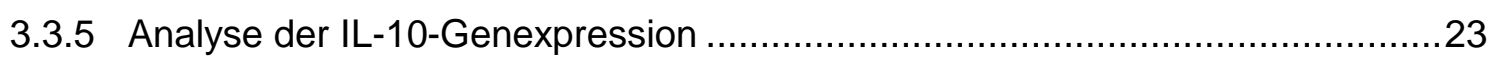

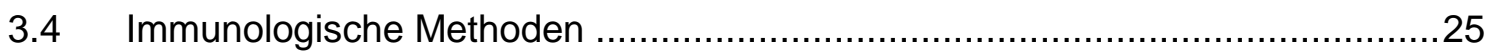

3.4.1 Enzyme-linked immunosorbent assay (ELISA) .........................................25 


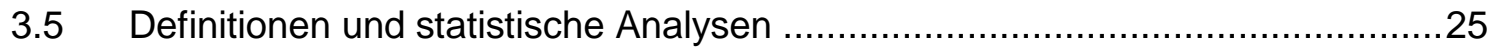

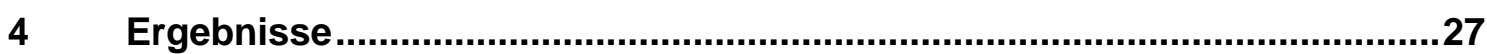

4.1 Identifizierung distaler Genvariationen des IL-10-Genlokus ...........................27

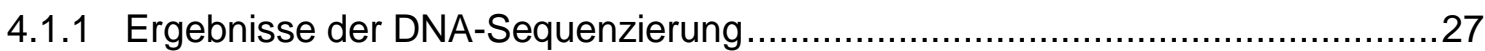

4.1.2 Etablierung eines Multiplex Assays zwecks Genotypisierung von IL-10-

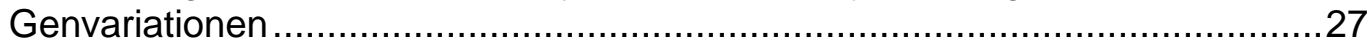

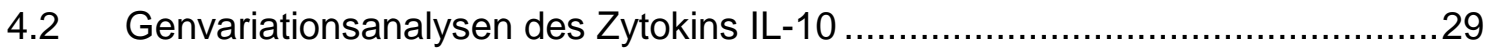

4.2.1 Überblick über die durchgeführten Genvariationsanalysen ............................29

4.2.2 Analyse von IL-10-Genvariationen bei DLBCL-Patienten .............................29

4.2.3 Analyse von IL-10-Genvariationen bei gesunden Kontrollprobanden................33

4.2.4 Vergleich der Genotypenverteilung bei DLBCL-Patienten und gesunden

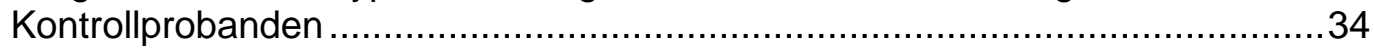

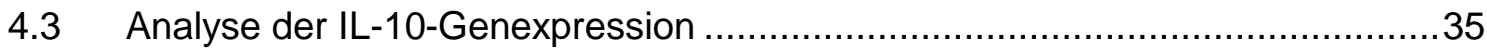

4.3.1 Nachweis interindividueller Unterschiede bei der IL-10-Sekretion mittels

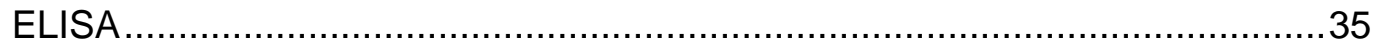

4.3.2 Nachweis interindividueller Unterschiede der IL-10-Transkriptmenge mittels

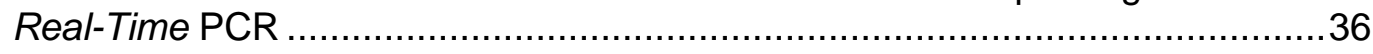

4.3.3 Bestimmung der IL-10-Transkriptmenge mittels Analyse von Restriktionsfragmentlängenpolymorphismen .................................................37

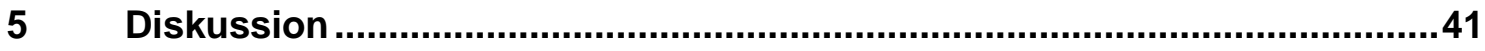

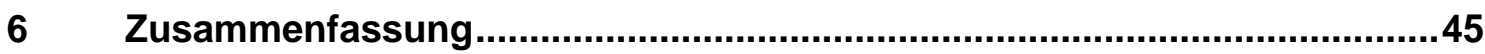

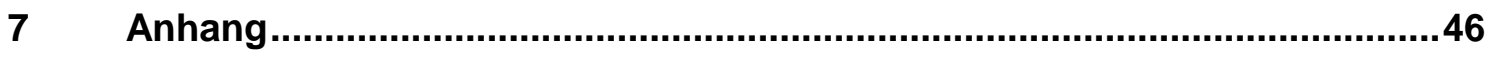

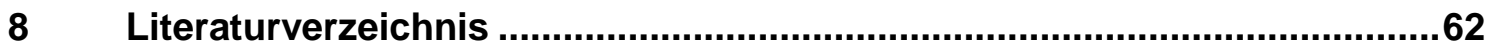




\section{Abbildungsverzeichnis}

Abbildung 1: Schematische Darstellung des IL-10-Genlokus .................................

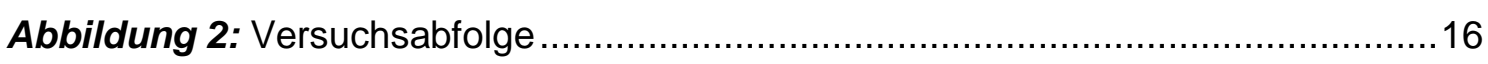

Abbildung 3: Schematische Darstellung der SNaPshot-Analyse...............................22

Abbildung 4: Elektropherogramm der Sequenzierungsreaktion eines Fragments der distalen 5'-untranslatierten Region des IL-10-Gens am Beispiel des SNPs IL-10-11.668GA der LCL-Zelle 8/2

Abbildung 5: Elektropherogramm eines Multiplex Assays mit simultaner Analyse mehrerer SNPs am Beispiel der LCL-Zelle 16 des internationalen HapMapProjektes.

Abbildung 6: Elektropherogramm eines Multiplex Assays mit simultaner Analyse mehrerer SNPs am Beispiel der LCL-Zelle 15 des internationalen HapMapProjektes.

Abbildung 7: Schematische Darstellung der Postition der Genvariation IL$10_{+4.259 \mathrm{AG}}$ sowie der Aufspaltungsmotive nach RestriktionsendonukleaseVerdau mit Fnu4HI. 38

Abbildung 8: Restriktionsendonuklease-Verdau mit Fnu4HI 39

Abbildung 9: Elektropherogramm der Analyse von Restriktionsfragmentlängenpolymorphismen. 


\section{Tabellenverzeichnis}

Tabelle 1: Klinische Charakteristika, Histologien und Therapieschemata von DLBCL-Patienten der NHL-B1-/B2-Studien.

Tabelle 2: Verwendete Chemikalien ........................................................................... 12

Tabelle 3: Verwendete Medien und Puffer ......................................................... 13

Tabelle 4: Verwendete Geräte ................................................................... 13

Tabelle 5: Gebrauchsfertige Reaktionssysteme............................................... 14

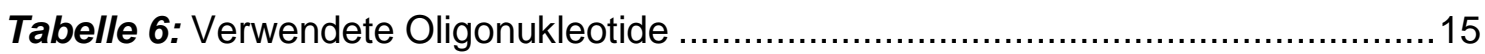

Tabelle 7: Analysierte Genvariationen bei 594 DLBCL-Patienten, Verteilung der Genotypen sowie Hardy-Weinberg-Gleichgewicht .30

Tabelle 8: Univariate Analyse der IL-10-Genvariationen bezüglich des Gesamtüberlebens und ereignisfreien Überlebens von DLBCL-Patienten 31

Tabelle 9: Multivariate Analyse der IL-10-Genvariationen bezüglich des Gesamtüberlebens und ereignisfreien Überlebens von DLBCL-Patienten

Tabelle 10: Analysierte Genvariationen bei 135 gesunden Kontrollprobanden sowie Verteilung der Genotypen ....

Tabelle 11: Genotypenverteilung bei 594 DLBCL-Patienten und 135 gesunden Kontrollprobanden.

Tabelle 12: IL-10-Sekretion von LCL-Zellen der eigenen Arbeitsgruppe .35

Tabelle 13: IL-10-Sekretion von LCL-Zellen des internationalen HapMap-Projektes...36

Tabelle 14: Bestimmung der IL-10-Transkriptmenge mitttels Real-Time PCR .36 


\section{Abkürzungsverzeichnis}

\begin{tabular}{|c|c|}
\hline cDNA & engl. complementary DNA \\
\hline CHOEP & $\begin{array}{l}\text { Cyclophosphamid, Hydroxydaunorubicin (= Doxorubicin), Oncovin } \AA \\
\text { (= Vincristin), Etoposid, Prednison }\end{array}$ \\
\hline $\mathrm{CHOP}$ & $\begin{array}{l}\text { Cyclophosphamid, Hydroxydaunorubicin (= Doxorubicin), Oncovin } \AA \\
\text { (= Vincristin), Prednison }\end{array}$ \\
\hline CT & engl. cycle threshold \\
\hline ddNTP & Didesoxyribonukleosid-Triphosphat \\
\hline $\mathrm{dH}_{2} \mathrm{O}$ & destilliertes Wasser \\
\hline $\mathrm{ddH}_{2} \mathrm{O}$ & doppelt destilliertes Wasser \\
\hline DLBCL & engl. diffuse large B-cell lymphoma \\
\hline DNA & engl. deoxyribonucleic acid \\
\hline dNTP & Desoxyribonukleosid-Triphosphat \\
\hline DSHNHL & Deutsche Studiengruppe Hochmaligne Non-Hodgkin-Lymphome \\
\hline EBV & Epstein-Barr-Virus \\
\hline ECOG & engl. Eastern Cooperative Oncology Group \\
\hline EFS & engl. event-free survival \\
\hline ELISA & engl. enzyme-linked immunosorbent assay \\
\hline HWG & Hardy-Weinberg-Gleichgewicht \\
\hline IFN & Interferon \\
\hline IL & Interleukin \\
\hline IMISE & $\begin{array}{l}\text { Institut für Medizinische Informatik, Statistik und Epidemiologie } \\
\text { (Medizinische Fakultät der Universität Leipzig) }\end{array}$ \\
\hline$|P|$ & engl. International Prognostic Index \\
\hline $\mathrm{KI}$ & Konfidenzintervall \\
\hline LCL & engl. lymphoblastoid cell line \\
\hline LDH & Laktatdehydrogenase \\
\hline n. d. & engl. no data \\
\hline $\mathrm{NHL}$ & Non-Hodgkin-Lymphom \\
\hline OS & engl. overall survival \\
\hline PBS & engl. phosphate buffered saline \\
\hline PCR & engl. polymerase chain reaction \\
\hline RNA & engl. ribonucleic acid \\
\hline $\mathrm{RR}$ & relatives Risiko \\
\hline SNP & engl. single nucleotide polymorphism \\
\hline TNF & Tumornekrosefaktor \\
\hline
\end{tabular}




\section{$1 \quad$ Einleitung}

Krebserkrankungen stehen in entwickelten Ländern nach kardiovaskulären Erkrankungen an zweiter Stelle der häufigsten Todesursachen. In Deutschland erkrankten im Jahr 2006 ca. 426.800 Menschen neu an Krebs. Für das Jahr 2010 wurden rund 450.000 Neuerkrankungen erwartet, womit in Deutschland derzeit etwa 1,5 Millionen Menschen von Krebs betroffen sind. Diese Angaben beruhen auf Schätzungen, welche die Gesellschaft der epidemiologischen Krebsregister in Deutschland e.V. und das Robert Koch-Institut im Februar 2010 veröffentlicht haben (Husmann et al. 2010). Die Zahl der Neuerkrankungen wächst stetig und lässt sich nicht zuletzt auf den demographischen Wandel zurückführen, da die Wahrscheinlichkeit für eine maligne Entartung von Zellen mit zunehmendem Alter steigt. Folglich treten die meisten Krebsarten bei älteren Menschen deutlich häufiger auf als bei jungen Menschen. So kommen auf einen Patienten unter 15 Jahre etwa 200 bis 300 Patienten über 80 Jahre (Husmann et al. 2010).

Im Jahr 2006 war etwa jeder vierte Todesfall in Deutschland auf Krebs zurückzuführen, woran insgesamt 210.930 Menschen verstarben. Männer sterben hierzulande am häufigsten an den Folgen eines Bronchialkarzinoms, wohingegen bei Frauen die krebsbedingte Todesursachenstatistik von den Mammakarzinomen angeführt wird. Platz 2 wird bei beiden Geschlechtern von den Kolonkarzinomen belegt (Husmann et al. 2010).

Unter Krebs versteht man die maligne Entartung von Zellen, welche sich durch destruktives und infiltratives Wachstum sowie die Fähigkeit zur Metastasierung auszeichnet. Bei der Tumorentstehung handelt es sich um einen multifaktoriellen und mehrstufigen Vorgang, der nach heutigem Kenntnisstand zu einer Modifikation grundlegender zellphysiologischer Funktionen führt (Hanahan et al. 2000). Grundlage für eine maligne Entartung ist die kontinuierliche Exposition der Körperzellen mit wachstumsfördernden Signalen. Dies kann die Folge von Mutationen in sogenannten Proto-Onkogenen sein. Proto-Onkogene sind an normalen Wachstums- und Differenzierungsprozessen beteiligt. Infolge einer Mutation kommt es meist zum Funktionsverlust, was in der Regel den programmierten Zelltod, die sogenannte Apoptose, nach sich zieht. Eine Mutation kann jedoch auch zu einer Förderung der Zellteilung führen und damit eine maligne Entartung unterstützen. Neben Mutationen in Proto-Onkogenen können auch Mutationen in Tumorsuppressorgenen zur stetigen Versorgung von Zellen mit wachstumsfördernden Signalen führen, da hierbei wachstumsinhibierende Faktoren ausgeschaltet werden. Hinzu kommt, dass 
Tumorzellen häufig eine Resistenz gegenüber der Apoptoseinduktion aufweisen und aberrant proliferierende Zellen somit nicht vom Immunsystem erkannt und eliminiert werden können. Als eine weitere Ursache für die oft geringe Immunogenität von Tumorzellen kann die niedrige Expression von Proteinen des humanen Leukozytenantigen-Systems betrachtet werden.

Die in der vorliegenden Dissertation betrachteten Non-Hodgkin-Lymphome (Abk. NHL) belegen in Deutschland bei Männern Platz 12, bei Frauen Platz 8 der krebsbedingten Todesursachenstatistik, was 2,4 bzw. 2,8 \% aller krebsbedingten Todesfälle entspricht (Husmann et al. 2010). Trotz stetig verbesserter Therapiestrategien gibt es zahlreiche Patienten, welche keine komplette Remission erreichen bzw. nach initialem Therapieerfolg ein Rezidiv erleiden. Deshalb ist es unbedingt erforderlich, neue individuelle Risikofaktoren zu identifizieren und die bestehenden Therapiemöglichkeiten dementsprechend weiterzuentwickeln bzw. zu adaptieren.

\subsection{Maligne Lymphome}

Maligne Lymphome entstehen aus Lymphozyten verschiedener Entwicklungsstadien und Herkunft. Die Einteilung erfolgt nach der im Jahre 2001 von der WHO (engl. World Health Organization) eingeführten Klassifikation, welche regelmäßig überarbeitet wird und deren Neuformulierung 2008 veröffentlicht wurde. Unterschieden wird hierbei zwischen Hodgkin- und Non-Hodgkin-Lymphomen. Beide Tumorentitäten lassen sich wiederum in verschiedene Subtypen unterteilen, welche sowohl hinsichtlich ihrer Pathogenese als auch dem klinischem Verlauf unterschiedliche Merkmale aufweisen. So lassen sich die Non-Hodgkin-Lymphome beispielsweise in aggressive Lymphome mit hohem und indolente Lymphome mit niedrigem Malignitätsgrad gliedern. Auch werden Parameter wie Zellmorphologie, Teilungsrate sowie Oberflächenmerkmale berücksichtigt (Jaffe et al. 2001).

Im Jahr 2006 erkrankten in Deutschlad 2.020 Menschen an Morbus Hodgkin sowie 12.760 Menschen an einem Non-Hodgkin-Lymphom. Letzteres belegt somit durchschnittlich Platz 10 aller Krebsneuerkrankungen (Platz 9 bei Männern, Platz 11 bei Frauen). Im gleichen Zeitraum verstarben 342 der Morbus Hodgkin-Patienten, wohingegen etwa 5.466 Patienten ihre Erkrankung an einem Non-Hodgkin-Lymphom nicht überlebten (Husmann et al. 2010).

\subsubsection{Non-Hodgkin-Lymphome}

Als Non-Hodgkin-Lymphome werden maligne Erkrankungen des lymphatischen Systems bezeichnet, bei denen im Gegensatz zum Morbus Hodgkin mikroskopisch 
kein Nachweis von Sternberg-Reed-Zellen gelingt. Es handelt sich um eine sehr heterogene Gruppe von Erkrankungen, welche sich auch im klinischen Verlauf sehr unterscheiden. Non-Hodgkin-Lymphome sind überwiegend B- und nur selten Tlymphozytären Ursprungs (Bräuninger et al. 2006).

Die in dieser Dissertation betrachteten diffus großzelligen B-Zell-Lymphome (engl. diffuse large B-cell lymphoma, Abk. DLBCL) gehören zu den aggressiven Lymphomen und sind mit einem Anteil von etwa $30 \%$ die am häufigsten auftretenden Non-HodgkinLymphome. Diffus großzellige B-Zell-Lymphome werden in die Subentitäten zentroblastisches, immunoblastisches, großzellig-anaplastisches sowie T-Zell-reiches B-Zell-Lymphom unterteilt.

Die Inzidenz des Non-Hodgkin-Lymphoms ist sechs Mal höher als die des HodgkinLymphoms. Das mittlere Erkrankungsalter liegt für Frauen bei rund 70 Jahren, für Männer bei rund 67 Jahren (Husmann et al. 2010). Für die Erkrankung an einem NonHodgkin-Lymphom existiert eine Vielzahl an Risikofaktoren. So kann eine Schwächung des Immunsystems, wie sie beispielsweise bei einer HIV-Infektion (engl. Human Immunodeficiency Virus) oder während einer immunsupprimierenden Therapie vorliegt, mit einem erhöhten Erkrankungsrisiko assoziiert sein (Alexander et al. 2007; Grulich und Vajdic 2005). Auch konnte der Zusammenhang zwischen einer Infektion mit dem Epstein-Barr-Virus (Abk. EBV) sowie Plasmodium falciparum - dem Erreger der Malaria tropica - und dem überwiegend in Afrika vorkommenden sogenannten endemischen Burkitt-Lymphom nachgewiesen werden (Bellan et al. 2003). Weiterhin scheint eine chronische, auf dem Befall mit Helicobacter pylori beruhende Gastritis die Wahrscheinlichkeit, an einem MALT-Lymphom (engl. mucosa associated lymphoid tissue) zu erkranken, deutlich zu erhöhen (Fischbach et al. 1998). In den letzten Jahren werden außerdem zunehmend Genvariationen in Zytokinen als bedeutsam im Zusammenhang mit einer Erkrankung an einem Non-Hodgkin-Lymphom bzw. dem Erkrankungsverlauf diskutiert (Breen et al. 2002; Cunningham et al. 2003; LechMaranda et al. 2004 und 2006).

Neben der Bestimmung der Tumor-Subentität müssen weitere Risikofaktoren, die den klinischen Verlauf beeinflussen, identifiziert werden, um eine klare Risikoeinschätzung des Patienten zu ermöglichen und auf dieser Basis eine Entscheidung für eine niedrig oder hoch dosierte Chemotherapie treffen zu können. So richtet sich die Intensität der grundsätzlich kurativ ausgerichteten Behandlung aggressiver B- und T-Zell-Lymphome nach den Risikofaktoren des International Prognostic Index (Abk. IPI), welcher die Patienten in vier Risikogruppen einteilt. Der IPI berücksichtigt die Faktoren Alter, Krankheitsstadium nach Ann Arbor, Anzahl der Extranodalbefälle, Performance-Status 
der Eastern Cooperative Oncology Group (Abk. ECOG) sowie Serum-LDH. Als weitere Risikofaktoren, welche vom IPI nicht berürcksichtigt werden, gelten bulky disease sowie zyto- und molekulargenetische Merkmale des Lymphoms. Therapiert wird mithilfe eine Polychemotherapie gemäß CHOP- bzw. CHOEP-Schema (Cyclophosphamid, Doxorubicin, Vincristin, ggf. Etoposid, Prednison) in Kombination mit dem humanisierten, monoklonalen Antikörper Rituximab, welcher an das Transmembran-Antigen CD20 (engl. cluster of differentiation) auf prä-B- und reifen BLymphozyten sowie den entsprechenden neoplastischen Zellen bindet, was eine Zelllyse zur Folge hat (Preiß et al. 2008). Nachdem für die Raten von Inzidenz und Mortalität jahrelang ein Anstieg zu verzeichnen war, sind die Werte für beide Parameter seit der Jahrtausendwende wieder rückläufig. Die 5-Jahres-Überlebensrate wird je nach Publikation mit etwa 30 bis $80 \%$ (abhängig von Alter, Geschlecht und Subtyp) angegeben und ist damit deutlich schlechter als beim Hodgkin-Lymphom (Husmann et al. 2010; Pfreundschuh et al. 2004 a und b).

\subsection{Das Zytokin Interleukin-10}

Als Zytokine bezeichnet man Glykoproteine, welche von einer Vielzahl unterschiedlicher Zellarten gebildet sowie sezerniert werden und eine zentrale Rolle bei der Aufrechterhaltung von Homöostase und Modulation des Immunsystems einnehmen (Hofmann et al. 2002). Die Produktion der verschiedenen Zytokine wird in erster Linie durch Antigenkontakt induziert, erfolgt jedoch auch in Abhängigkeit von genetischen Komponenten, weshalb neben Unterschieden zwischen ethnischen Gruppen auch individuelle Unterschiede bestehen (Eskdale et al. 1998; Gibson et al. 2001; Turner et al. 1997). Die Höhe der Expression einzelner Zytokine wird durch unterschiedliche Transkriptionsfaktoren sowie eine Zelltyp-spezifische Chromatinstruktur reguliert (Holloway et al. 2002).

Zytokine werden im Wesentlichen in die drei Hauptgruppen Interferone (Abk. IFN), Interleukine (Abk. IL) und Tumornekrosefaktoren (Abk. TNF) unterteilt. Interleukine werden von Leukozyten sezerniert und weisen analog zu ihrer Vielzahl an Untergruppen zahlreiche Funktionen auf. So sind sie beispielsweise für die Regulation von Proliferation und Differenzierung von Zellen verantwortlich.

Bei dem Zytokin Interleukin-10 handelt es sich um eine Schlüsselkomponente in der Regulation der Immunantwort. IL-10 ist Teil eines balancierten Netzwerkes, welches sich aus zahlreichen unterschiedlichen Zytokinen zusammensetzt, und wird von einer Vielzahl gesunder als auch neoplastischer Zellen produziert, so beispielsweise von Makrophagen und Monozyten, aber auch von B-Lymphozyten oder Untergruppen von 
T-Lymphozyten (Lalani et al. 1997; Moore et al. 1993). IL-10 weist ausgeprägte antiinflammatorische Eigenschaften auf, da dessen Anwesenheit zur konsekutiven Herabregulierung anderer Zytokine wie z. B. IL-1, IL-8, IFN- $\gamma$ sowie TNF- $\alpha$ führt (de Waal et al. 1991). Desweiteren werden durch IL-10 Makrophagen, natürliche Killerzellen sowie T-Lymphozyten inhibiert, welche im Rahmen inflammatorischer Reaktionen sowohl zur Elimination des Pathogens beitragen als auch Gewebeschäden verursachen können. Neben der Regulation entzündlicher Prozesse ist IL-10 an der Entstehung von Autoimmunkrankheiten wie beispielsweise dem systemischen Lupus Erythematodes oder der rheumatoiden Arthritis sowie bei Komplikationen im Rahmen von Transplantationen beteiligt (Cavet et al. 1999; D'Alfonso et al. 2000; Eskdale et al. 1997; Hajeer et al. 1998; Tagore et al. 1999). Auch spielt IL-10 eine zentrale Rolle bei der Entstehung infektiöser Erkrankungen wie der Malaria tropica oder von EBVassoziierten Tumoren (Beatty et al. 1997; Kurtzhals et al. 1998).

\section{IL-10 und Non-Hodgkin-Lymphome}

IL-10 fungiert als autokriner Wachstumsfaktor für humane B-Lymphozyten und ist in die Pathophysiologie von Non-Hodgkin-Lymphomen involviert (Benjamin et al. 1994; Blay et al. 1993). Eine deregulierte Immunantwort, für welche beispielsweise ein spezifisches Zytokin, das im Bereich eines Tumors eine akute oder chronische Entzündungsreaktion hervorruft, ursächlich sein kann, könnte sowohl mit dem Auftreten als auch dem klinischen Verlauf einer Lymphomerkrankung assoziiert sein (Lin et al. 2007). Einerseits ist IL-10 dazu in der Lage, neben der Tumorprogression die -dissemination zu fördern, da es beispielsweise durch eine Hemmung von regulatorischen T-Zellen immunsupprimierend wirkt - maligne Zellen somit nicht durch das Immunsystem eliminiert werden - sowie die Proliferation und Differenzierung von Zellen stimuliert (Moore et al. 2001). Andererseits kann die Gegenwart von IL-10 auch zu einer Hemmung des Tumorwachstums führen, da es der Angiogenese im Mikromilieu des Tumors entgegenwirkt (Cervenak et al. 2000).

IL-10 konnte im Serum von akut erkrankten NHL-Patienten detektiert werden, wohingegen der Nachweis bei Patienten, die sich in teilweiser oder kompletter Remission befanden, nur selten, bei gesunden Kontrollprobanden hingegen überhaupt nicht gelang. Bei Patienten mit Non-Hodgkin-Lymphomen in intermediären und späten Stadien war der Nachweis von IL-10 im Serum mit einer schlechten Prognose verbunden (Blay et al. 1993; Lech-Maranda et al. 2006). 


\subsubsection{Genvariationen bei Zytokinen}

Genetische Varianten sind im Bereich des gesamten humanen Genoms zu finden und können mit einer Veränderung des Genprodukts - dem Protein - einhergehen. Der anteilig häufigste Mutationstyp ist die sogenannte Punktmutation. Hierbei ist es zum Austausch von lediglich einer Base gekommen. Wenn sich diese Punktmutation im Bereich einer kodierenden DNA-Sequenz (engl. deoxyribonucleic acid) befindet, spricht man von einem single nucleotide polymorphism (Abk. SNP). Man unterscheidet kodierende SNPs, die mit einem Aminosäureaustausch im Protein einhergehen, von den weitaus häufigeren regulatorischen SNPs, welche sich im Bereich von IntronSequenzen sowie 3'- und 5'-untranslatierten Regionen befinden. Bis heute wurden mehrere Millionen SNPs identifiziert und in einer öffentlichen Datenbank zugänglich gemacht (http://www.ncbi.nlm.nih.gov/snp). Da die klinische Relevanz der überwiegenden Anzahl an SNPs jedoch noch nicht bekannt ist, versuchen Konsortien wie das International HapMap Project, Aussagen über eine mögliche Assoziation von SNPs mit diversen Krankheiten treffen zu können.

Zahlreiche Veröffentlichungen unterstützen die Hypothese, dass Polymorphismen innerhalb von Genen, die an immunologischen - respektive inflammatorischen Reaktionen beteiligt sind, sowohl die Suszeptibilität für unterschiedliche Tumorarten beeinflussen als auch Auswirkungen auf den klinischen Verlauf hinsichtlich therapiebedingter Nebenwirkungen haben könnten (Hollegaard et al. 2006; Howell et al. 2002 und 2006; Lossos et al. 2006). Regulatorische Polymorphismen scheinen zumindest teilweise dafür verantwortlich zu sein, wie die Immunantwort bei verschiedenen Individuen ausfällt (Hill et al. 2001). Desweiteren wird angenommen, dass Polymorphismen in regulatorischen Regionen die Expressionshöhe von Zytokinen bestimmen könnten. So wurde nachgewiesen, dass Genpolymorphismen zu unterschiedlicher In-vitro-Expression pro- oder antiinflammatorischer Genprodukte führen sowie die Suszeptibilität für gutartige immunologisch vermittelte Erkrankungen und einige Darmerkrankungen beeinflussen (Howell et al. 2002).

\section{IL-10-Genvariationen und Non-Hodgkin-Lymphome}

Da IL-10 wie bereits aufgeführt erheblich zur Modulation der Immunantwort beiträgt, könnten Polymorphismen in regulatorischen Bereichen des IL-10-Gens - einhergehend mit einer unterschiedlich hohen Expression des Genprodukts - in die Pathophysiologie von Non-Hodgkin-Lymphomen involviert sein. Im Bereich der Promotorregion des IL10-Gens wurden die proximalen Genvariationen IL-10-1.087AG, IL-10-824CT und IL-10-597AC am häufigsten analysiert. Von den distalen Polymorphismen wurden bisher 
insbesondere IL-10-7400InDel, IL-10-6.752AT, IL-10-6.208GC und IL-10-3.538AT untersucht (Kube et al. 2001). In Abbildung 1 ist der IL-10-Genlokus, lokalisiert auf Chromosom 1 zwischen q31 und q32, einschließlich der bisher beschriebenen Genvariationen, Mikrosatelliten und einer Insertion/Deletion schematisch dargestellt.

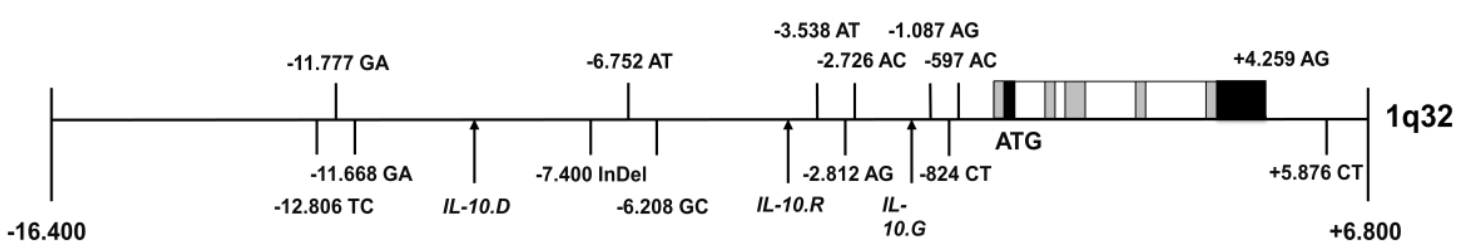

Abbildung 1: Schematische Darstellung des IL-10-Genlokus. Abgebildet sind der IL-10-Genlokus auf Chromosom 1q31/32 (-16.400 bp bis +6.800 bp) einschließlich SNPs und der Insertion/Deletion bei -7.400 bp, weiterhin die Mikrosatelliten IL-10.R und IL-10.G sowie die komplexe repititive Sequenz IL-10.D (letztere drei jeweils kursiv). Zwischen den Genvariationen IL-10-597AC und IL-10 +4.259 AG befinden sich Exons (grau), Introns (weiß) sowie die UTR (engl. untranslated region, schwarz).

Mithilfe einer In-vitro-Stimulation von Leukozyten des peripheren Blutes mit Lipopolysaccharid (Abk. LPS) wurde nachgewiesen, dass die IL-10-Produktion großen interindividuellen Schwankungen unterliegt (Gibson et al. 2001; Mörmann et al. 2004; Rieth et al. 2004; Turner et al. 1997). Dabei kann die höchstmögliche IL-10-Sekretion das 20-fache der niedrigsten IL-10-Sekretion betragen (Mörmann et al. 2004). Je nach Arbeitsgruppe beruhen 50 bzw. bis zu 75 \% dieser Unterschiede auf genetischen Faktoren (Reuss et al. 2002; Westendorp et al. 2001); beispielsweise besteht vermutlich ein Zusammenhang zwischen Polymorphismen im Bereich der 5'-Region des IL-10-Gens sowie der Sekretionshöhe (Turner et al. 1997). Desweiteren lassen sich interindividuelle Unterschiede des IL-10-Spiegels möglicherweise auf der Transkriptionsebene erklären, da IL-10-Allele in Zellen heterozygoter Individuen unterschiedlich transkribiert werden und IL-10-Haplotypen ggf. die Produktion von IL10 beeinflussen (Kurreeman et al. 2004). Die individuellen Unterschiede bei der Produktionshöhe von IL-10 haben laut Arbeitsgruppe von Mörmann verschieden ausgeprägte Reaktionen des Immunsystems zur Folge (Mörmann et al. 2004); so konnte nachgewiesen werden, dass hohe IL-10-Werte im Serum von Patienten mit einem Non-Hodgkin-Lymphom mit einer schlechten Prognose einhergehen (Blay et al. 1993; Lech-Maranda et al. 2006). Auch könnte der klinische Verlauf von DLBCLPatienten mit bestimmten Promotorpolymorphismen des IL-10-Gens, welche eine niedrige IL-10-Produktion zur Folge haben, assoziiert sein (Cunningham et al. 2003). Weiterhin wurde beobachtet, dass der proximale Promotorpolymorphismus IL-10-1.087AG im Zusammenhang mit dem IL-10-Serumwert sowie dem klinischen Verlauf von 
Patienten mit DLBCL steht (Lech-Maranda et al. 2004). Diese Ergebnisse konnten von einer skandinavischen Arbeitsgruppe jedoch nicht validiert werden, was unter anderem darauf zurückzuführen sein könnte, dass sich die analysierten Patientenkollektive erheblich bezüglich des durchschnittlichen Alters unterschieden und die Altersverteilung insgesamt eher untypisch für die Erkrankung an einem DLBCL war (Berglund et al. 2005). Eine andere Studie legte nahe, dass bei AIDS-Patienten (engl. Acquired Immune Deficiency Syndrome) mit Genotypen, die mit einer hohen IL-10Produktion korrelieren, das Risiko, an einem Lymphom zu erkranken, erhöht ist (Breen et al. 2003). Distale Promotorpolymorphismen scheinen in diesem Zusammenhang eine hohe biologische Signifikanz aufzuweisen (Gibson et al. 2001). So konnte die eigene Arbeitsgruppe nachweisen, dass der Genotyp IL-10-7.400DelDel (Deletion der Basenabfolge GGA) bei NHL-Patienten mit einem signifikant kürzeren kumulativen Gesamtüberleben assoziiert ist (Kube et al. 2008). Die 3-Jahres-Überlebensrate wurde mit 43,4 \% angegeben, während sie bei Patienten mit den Genotypen IL-10-7.400Inın sowie IL-10-7.400InDel zusammengenommen $73,4 \%$ betrug. Das relative Risiko für einen schlechten klinischen Verlauf für Patienten mit dem Genotyp IL-10-7.400DelDel ist mit 1,9 hingegen erhöht; der Genotyp IL-10-7.400DelDel tritt bei Kaukasiern jedoch nur selten auf (Kube et al. 2008). Eine signifikant verminderte Wahrscheinlichkeit für ereignisfreies Überleben war mit dem Haplotypen TCA der drei distalen Genvariationen IL-10-6.752TT, IL-10-6.208cc sowie IL-10-3.538AA assoziiert (Kube et al. 2008).

Bei Kenntnis der vorliegenden IL-10-Genvariationen könnte folglich der klinische Verlauf von Patienten mit aggressiven Non-Hodgkin-Lymphomen prädiktiert werden. Um diese Hypothese zu stärken, müssen jedoch weitere Polymorphismen und größere Patientenkolllektive untersucht werden.

\subsection{Zielstellung der Dissertation}

Die in dieser Dissertation betrachteten Non-Hodgkin-Lymphome sind dank der aktuellen Therapiestrategien prinzipiell heilbar. Dennoch gibt es eine Vielzahl von Patienten, bei denen die Therapie nicht zur Remission führt oder mit einer hoher Toxizität assoziiert ist. Weiterhin kann das Risiko für das Auftreten eines Zweittumors erhöht sein. Um die Therapie dieser Patientengruppe langfristig mittels Steigerung der Effektivität bei simultaner Reduktion der Toxizität zu optimieren, erfolgte die Analyse von IL-10-Genvariationen bei diffus großzelligen B-Zell-Lymphomen. Ziel war es, herauszufinden, ob bestimmte Genvariationen des IL-10-Genlokus bisher unentdeckte Risikofaktoren für einen schlechten klinischen Verlauf von DLBCL-Patieten darstellen könnten. Da eine Vorarbeit der Arbeitsgruppe nachweisen konnte, dass der Genotyp 
IL-10-7.400DelDel mit einer ungünstigen Prognose assoziiert ist, dieser bei Kaukasiern jedoch nur selten auftritt, wurden in der vorliegenden Dissertation weitere distale IL-10Genvariationen analysiert, von denen man sich eine höhere klinische Relevanz versprach (Kube et al. 2008). Weiterhin sollte untersucht werden, ob Genvariationen des IL-10-Genlokus die Expressionshöhe von IL-10 in B-Zellen beeinflussen können, welche mit dem klinischen Verlauf von Patienten mit aggressiven Non-HodgkinLymphomen korrelieren könnte.

Mithilfe neuer klinisch relevanter und praktisch anwendbarer prognostischer Faktoren könnten die bestehenden Therapiemöglichkeiten dem individuellen Risikoprofil von jedem betroffenen Patienten entsprechend angepasst und somit optimiert werden. 


\section{Material}

\subsection{Biologisches Material}

\section{Zelllinien}

In der vorliegenden Dissertation kamen 31 LCL-Zellen (engl. lymphoblastoid cell line, Bezeichnung bspw. 7/3 oder 9/1) zum Einsatz, welche zuvor von Mitarbeitern der Arbeitsgruppe aus mononukleären Zellen des peripheren Blutes gesunder Spender gewonnen und mittels Infektion mit EBV immortalisiert worden waren. Die DNA dieser Zellen wurde mittels SNaPshot analysiert und teilweise auch sequenziert.

Desweiteren wurden 25 LCL-Zellen des internationalen HapMap-Projektes verwendet, welche von Dr. Mladen Tzvetkov zur Verfügung gestellt wurden. Diese Zellen wurden mittels ELISA (engl. enzyme-linked immunosorbent assay) und SNaPshot analysiert sowie für die Bestimmung der IL-10-Genexpression mithilfe von Real-Time PCRs (engl. polymerase chain reaction) und Analysen von Restriktionsfragmentlängenpolymorphismen eingesetzt.

\section{DNA von Lymphompatienten}

Für die Analyse von IL-10-Genvariationen bei Lymphompatienten wurde DNA aus dem Kollektiv der NHL-B1-/B2-Studien der Deutschen Studiengruppe Hochmaligne NonHodgkin-Lymphome (Abk. DSHNHL) eingesetzt; ein positives Ethik-Votum liegt vor (Antragsnummer 4/11/01). Im Rahmen dieser Studien wurde untersucht, ob die Gabe von CHOP im Abstand von zwei Wochen anstelle der sonst üblichen drei Wochen sowie die zusätzliche Applikation von Etoposid die Therapieerfolge bei Patienten mit aggressivem Non-Hodgkin-Lymphom verbessern kann (Pfreundschuh et al. 2004 a und b). Aus dem Gesamtkollektiv ( $n=1.697$ ) wurde eine Kohorte von 594 Patienten mit diffus großzelligem B-Zell-Lymphom ausgewählt, welche als repräsentativ für alle an einem DLBCL erkrankten Personen innerhalb der NHL-B1-/B2-Studien betrachet werden kann. Tabelle 1 führt klinische Charakteristika, die histologische Verteilung der Subtypen sowie die unterschiedlichen Therapieschemata des untersuchten Patientenkollektivs sowie des Gesamtkollektivs der NHL-B1-/B2-Studien auf. Die mediane Beobachtungszeit des ausgewählten Patientenkollektivs betrug 56,3 Monate, die des Gesamtkollektivs 58,1 Monate. 
Tabelle 1: Klinische Charakteristika, Histologien und Therapieschemata von DLBCL-Patienten der NHL-B1-/B2-Studien

\begin{tabular}{|c|c|c|}
\hline & $\begin{array}{c}\text { untersuchtes } \\
\text { Patientenkollektiv } \\
(\mathrm{n}=594)\end{array}$ & $\begin{array}{l}\text { Gesamtkollektiv aller } \\
\text { Patienten mit DLBCL } \\
(\mathrm{n}=913)\end{array}$ \\
\hline \multicolumn{3}{|l|}{ Klinische Charakteristika } \\
\hline Geschlecht: männlich & $319(53,7 \%)$ & $507(55,5 \%)$ \\
\hline weiblich & $275(46,3 \%)$ & $406(44,5 \%)$ \\
\hline durchschnittliches Alter (min./max.) & $62(22 / 75)$ & $61(18 / 75)$ \\
\hline Serum-LDH oberhalb des Referenzwertes & $150(25,3 \%)$ & $225(24,6 \%)$ \\
\hline Alter > 60 Jahre & $319(53,7 \%)$ & $489(53,6 \%)$ \\
\hline ECOG Performance-Status > 1 & $74(12,5 \%)$ & $110(12,1 \%)$ \\
\hline Ann Arbor Klassifikation > II & $238(40,1 \%)$ & $371(40,6 \%)$ \\
\hline$>1$ extranodale Manifestation & $108(18,2 \%)$ & $166(18,2 \%)$ \\
\hline \multicolumn{3}{|l|}{ International Prognostic Index (IPI): } \\
\hline low (0 Punkte, 1 Punkt) & $343(57,7 \%)$ & $531(58,2 \%)$ \\
\hline low intermediate (2 Punkte) & $111(18,7 \%)$ & $164(18,0 \%)$ \\
\hline high intermediate (3 Punkte) & $85(14,3 \%)$ & $131(14,4 \%)$ \\
\hline high (4 oder 5 Punkte) & $55(9,3 \%)$ & $87(9,5 \%)$ \\
\hline B-Symptome & $164(27,6 \%)$ & $247(27,1 \%)$ \\
\hline bulky disease & $199(33,5 \%)$ & $296(33,4 \%)$ \\
\hline Extranodalbefall & $286(48,2 \%)$ & $448(49,1 \%)$ \\
\hline Knochenmarkbefall & $51(8,6 \%)$ & $72(7,9 \%)$ \\
\hline \multicolumn{3}{|l|}{ Histologien } \\
\hline diffus großzelliges B-Zell-Lymphom & $594(100 \%)$ & $913(100 \%)$ \\
\hline zentroblastisch & $139(23,4 \%)$ & $198(21,7 \%)$ \\
\hline monomorph & $54(9,1 \%)$ & $83(9,1 \%)$ \\
\hline multilobulär & $31(5,2 \%)$ & $57(6,2 \%)$ \\
\hline polymorph & $230(38,7 \%)$ & $349(38,2 \%)$ \\
\hline immunoblastisch & $72(12,1 \%)$ & $114(12,5 \%)$ \\
\hline anaplastisch & $20(3,4 \%)$ & $28(3,1 \%)$ \\
\hline T-Zell-reich & $13(2,2 \%)$ & $24(2,6 \%)$ \\
\hline nicht spezifiziert & $35(5,9 \%)$ & $60(6,6 \%)$ \\
\hline \multicolumn{3}{|l|}{ Therapieschemata } \\
\hline CHOP-14 & $154(25,9 \%)$ & $227(24,9 \%)$ \\
\hline CHOEP-14 & $159(26,8 \%)$ & 235 (25,7 \%) \\
\hline CHOP-21 & $135(22,7 \%)$ & $219(24,0 \%)$ \\
\hline CHOEP-21 & $146(24,6 \%)$ & $232(25,4 \%)$ \\
\hline
\end{tabular}

Das vorliegende Patientenmaterial wurde mittels SNaPshot-Analysen in Hinblick auf vier unterschiedliche Polymorphismen des IL-10-Gens untersucht. 
DNA von gesunden Spendern

Für die Analyse von Genvariationen bei gesunden Kontrollprobanden kam DNA von insgesamt 91 nicht verwandten Spendern zum Einsatz, die zuvor von Mitarbeitern der Arbeitsgruppe aus Buffy coats isoliert worden war (Bezeichnung: ,Gö’ plus Ziffernfolge, z. B. Gö299). Auch hier war das alleinige Ausschlusskriterium das Vorliegen einer chronischen Erkrankung. Diese Proben wurden mittels SNaPshot analysiert und teilweise auch sequenziert.

\subsection{Chemikalien und Verbrauchsmaterialien}

Sämtliche in Tabelle 2 aufgeführten und verwendeten Chemikalien wiesen jeweils den höchsten Reinheitsgrad auf. Plastik-Einmalartikel und Verbrauchsmaterialien wie Pipettenspitzen, Reaktionsgefäße und Zellkulturflaschen stammten von den Firmen Applied Biosystems (USA), Biozym (Oldendorf), Eppendorf (Hamburg), Gilson (Limburg), Greiner (Nürtingen), Nalgene Labware (Dänemark), Nunc (Wiesbaden) und Sarstedt (Nürnbrecht).

Tabelle 2: Verwendete Chemikalien

\begin{tabular}{|c|c|}
\hline Chemikalie & Hersteller \\
\hline 10x NEBuffer 4 & New England BioLabs, Frankfurt a. M., Deutschland \\
\hline 10x PCR-Puffer & Invitrogen, Karlsruhe, Deutschland \\
\hline $18 \mathrm{~S}$ & Applied Biosystems, USA \\
\hline Borsäure & Sigma-Aldrich, Taufkirchen, Deutschland \\
\hline BSA & Serva, Heidelberg, Deutschland \\
\hline BSA (Zellkultur-getestet) & Sigma-Aldrich, Taufkirchen, Deutschland \\
\hline DMSO & Sigma-Aldrich, Taufkirchen, Deutschland \\
\hline dNTP-Mix (dATP, dCTP, dGTP, dTTP) & Promega, Mannheim, Deutschland \\
\hline EDTA & Sigma-Aldrich, Taufkirchen, Deutschland \\
\hline Ethanol & J.T.Baker, Niederlande \\
\hline Ethidiumbromid & Serva, Heidelberg, Deutschland \\
\hline Exonuclease $1(10 \mathrm{U} / \mu \mathrm{l})$ & Fermentas, St. Leon-Roth, Deutschland \\
\hline FCS & Biochrom AG, Berlin, Deutschland \\
\hline Fnu4HI (5.000 U/ml) & New England BioLabs, Frankfurt a. M., Deutschland \\
\hline Gene Ruler ${ }^{I M} 1 \mathrm{~kb}$ DNA Ladder Plus & Fermentas, St. Leon-Roth, Deutschland \\
\hline GeneScan $^{\mathrm{TM}} 120 \mathrm{LIZ} \circledast$ Size Standard & Applied Biosystems, USA \\
\hline GeneScan ${ }^{1 \mathrm{M}} 400 \mathrm{HD}$ ROX ${ }^{\mathrm{IM}}$ Size Standard & Applied Biosystems, USA \\
\hline Hi-Di ${ }^{\mathrm{TM}}$ Formamide & Applied Biosystems, USA \\
\hline L-Glutamin-Penicillin-Streptomycin-Lösung & Sigma-Aldrich, Taufkirchen, Deutschland \\
\hline Loading Dye Solution & Fermentas, St. Leon-Roth, Deutschland \\
\hline Methanol & J.T. Baker, Niederlande \\
\hline $\mathrm{MgCl}_{2}(50 \mathrm{mM})$ & Invitrogen, Karlsruhe, Deutschland \\
\hline
\end{tabular}


Natriumazid

Natriumchlorid

PBS

ROTI®GAROSE

RPMI-1640 Zellkulturmedium

$\operatorname{SAP}(1 \mathrm{U} / \mu \mathrm{l})$

SAP 10x Reaction Buffer

Schwefelsäure

Taq Polymerase

Tris

Trypanblau

Tween $\AA 20$

$\beta$-Mercaptoethanol
Serva, Heidelberg, Deutschland

Merck, Darmstadt, Deutschland

Invitrogen, Karlsruhe, Deutschland

Carl Roth, Karlsruhe, Deutschland

Sigma-Aldrich, Taufkirchen, Deutschland

USB, United Kingdom

USB, United Kingdom

J.T. Baker, Niederlande

Invitrogen, Karlsruhe, Deutschland

Sigma-Aldrich, Taufkirchen, Deutschland

Sigma-Aldrich, Taufkirchen, Deutschland

Serva, Heidelberg, Deutschland

Sigma-Aldrich, Taufkirchen, Deutschland

\subsection{Medien und Puffer}

Die jeweiligen Zusammensetzungen regelmäßig verwendeter Medien und Puffer sind in Tabelle 3 wiedergegeben.

Tabelle 3: Verwendete Medien und Puffer

\section{Zellkultur}

Einfriermedium:

$90 \%$ (v/v) FCS

$10 \%(v / v)$ DMSO

Nährmedium:

RPMI-1640

$10 \%(v / v)$ FCS

200 U/ml Penicillin

$200 \mu \mathrm{g} / \mathrm{ml}$ Streptomycin

4 mM L-Glutamin

\section{Gelelektrophorese}

TBE-Puffer:
$54 \mathrm{~g}$ Tris
27,5 g Borsäure

$20 \mathrm{ml}$ EDTA $0,5 \mathrm{M}$

\subsection{Häufig verwendete Geräte}

In Tabelle 4 sind die bei dieser Dissertation häufig verwendeten Geräte aufgeführt.

Tabelle 4: Verwendete Geräte

\begin{tabular}{ll}
\hline Gerät & Hersteller \\
\hline 3130 Genetic Analyzer & Applied Biosystems, USA
\end{tabular}


7900 HT Fast Real-Time PCR System

Brutschrank Cytoperm

Electrophoresis Power Supply ST 304

Elektrophorese-Kammer

HERAfreeze ${ }^{\circledR}-80^{\circ} \mathrm{C}$ Kühleinheit

KS 260 Schüttler

IKAMAG ${ }^{8}$ RCT Heizplatte/Magnetrührer

Mastercycler 384

Microflow Laminar Downflow Workstation

Mikrokühlzentrifuge 1-15 K

Mikrowelle MWS 2820

MULTIFUGE 3 L-R

NanoDrop ${ }^{\circledR}$ ND-1000 Spectrophotometer

Premium Kühlschrank

PTC-100 ${ }^{1 \mathrm{M}}$ Programmable Thermal Controller

Synergy HT Multi-Mode Microplate Reader

T3000 Thermocycler

Telaval 31 Mikroskop

Thermocycler 60

Ultra Low $-150^{\circ} \mathrm{C}$ Kühleinheit

UV-Transilluminator TI 3 und Videosystem

Vortex-Genie 2 ${ }^{\circledR}$

Wasserbad
Applied Biosystems, USA

Heraeus Instruments, Hanau, Deutschland

Gibco, Karlsruhe, Deutschland

Biotec-Fischer, Reiskirchen, Deutschland

Heraeus Instruments, Hanau, Deutschland

IKA, Staufen, Deutschland

IKA, Staufen, Deutschland

Eppendorf, Hamburg, Deutschland

Nunc, Wiesbaden, Deutschland

Sigma, Osterode, Deutschland

Bauknecht, Stuttgart, Deutschland

Heraeus Instruments, Hanau, Deutschland

Kisker, Steinfurt, Deutschland

Liebherr, Dortmund, Deutschland

MJ Research, USA

BioTek, Bad Friedrichshall, Deutschland

Biometra, Jena, Deutschland

Carl Zeiss AG, Oberkochen, Deutschland

Bio-med, Theres, Deutschland

Sanyo, Japan

Biometra, Jena, Deutschland

Scientific Industries, USA

Köttermann Labortechnik, Hänigsen, Deutschland

\subsection{Gebrauchsfertige Reaktionssysteme}

Tabelle 5 listet sämtliche gebrauchsfertigen Reaktionssysteme auf, welche in dieser Dissertation zur Anwendung kamen.

Tabelle 5: Gebrauchsfertige Reaktionssysteme

\begin{tabular}{|c|c|}
\hline Bezeichnung & Hersteller \\
\hline ABI PRISM ${ }^{\circledR}$ SNaPshot ${ }^{T M}$ Multiplex Kit & Applied Biosystems, USA \\
\hline BigDye ${ }^{\circledR}$ Terminator Cycle Sequencing Kit v1.1 & Applied Biosystems, USA \\
\hline DyeEx ${ }^{1 \mathrm{M}} 2.0$ Spin Kit & Qiagen, Hilden, Deutschland \\
\hline IL-10 Eli-pair ELISA Kit & Diaclone, Gießen, Deutschland \\
\hline QIAamp ${ }^{\prime M}$ DNA Blood Mini Kit & Qiagen, Hilden, Deutschland \\
\hline QIAquick ${ }^{I M}$ PCR Purification Kit & Qiagen, Hilden, Deutschland \\
\hline RNeasy ${ }^{\text {IM }}$ Mini Kit & Qiagen, Hilden, Deutschland \\
\hline SuperScript $^{\mathrm{TM}}$ II Reverse Transcriptase & Invitrogen, Karlsruhe, Deutschland \\
\hline SYBR $®$ Green Master Mix & Applied Biosystems, USA \\
\hline
\end{tabular}




\subsection{Oligonukleotide}

In Tabelle 6 sind die Sequenzen der in dieser Dissertation eingesetzten Oligonukleotide sowie deren Verwendungszweck aufgelistet. Die Nummerierung basiert auf der von der eigenen Arbeitsgruppe publizierten IL-10-Sequenz (Kube et al. 2001). Die Herstellung erfolgte überwiegend durch die Firma IBA (Göttingen); lediglich die für den Multiplex Assay eingesetzten Oligonukleotide stammen von der Firma Eurofins MWG Operon (Ebersberg).

Tabelle 6: Verwendete Oligonukleotide

\begin{tabular}{|c|c|c|}
\hline Name & Sequenz & Verwendung \\
\hline 6-FamIL10+4.259antisense & (6-FAM)AATAACAAGCTGGCCACAGC & PCR (IL-10-Genexpression) \\
\hline 6-FamIL10+4.259sense & (6-FAM)ACTGAGCTTCTCTGTGAACG & PCR (IL-10-Genexpression) \\
\hline HexIL10+4.259antisense & (HEX)AATAACAAGCTGGCCACAGC & PCR (IL-10-Genexpression) \\
\hline HexIL10+4.259sense & (HEX)ACTGAGCTTCTCTGTGAACG & PCR (IL-10-Genexpression) \\
\hline \multirow[t]{2}{*}{ IL10-11.668AG } & 5'GATCGATCGATCGATCGATCGATCA & Multiplex Assay \\
\hline & GCCTGAGCCAGTCAGTCTTTCTACT'3 & \\
\hline IL10-11.777AG & 5'AGCCCTTGGATTATTGATGC'3 & Multiplex Assay \\
\hline \multirow[t]{2}{*}{ IL10-12.806CT } & 5'GACTAGATCGATCGATCGATTATGT & Multiplex Assay \\
\hline & TTGTGTTCCATGGGT'3 & \\
\hline \multirow[t]{2}{*}{ IL10+545Ex5 } & 5'GATCCTGGTTTCTCTTCCTAAGAGTA & Multiplex Assay \\
\hline & TTTG'3 & \\
\hline IL10-12.800-rev & GTTTCACGAAAGCGGCTAAG & PCR \\
\hline IL10+4.259antisense & AATAACAAGCTGGCCACAGC & PCR \\
\hline IL10+4.259sense & ACTGAGCTTCTCTGTGAACG & PCR \\
\hline IL10-12.800-fwd & СTGTCCCAGCTCACAGATCA & PCR, Sequenzierung \\
\hline Random Hexamer Primer & NNNNNN & Reverse Transkription \\
\hline IL10-11.250-rev & GCTCTGTCTTTGGGCTTGTC & Sequenzierung \\
\hline IL10-12.000-fwd & ACAGGTGAACACACGCAAAA & Sequenzierung \\
\hline IL10-12.500-rev & TGTACTTGGCTCCTGACGTG & Sequenzierung \\
\hline qRT_IL-10_fwd & AAGACCCTCAGGCTGAGGCTAC & SYBR Green qRT-PCR \\
\hline qRT_IL-10_rev & CCACGGCCTTGCTCTTGTT & SYBR Green qRT-PCR \\
\hline
\end{tabular}




\section{Methoden}

\section{1 Übersicht}

Um die Zielstellung dieser Dissertation verwirklichen zu können, wurde eine Vielzahl etablierter Methoden angewandt; parallel konnte die bereits bekannte SNaPshotAnalyse zu einem Multiplex Assay weiterentwickelt werden. Durch Kultivierung der LCL-Zellen wurden Überstände gewonnen, die mittels ELISA auf den Grad ihrer IL-10Sekretion untersucht wurden. Außerdem wurde DNA isoliert, welche mithilfe verschiedener PCRs amplifiziert und daraufhin sowohl für Sequenzierungen, SNaPshot als auch die Analyse von Restriktionsfragmentlängenpolymorphismen eingesetzt wurde. Sequenzierungen und SNaPshot-Analysen dienten der Genotypisierung der vorliegenden Proben. Weiterhin erfolgte die Isolation von RNA (engl. ribonucleic acid) sowie die darauf folgende reverse Transkription zu cDNA (engl. complementary DNA), welche ebenfalls zur Fragmentlängenanalyse sowie für eine Real-Time PCR eingesetzt wurde. Letztere beiden Methoden wurden mit dem Ziel angewendet, die IL-10Transkriptmengen zu quantifizieren. Abbildung 2 informiert über die exakte Versuchsabfolge.

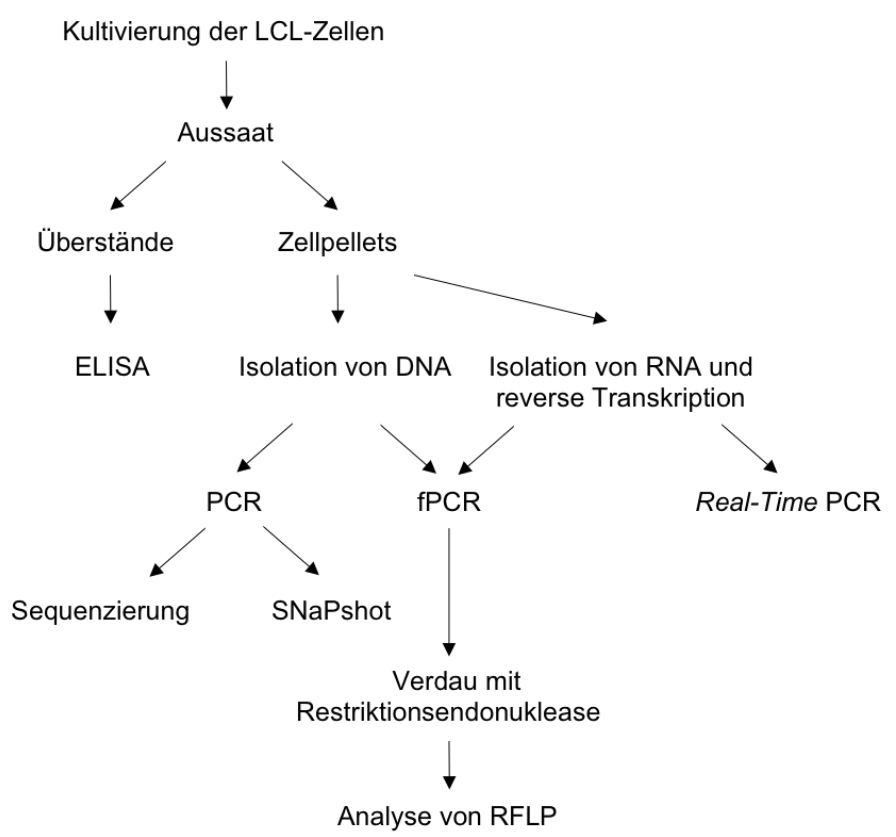

Analyse der IL-10-Genexpression

Abbildung 2: Versuchsabfolge. fPCR: fluoreszenzmarkierte PCR. RFLP: Restriktionsfragmentlängenpolymorphismen. 


\subsection{Methoden der Zellkultur}

\subsubsection{Auftauen und Kryokonservierung der Zellen}

Die bei $-150^{\circ} \mathrm{C}$ gelagerten Zellen wurden bei $37^{\circ} \mathrm{C}$ aufgetaut und zügig in jeweils $10 \mathrm{ml}$ Nährmedium überführt. Nach Sedimentation für fünf Minuten bei Raumtemperatur und 750 rpm wurde der Überstand vollständig abgenommen. Daraufhin erfolgte die Resuspension der Zellen mit jeweils $5 \mathrm{ml}$ frischem Nährmedium und die Überführung in Zellkulturflaschen mit Belüftungskappe zur anschließenden Lagerung im Brutschrank.

Zwecks Kryokonservierung wurden der Zellkultur etwa 1 × $10^{6}$ Zellen entnommen und diese für fünf Minuten bei Raumtemperatur und 750 rpm sedimentiert. Der Überstand wurde verworfen, die Zellen in $0,5 \mathrm{ml}$ Einfriermedium resuspendiert sowie in Kryoröhrchen überführt. Daraufhin erfolgte über Nacht die Lagerung in einer mit Isopropanol-gefüllten Einfrierbox bei $-80^{\circ} \mathrm{C}$, wodurch eine langsame und somit zellverträgliche Absenkung der Temperatur um $1^{\circ} \mathrm{C}$ pro Minute bis auf $-80^{\circ} \mathrm{C}$ möglich war. Am nächsten Tag wurden die Kryokulturen bei $-150^{\circ} \mathrm{C}$ eingelagert.

\subsubsection{Kultivierung der Zellen}

Die Kultivierung der Zellen erfolgte unter sterilen Bedingungen bei $37^{\circ} \mathrm{C}, 5 \% \mathrm{CO}_{2}$ und $90 \%$ Luftfeuchtigkeit im Inkubator. Je nach Proliferation wurde alle zwei bis drei Tage frisches, vorgewärmtes Nährmedium hinzugegeben. Abhängig vom Volumen der Zellsuspensionen wurden diese in $25 \mathrm{~cm}^{2}$ ( 5 bis $10 \mathrm{ml}$ ), $75 \mathrm{~cm}^{2}$ (30 bis $50 \mathrm{ml}$ ) oder 175 $\mathrm{cm}^{2}$ (50 bis $120 \mathrm{ml}$ ) Zellkulturflaschen inkubiert.

Im Falle eines nicht zufriedenstellenden Wachstums wurden die Zellen mit konditioniertem Nährmedium versetzt, welches aus steril gefiltertem Überstand gut wachsender LCL-Zellen hergestellt wurde.

\subsubsection{Bestimmung der Zellzahl}

Die Zellzahl wurde mittels Verwendung einer Neubauer improved-Zählkammer bestimmt, indem die Zellen in einem definierten Volumen mithilfe eines Mikroskops gezählt wurden. Das Ergebnis ließ sich daraufhin in „Zellen pro ml“ umrechnen. Um tote von vitalen Zellen unterscheiden zu können, erfolgte zuvor die Anfärbung mit Trypanblaulösung $(0,5 \%$ (w/v) Trypanblau in phosphate buffered saline (Abk. PBS). Da nur bereits abgestorbene Zellen für den Farbstoff permeabel sind, waren diese folglich leicht zu erkennen. 


\subsubsection{Gewinnung von Überständen für ELISA}

Um für die Messung der IL-10-Sekretion mittels ELISA standardisierte Bedingungen zu erreichen, wurden zu zwei verschiedenen Zeitpunkten im Abstand von einer Woche Überstände der kultivierten Zellen gewonnen. Hierfür wurden die Zellsuspensionen an Tag 1 für fünf Minuten bei Raumtemperatur und 750 rpm zentrifugiert. Die Überstände wurden verworfen und die verbleibenden Zellpellets in frischem Medium resuspendiert. Mithilfe der Neubauer improved-Zählkammer erfolgte die Einstellung auf $5 \times 10^{5}$ Zellen/ml, woraufhin das Zielzellvolumen in Zellkulturflaschen überführt, mit Nährmedium versetzt und über Nacht im Brutschrank inkubiert wurde.

An Tag 2 wurden die Zellsuspensionen erneut für fünf Minuten bei Raumtemperatur und $750 \mathrm{rpm}$ zentrifugiert. Auch dieses Mal wurden die Überstände verworfen, die verbleibenden Zellpellets mit $10 \mathrm{ml}$ PBS gewaschen sowie unter den soeben genannten Bedingungen nochmals sedimentiert. Nachdem die Überstände verworfen wurden, erfolgte die Zugabe von frischem Medium. Die Zellsuspensionen wurden wieder auf $5 \times 10^{5}$ Zellen/ml eingestellt und für 24 Stunden im Brutschrank inkubiert. An Tag 3 erfolgte eine Zentrifugation für zehn Minuten bei $4^{\circ} \mathrm{C}$ und $1.000 \mathrm{rpm}$, woraufhin pro Probe je zwei Mal $1 \mathrm{ml}$ Überstand abgenommen und bei $-20^{\circ} \mathrm{C}$ gelagert wurde.

\subsubsection{Vorbereitung der Zellen für die Isolation von RNA}

Der nächste Schritt bestand in der Vorbereitung der verbliebenen Zellpellets für die RNA-Isolation. Hierfür wurden diese in je $1 \mathrm{ml}$ PBS gelöst und für zehn Minuten bei $4^{\circ} \mathrm{C}$ und $2.300 \mathrm{rpm}$ zentrifugiert. Daraufhin wurden die Überstände verworfen, die Zellpellets mit $350 \mu \mathrm{l}$ RLT-Puffer und $1 \% \beta$-Mercaptoethanol resuspendiert sowie bis zur weiteren Verwendung bei $-20^{\circ} \mathrm{C}$ aufbewahrt.

\subsection{Molekularbiologische Methoden}

\subsubsection{Isolation von genomischer DNA}

Die Isolation von genomischer DNA aus kultivierten LCL-Zellen erfolgte mithilfe des QIAamp $^{\text {TM }}$ DNA Blood Mini Kits gemäß Protokoll. Für die Isolation wurden ca. $1 \times 10^{6}$ Zellen eingesetzt. Die gewonnene DNA wurde in einem Volumen von $100 \mu$ l eluiert und bis zur weiteren Verwendung bei $4^{\circ} \mathrm{C}$ gelagert. 


\subsubsection{Isolation von RNA und reverse Transkription}

Die Isolation von RNA aus den vorbereiteten Zellsuspensionen (siehe Punkt 3.2.5) erfolgte mithilfe des RNeasy ${ }^{\mathrm{TM}}$ Mini Kits nach Vorgaben des Herstellers. Die RNA wurde in einem Volumen von $40 \mu$ eluiert und bei $-80^{\circ} \mathrm{C}$ aufbewahrt.

Unter Verwendung des Kits SuperScript ${ }^{\mathrm{TM}}$ II Reverse Transcriptase erfolgte die reverse Transkription der zuvor gewonnenen RNA zu Erststrang-cDNA. $2 \mu$ Random Hexamer Primer $(100 \mu \mathrm{M}), 3 \mu \mathrm{g}$ RNA sowie destilliertem Wasser (Abk. $\mathrm{dH}_{2} \mathrm{O}$, ad $9 \mu \mathrm{l}$ ) wurden für zehn Minuten bei $70^{\circ} \mathrm{C}$ inkubiert und sofort auf Eis gestellt. Daraufhin wurde der Reaktionsansatz mit $4 \mu \mathrm{l} 5 \mathrm{x}$ Erststrang-Puffer, $2 \mu \mathrm{DTT}(0,1 \mathrm{M}), 1 \mu$ SuperScript $^{\mathrm{TM}}$ II RT (200 U/ $\mu \mathrm{l}), 1 \mu \mathrm{l}$ Desoxyribonukleosid-Triphosphat-Mix (Abk. dNTP, je $10 \mathrm{mM}$ ) sowie $1 \mu \mathrm{l} \mathrm{dH}_{2} \mathrm{O}$ versetzt, kurz abzentrifugiert, für 60 Minuten bei $42^{\circ} \mathrm{C}$ inkubiert und anschließend 10 Minuten lang bei $65^{\circ} \mathrm{C}$ inaktiviert. Bis zur weiteren Verwendung wurde die zu cDNA umgeschriebene RNA bei $-20^{\circ} \mathrm{C}$ gelagert.

\subsubsection{Konzentrationsbestimmung von Nukleinsäuren}

Die Bestimmung der Konzentration isolierter DNA sowie RNA erfolgte mittels photometrischer Messung bei einer Wellenlänge von $260 \mathrm{~nm}$ unter Verwendung des NanoDrop ${ }^{\circledR}$ ND-1000 Spectrophotometers.

\subsubsection{Genotypisierungsanalysen}

PCR-Analysen

Mittels PCR wurden die bereits vorliegenden DNA-Proben amplifiziert. Ein Reaktionsansatz setzte sich aus $5 \mu \mathrm{l}$ 10x PCR-Puffer, $1,5 \mu \mathrm{MgCl}_{2}, 1 \mu \mathrm{l}$ dNTP-Mix (je $10 \mathrm{mM}), 1 \mu \mathrm{l} \mathrm{IL} 10+4.259$ antisense Primer $(10 \mu \mathrm{M}), 1 \mu \mathrm{l} \mathrm{IL} 10+4.259$ sense Primer (10 $\mu \mathrm{M})$ und 0,3 $\mu \mathrm{l}$ Taq Polymerase zusammen. Desweiteren wurden $100 \mathrm{ng}$ DNA sowie doppelt destilliertem Wasser $\left(\right.$ Abk. $\mathrm{ddH}_{2} \mathrm{O}$, ad $\left.50 \mu \mathrm{l}\right)$ hinzugefügt. Nachfolgend die exakten PCR-Konditionen:

\begin{tabular}{|c|c|c|}
\hline Schritt 1 & $95^{\circ} \mathrm{C}$ & $5 \mathrm{~min}$ \\
\hline Schritt 2 & $60^{\circ} \mathrm{C}$ & $3 \mathrm{~min}$ \\
\hline Schritt 3 & $72^{\circ} \mathrm{C}$ & $2 \mathrm{~min}$ \\
\hline Schritt 4 & $95^{\circ} \mathrm{C}$ & $30 \mathrm{sec}$ \\
\hline Schritt 5 & $60^{\circ} \mathrm{C}$ & $30 \mathrm{sec}$ \\
\hline Schritt 6 & $72^{\circ} \mathrm{C}$ & $30 \mathrm{sec}$ \\
\hline
\end{tabular}


Desweiteren erfolgte die Amplifikation von DNA-Fragmenten, welche die distalen Genvariationen IL-10 ${ }_{12.806 \mathrm{TC}}$ (rs17015865), IL-10-11.777GA (rs4072227) sowie IL-10 -11.668GA $_{\text {A }}$ (rs4072226) beinhalteten. Der Reaktionsansatz entsprach dem oben aufgeführten, als Primer wurden die Oligonukleotide IL10-12.800-fwd sowie IL10-12.800-rev (je $10 \mu \mathrm{M}$ ) eingesetzt. Nachfolgend die exakten PCR-Konditionen:

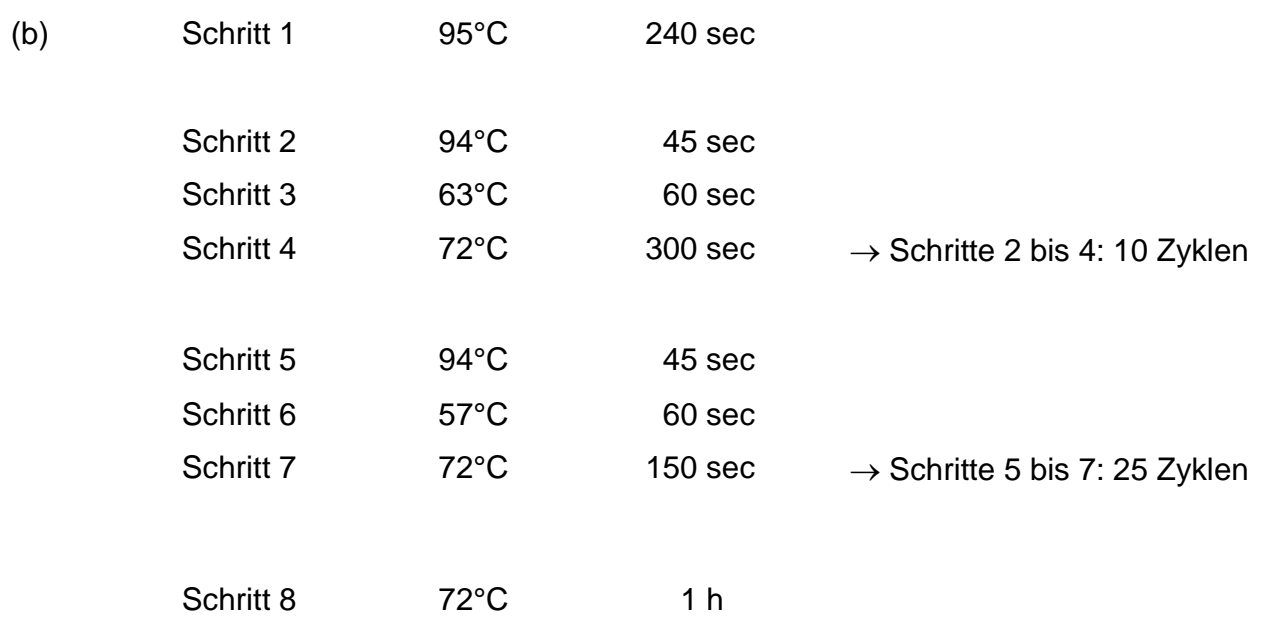

Außerdem wurden PCRs mit fluoreszenzmarkierten Primern durchgeführt. 1 ng DNA wurde mithilfe der Oligonukleotide HexIL10+4.259antisense und HexIL10+4.259sense $(10 \mu \mathrm{M})$ amplifiziert, $500 \mathrm{ng} \mathrm{zu}$ cDNA umgeschriebene RNA mithilfe der Oligonukleotide 6-FamIL10+4.259antisense sowie 6-FamIL10+4.259sense. Auch hier entsprach ein Reaktionsansatz dem oben aufgeführten; die PCR-Konditionen sind bereits unter (b) wiedergegeben.

Der Erfolg der jeweiligen DNA-Amplifikationen wurde mithilfe eines 1\%igen AgaroseGels überprüft.

\section{DNA-Sequenzierung}

Zunächst wurden die mittels PCR amplifizierten DNA-Fragmente mithilfe des QIAquick $^{\text {TM }}$ PCR Purification Kits gemäß Protokoll aufgereinigt. Daraufhin erfolgte die Analyse der Nukleotidsequenzen unter Verwendung des BigDye ${ }^{\circledR}$ Terminator Cycle Sequencing Kits v1.1. Ein Reaktionsansatz setzte sich aus $0,5 \mu \mathrm{l}$ Primer $(10 \mathrm{pmol} / \mu \mathrm{l}$, forward bzw. reverse), 1,5 $\mu$ l Sequenzierungsmix und 1,25 $\mu$ l 5x Sequenzierungspuffer zusammen. Diesem wurden 30 ng DNA sowie ddH2O (ad $10 \mu l$ ) hinzugefügt. Die 
verwendeten Oligonukleotide sind Tabelle 6 zu entnehmen. Nachfolgend die exakten Inkubationsbedingungen:

$\begin{array}{llll}\text { Schritt 1 } & 96^{\circ} \mathrm{C} & 30 \mathrm{sec} & \\ \text { Schritt 2 } & 50^{\circ} \mathrm{C} & 15 \mathrm{sec} & \\ \text { Schritt 3 } & 60^{\circ} \mathrm{C} & 240 \mathrm{sec}\end{array} \rightarrow$ Schritte 1 bis 3: 25 Zyklen

Nachdem die PCR-Fragmente unter Verwendung des DyeEx ${ }^{\mathrm{TM}} 2.0$ Spin Kits nach Herstellerangaben aufgereinigt worden waren, wurden je $10 \mu \mathrm{l}$ der

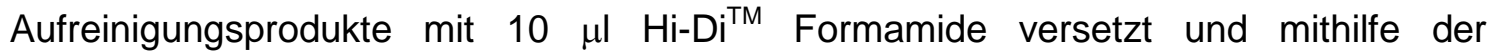
Sequencing Analysis Software v5.2 im 3130 Genetic Analyzer sequenziert. Zwecks Durchführung der Alignments wurde die Software CLC Free Workbench v.3.2.2 eingesetzt.

\section{SNaPshot}

Zwecks simultaner Genotypisierung mehrerer SNPs wurde die SNaPshot-Analyse zu einem Multiplex Assay weiterentwickelt. Das SNaPshot-Verfahren beginnt wie eine PCR mit den Schritten Denaturierung, Primerhybridisierung und Elongation. Nach der Denaturierung der Doppelstränge zu Einzelsträngen erfolgt genau eine Base vor dem zu untersuchenden SNP die Anlagerung eines Extensionsprimers an das 3'-Ende des Einzelstrangs, was als Primerhybridisierung bezeichnet wird. Während der Elongationsphase bindet dann ein zur Base des SNPs komplementäres Didesoxyribonukleosid-Triphosphat (Abk. ddNTP) an den betreffenden SNP. Da das zum Einsatz kommende ddNTP bereits hydrolysiert ist, wird die Elongation unterbrochen. Weiterhin wurde jedes der vier ddNTPs spezifisch fluoreszenzmarkiert, so dass aufgrund von farblichen Signalen später ermittelt werden kann, welches Allel an der Stelle des SNPs exprimiert wird ( $\mathrm{A}=$ grün, $\mathrm{C}=$ schwarz, $\mathrm{G}=$ blau, $\mathrm{T}=\mathrm{rot}$ ). $\mathrm{Da}$ gleichzeitig mehrere SNPs untersucht werden sollten, wurden die eingesetzten Primer so gewählt, dass aufgrund unterschiedlicher Sequenzlängen eine spätere Zuordnung zu den jeweiligen SNPs möglich war. Im Anschluss erfolgte die Aufreinigung bereits amplifizierter DNA-Fragmente, um nicht eingebaute ddNTPs sowie überschüssige Primer aus dem Reaktionsansatz zu entfernen. Das Prinzip der SNaPshot-Analyse wird nochmals in Abbildung 3 dargestellt. 


$$
\text { NNAGCATGCTCAATCGAATCCAGNNNNN }
$$

\section{NNTCGTACGAGTTAGCTTAGGTCNNNNN}

(2)
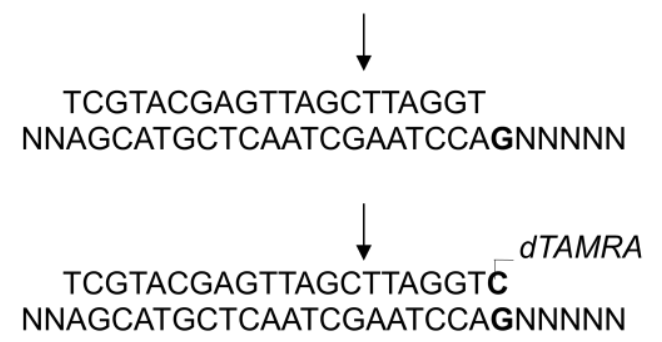

(4)

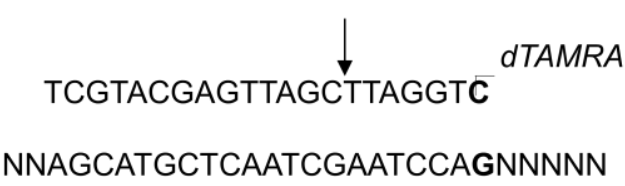

Abbildung 3: Schematische Darstellung der SNaPshot-Analyse. Nach Denaturierung der Doppelstränge zu Einzelsträngen (1) und Primerhybridisierung (2) bindet ein zum Zielnukleotid komplementäres fluoreszenzmarkiertes Didesoxynukleotid an den Primer (3). Der Aufreinigung folgt eine erneute Denaturierung (4). dTAMRA: Fluoreszenzfarbstoff.

Zwecks Aufreinigung wurden je 1,5 $\mu \mathrm{l}$ 10x SAP-Reaktionspuffer mit 3,3 $\mu \mathrm{LSAP}, 0,2 \mu \mathrm{l}$ Exonuklease 1 sowie $10 \mu \mathrm{l}$ der PCR-Produkte versetzt. Da es sich bei den SNaPshotAnalysen um einen Multiplex Assay handelte, mifhilfe dessen vier verschiedene SNPs (IL-10-12.806TC, IL-10 -11.777GA, IL-10 $_{-11.668 \mathrm{GA}}$, IL-10 $\left.{ }_{+4.259 \mathrm{AG}}\right)$ simultan untersucht werden sollten, setzten sich die $10 \mu \mathrm{l}$ PCR-Produkt aus je $5 \mu$ der mithilfe der Oligonukleotide IL10-12.800-fwd und IL10-12.800-rev (IL-10-12.806TC, IL-10-11.777GA, IL-10-11.668GA) sowie IL10+4.259antisense und IL10+4.259sense (IL-10+4.259AG) amplifizierten DNAFragmente zusammen. Daraufhin erfolgten eine einstündige Inkubation bei $37^{\circ} \mathrm{C}$ sowie - zwecks Hitzeinaktivierung der Enzyme - ein 15-minütiges Intervall bei $80^{\circ} \mathrm{C}$. Der nächste Schritt bestand in der eigentlichen SNaPshot-Reaktion, wobei das ABI PRISM ${ }^{\circledR}$ SNaPshot ${ }^{\mathrm{TM}}$ Multiplex Kit zum Einsatz kam. Ein Reaktionsansatz setzte sich aus 0,64 $\mu \mathrm{l}$ SNaPshot Multiplex Ready Reaction Mix, 0,25 $\mu$ l gepooltem Primer-Mix, 2,11 $\mu \mathrm{lddH} 2 \mathrm{O}$ und $2 \mu \mathrm{l}$ des aufgereinigten PCR-Produkts zusammen. Der gepoolte Primer-Mix wurde aus den Oligonukleotiden IL10-12.806CT (3,5 $\mu$ l), IL10-11.777AG (2 $\mu \mathrm{l})$, IL10-11.668AG $(1,5 \mu \mathrm{l})$ und IL10+545Ex5 (2 $\mu \mathrm{l})$ sowie ddH2O (ad $100 \mu \mathrm{l})$ hergestellt. Die Konzentrationen der Stammlösungen betrugen jeweils $100 \mu \mathrm{M}$. Die Reaktionen wurden auf einer 384-Loch-Platte durchgeführt, welche nach kurzer Zentrifugation unter folgenden Bedingungen im PTC-100 ${ }^{\mathrm{TM}}$ Programmable Thermal Controller inkubiert wurde: $96^{\circ} \mathrm{C}$ für 10 Sekunden, $50^{\circ} \mathrm{C}$ für 5 Sekunden sowie $60^{\circ} \mathrm{C}$ für 
30 Sekunden bei einer Zyklenanzahl von 24. Im Anschluss erfolgte eine weitere Aufreinigung der Proben, wofür diesen jeweils $0,5 \mu \mathrm{l}$ SAP sowie $0,5 \mu \mathrm{l} 10 \mathrm{x}$ SAPReaktionspuffer hinzugegeben wurde. Die Inkubationsbedingungen entsprachen denen nach dem ersten Aufreinigungsschritt: $37^{\circ} \mathrm{C}$ für eine Stunde, gefolgt von $80^{\circ} \mathrm{C}$ für 15 Minuten. Nun konnten die Proben für die endgültige Analyse im 3130 Genetic Analyzer, welche einer Kapillarelektrophorese entspricht, vorbereitet werden. Hierfür wurden je 9,85 $\mu \mathrm{l} \mathrm{Hi-Di{ } ^ { \mathrm { TM } }}$ Formamide, 0,15 $\mu$ GeneScan $^{\mathrm{TM}} 120$ LIZ® Size Standard sowie $1 \mu$ Restriktionsprodukt (in einer Verdünnung von 1:10) auf einer 96-Loch-Platte bei $95^{\circ} \mathrm{C}$ für 5 Minuten denaturiert. Die Auswertung erfolgte mithilfe der GeneScan ${ }^{\circledR}$ Analysis Software v3.1.

\section{Restriktionsendonuklease-Verdau}

Zwecks späterer Bestimmung der IL-10-Transkriptmenge mithilfe einer Analyse von Restriktionsfragmentlängenpolymorphismen durchliefen die - nach Durchführung einer PCR mit fluoreszenzmarkierten Primern - bereits amplifizierten DNA- und zu cDNA umgeschriebenen RNA-Fragmente einen Restriktionsendonuklease-Verdau. Hierfür wurde das Restriktionsenzym Fnu4HI ausgewählt, welches die Schnittstellen 5'...GCNGC...3' sowie 3'...CGNCG...5' erkennt. Ein Reaktionsansatz (50 $\mu$ l) setzte sich aus $0,5 \mu \mathrm{l}$ Fnu4HI, $5 \mu \mathrm{l}$ 10x NEBuffer $4,19,5 \mu \mathrm{lddH} 2 \mathrm{O}$ sowie $25 \mu \mathrm{l}$ PCR-Produkt zusammen. Der Verdau erfolgte zunächst bei $37^{\circ} \mathrm{C}$ für zwei Stunden, gefolgt von einem 20-minütigen Intervall bei $65^{\circ} \mathrm{C}$ zwecks Hitzeinaktivierung des Restriktionsenzyms. Später wurde dazu übergegangen, den Verdau über Nacht durchzuführen, da die Spaltung auf diese Art und Weise besser gelang. In diesem Falle wurden nur $0,2 \mu \mathrm{l} \mathrm{Fnu4HI} \mathrm{eingesetzt} \mathrm{und} \mathrm{die} \mathrm{Proben} \mathrm{bei} 37^{\circ} \mathrm{C}$ für 16 Stunden inkubiert. Mithilfe eines 1,3\%igen Agarose-Gels wurde überprüft, ob der Restriktionsendonuklease-Verdau erfolgreich war.

\subsubsection{Analyse der IL-10-Genexpression}

Zwecks Bestimmung der IL-10-Transkriptmenge wurden zwei unterschiedliche Methoden angewendet. Zum einen erfolgte die Diskriminierung und Quantifizierung unterschiedlicher Transkriptmengen mittels Durchführung von Real-Time PCRAnalysen. Weiterhin wurde auf RNA-Ebene eine Analyse von Restriktionsfragmentlängenpolymorphismen vorgenommen. Untersucht wurde jeweils der

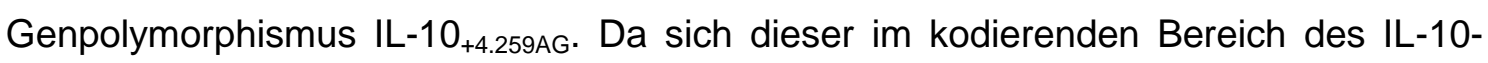
Gens befindet, war folglich auch ein Nachweis auf mRNA-Ebene (engl. messenger $R N A)$ möglich. 


\section{Real-Time PCR-Analysen}

Quantitative Real-Time PCR-Analysen wurden mithilfe eines auf SYBR Green basierenden Systems durchgeführt. Bei SYBR Green handelt es sich um einen Fluoreszenzfarbstoff, welcher von doppelsträngiger DNA gebunden wird und bei einer Wellenlänge von $521 \mathrm{~nm}$ grünes Licht emittiert. Dabei nimmt die Fluoreszenz proportional zu der Menge der PCR-Produkte zu. Ein Reaktionsansatz setzte sich aus $5 \mu \mathrm{l}$ SYBR ${ }^{\circledR}$ Green Master Mix, $1 \mu$ l zuvor zu cDNA umgeschriebener RNA (5 ng), 0,25 $\mu$ l qRT_IL-10_fwd $(10 \mu \mathrm{M}), 0,25 \mu \mathrm{l}$ qRT_IL-10_rev $(10 \mu \mathrm{M})$ und ddH2O (ad $10 \mu \mathrm{l})$ zusammen. Für jede Probe wurde eine Dreifachbestimmung durchgeführt. Als Housekeeping-Gen kam 18S zum Einsatz. Die Analysen erfolgten mittels 7900 HT Fast Real-Time PCR System. Nachfolgend die exakten PCR-Konditionen:

$\begin{array}{llll}\text { Schritt 1 } & 50^{\circ} \mathrm{C} & 2 \mathrm{~min} \\ \text { Schritt 2 } & 95^{\circ} \mathrm{C} & 10 \mathrm{~min} & \\ & & \\ \text { Schritt 3 } & 95^{\circ} \mathrm{C} & 15 \mathrm{sec} & \\ \text { Schritt 4 } & 60^{\circ} \mathrm{C} & 60 \mathrm{sec} & \rightarrow \text { Schritte 3 bis 4: } 40 \text { Zyklen }\end{array}$

Daraufhin wurde eine Schmelzkurvenanalyse $\left(95^{\circ} \mathrm{C}\right.$ für $15 \mathrm{sec}, 60^{\circ} \mathrm{C}$ für $15 \mathrm{sec}, 95^{\circ} \mathrm{C}$ für $15 \mathrm{sec}$ ) durchgeführt, anhand derer die Fragmentlängen und damit die spezifische Amplifikation eines PCR-Produkts überprüft werden konnten.

\section{Bestimmung der relativen Transkript-Menge}

Um einen Amplifikationsplot auswerten zu können, wurde der Schwellenwert in den exponentiellen Bereich der PCR gelegt, da sich hier einzelne Reaktionen untereinander vergleichen lassen. Der CT-Wert (engl. cycle threshold) für diese Reaktion entspricht dem Schnittpunkt einer Fluoreszenzkurve mit dem Schwellenwert und gibt Auskunft über den Zyklus, bei dem das Fluoreszenzsignal erstmalig signifikant über den Schwellenwert ansteigt. Je geringer der CT-Wert ausfällt, desto höher war die Transkript-Menge der Probe.

Um die relativen RNA-Mengen zu berechnen, wurde die Differenz aus den spezifischen CT-Werten sowie dem CT-Wert des Housekeeping-Gens $18 \mathrm{~S}$ berechnet: 


$$
\mathrm{CT}_{\text {spez. }}-\mathrm{CT}_{18 \mathrm{~S}}=\Delta \mathrm{CT}
$$

\section{Analyse von Restriktionsfragmentlängenpolymorphismen}

Nach Durchführung des Restriktionsendonuklease-Verdaus mit Fnu4H1 erfolgte die Vorbereitung der Proben für die endgültige Analyse im 3130 Genetic Analyzer. Hierfür wurden je $12 \mu \mathrm{l} \mathrm{Hi-Di{ } ^ { T M }}$ Formamide, 0,15 $\mu$ GeneScan $^{\mathrm{TM}}$ 400HD ROX ${ }^{\mathrm{TM}}$ Size Standard sowie $2 \mu$ l Restriktionsprodukt (Zusammensetzung: $1 \mu$ l Restriktionsprodukt der zuvor amplifizierten und aufgereinigten DNA sowie $1 \mu$ l Restriktionsprodukt der bereits amplifizierten und aufgereinigten zu cDNA umgeschriebenen RNA, jeweils in einer Verdünnung von 1:10) auf einer 96 -Loch-Platte bei $95^{\circ} \mathrm{C}$ für 5 Minuten denaturiert. Die Auswertung erfolgte mithilfe der GeneScan ${ }^{\circledR}$ Analysis Software v3.1, die Bestimmung der IL-10-Transkriptmenge bei heterozygoten Trägern mittels Berechnung der Flächen unter den Peaks.

\subsection{Immunologische Methoden}

\subsubsection{Enzyme-linked immunosorbent assay (ELISA)}

Die Höhe der IL-10-Sekretion wurde mittels ELISA unter Verwendung der zuvor - wie unter Punkt 3.2.4 beschrieben - gewonnenen Überstände der kultivierten LCL-Zellen bestimmt. Hierfür wurde das IL-10 Eli-pair ELISA Kit gemäß Herstellerangaben verwendet. Die Absorption der Proben wurde mithilfe des Synergy HT Multi-Mode Microplate Readers bei einer Wellenlänge von $450 \mathrm{~nm}$ detektiert.

\subsection{Definitionen und statistische Analysen}

In der vorliegenden Dissertation umfasst der Begriff Gesamtüberleben die Zeitspanne zwischen Therapiebeginn und Tod des Patienten aus jeglichen Gründen. Ereignisfreies Überleben definiert den Zeitraum zwischen Therapiebeginn und einer Vielzahl von Ereignissen wie Progression der Tumorerkrankung unter Therapie, ausbleibende komplette Remission, zusätzliche Anwendung weiterer Therapieschemata neben dem definiertem Therapieprotokoll, Rezidiv oder Tod des Patienten aus jeglichen Gründen.

Die erste Analyse der Daten erfolgte mithilfe der Software Genepop und beinhaltete Berechnungen des Hardy-Weinberg-Gleichgewichts sowie allelischer und genotypischer Unterschiede zwischen DLBCL-Patienten sowie gesunden Kontrollprobanden.

Die Berechnung von Gesamtüberleben und ereignisfreiem Überleben erfolgte nach Kaplan-Meier. Beide Überlebenskurven wurden mithilfe des log-rank Tests verglichen. 
Die zusätzliche Anwendung des Cox-Regressionsmodells diente der multivariaten Analyse zwecks simultaner Betrachtung verschiedener prognostischer Faktoren. Die statistische Überlebenszeitanalyse wurde von Dipl.-Inf. Markus Kreuz vom Institut für Medizinische Informatik, Statistik und Epidemiologie (Abk. IMISE) der Medizinischen Fakultät der Universität Leipzig durchgeführt. 


\section{$4 \quad$ Ergebnisse}

\subsection{Identifizierung distaler Genvariationen des IL-10-Genlokus}

\subsubsection{Ergebnisse der DNA-Sequenzierung}

Mittels DNA-Sequenzierung wurde ein distaler Teilbereich des IL-10-Genlokus analysiert und die in der SNP-Datenbank bereits beschriebenen, aber noch nicht weiter charakterisierten Polymorphismen IL-10-12.806TC, IL-10-11.777GA und IL-10-11.668GA (http://www.ncbi.nlm.nih.gov/snp) identifiziert. Innerhalb des sequenzierten Bereichs konnten keine weiteren, bisher unbekannten Polymorphismen gefunden werden. Die Ergebnisse der Sequenzierungsanalysen sind in Anhang $A$ aufgeführt. Abbildung 4 illustriert beispielhaft den Nachweis des Genotyps IL-10 ${ }_{-11.668 \mathrm{GG}}$ bei der LCL-Zelle 8/2.
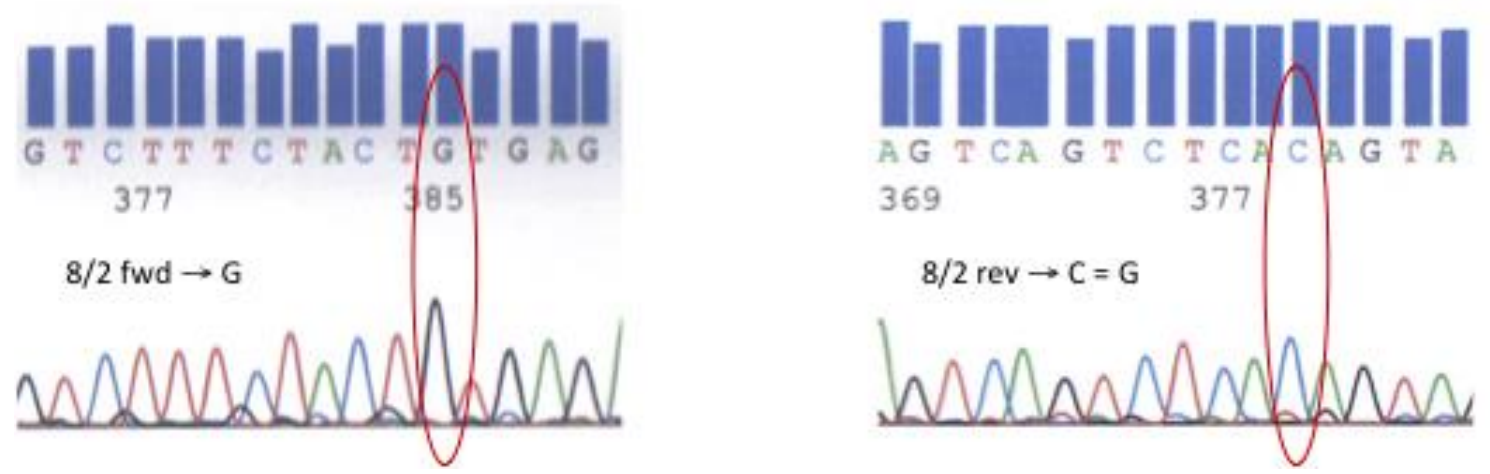

Abbildung 4: Elektropherogramm der Sequenzierungsreaktion eines Fragments der distalen 5'-

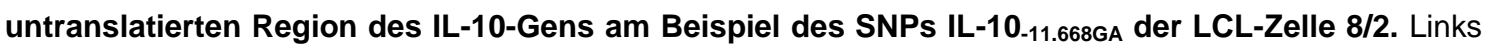
ist die DNA-Sequenz dargestellt, die mithilfe des forward Primers gelesen werden konnte und den Nachweis der Base G erbrachte; rechts die Sequenz des komplementären Gegenstrangs nach Einsatz des reverse Primers mit Nachweis der Base C, womit die links dargestellte Sequenz bestätigt werden konnte (= Genotyp IL-10 $11.668 G \mathrm{G})$.

\subsubsection{Etablierung eines Multiplex Assays zwecks Genotypisierung von IL-10- Genvariationen}

Im Rahmen der vorliegenden Dissertation konnte das SNaPshot-Verfahren erfolgreich weiterentwickelt werden. Die SNaPshot-Analysen wurden mit dem Ziel durchgeführt, sowohl an einem DLBCL erkrankte Patienten als auch gesunde Kontrollprobanden bezüglich bestimmter Promotorpolymorphismen zu genotypisieren. Das bereits bekannte Verfahren der SNaPshot-Analyse wurde zu einem Multiplex Assay erweitert,

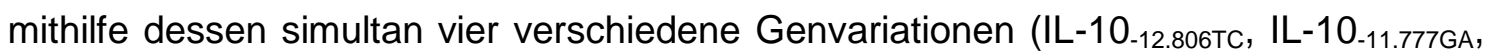


IL-10 ${ }_{-11.668 G A}$, IL-10 $\left.{ }_{+4.259 A G}\right)$ untersucht werden konnten. Die Etablierung dieser Methode war erfolgreich; die Ergebnisse sind in Anhang $B$ und $C$ aufgeführt.

Da spezifisch fluoreszenzmarkierte ddNTPs eingesetzt wurden, konnten die exprimierten Allele anhand von farblichen Signalen bestimmt werden. Grüne Peaks entsprachen dem Allel A, schwarze Peaks dem Allel G, blaue Peaks dem Allel G sowie rote Peaks dem Allel T. Bei homozygoten Trägern war jeweils nur ein Peak auszumachen, während sich heterozygote Träger durch das Vorhandensein von zwei verschiedenen Peaks auszeichneten. Abbildung 5 zeigt exemplarisch die für die in

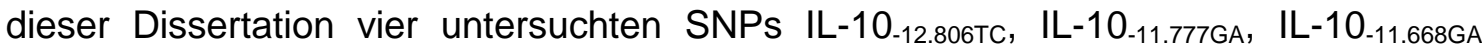
sowie IL-10 ${ }_{+4.259 A G}$ homozygote LCL-Zelle 16 des internationalen HapMap-Projektes.

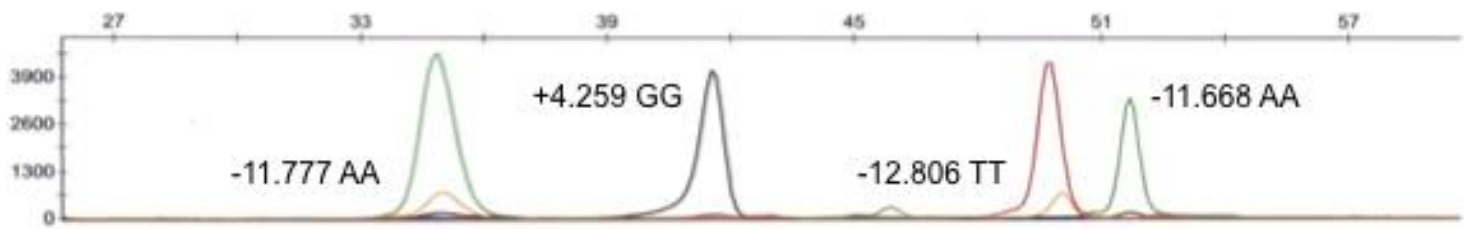

Abbildung 5: Elektropherogramm eines Multiplex Assays mit simultaner Analyse mehrerer SNPs am Beispiel der LCL-Zelle 16 des internationalen HapMap-Projektes. Dargestellt sind die Größe der einzelnen Fragmente (x-Achse) bzw. die Fluoreszenzintensität (y-Achse). Da fluoreszenzmarkierte ddNTPs zum Einsatz kamen, konnte anhand der farblichen Signale ermittelt werden, welches Allel an der Stelle des jeweiligen SNPs exprimiert wird. Beispielsweise wurde bei $35 \mathrm{bp}$, wo sich der SNP IL-10 $11.777 \mathrm{GA}$ darstellt, lediglich ein grün fluoreszierendes Fragment detektiert, welches dem Allel A entspricht, womit folglich der Genotyp IL-10-11.777AA nachgewiesen werden konnte. Die Genotypisierung hat ergeben, dass

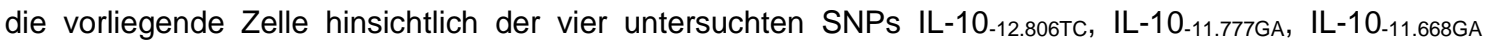
sowie IL-10+4.259AG jeweils homozygot ist.

Abbildung 6 zeigt exemplarisch die für sämtliche hier analysierten Polymorphismen heterozygote LCL-Zelle 15 des internationalen HapMap-Projektes. 


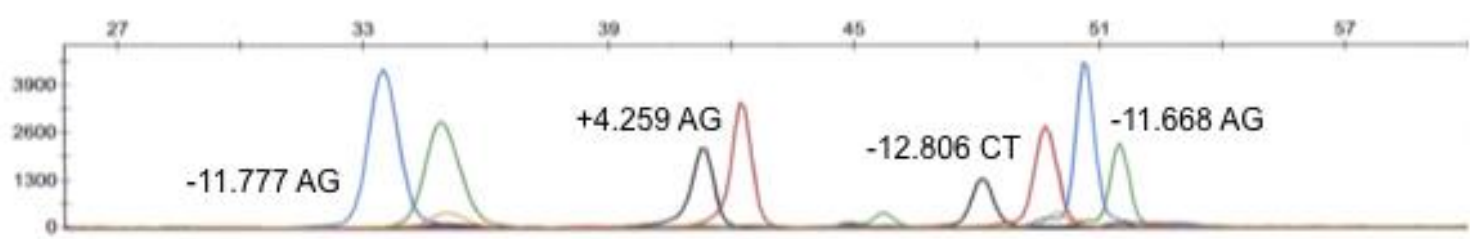

Abbildung 6: Elektropherogramm eines Multiplex Assays mit simultaner Analyse mehrerer SNPs am Beispiel der LCL-Zelle 15 des internationalen HapMap-Projektes. Dargestellt sind die Größe der einzelnen Fragmente (x-Achse) bzw. die Fluoreszenzintensität (y-Achse). Da fluoreszenzmarkierte ddNTPs zum Einsatz kamen, konnte anhand der farblichen Signale ermittelt werden, welches Allel an der Stelle des jeweiligen SNPs exprimiert wird. Beispielsweise wurden zwischen 33 und 36 bp, wo sich der SNP IL-10-11.777GA darstellt, ein blau sowie ein grün fluoreszierendes Fragment detektiert, welche den Allelen A bzw. G entsprechen, womit der Genotyp IL-10-11.777GA nachgewiesen werden konnte. Die Genotypisierung hat ergeben, dass die vorliegende LCL-Zelle hinsichtlich der vier untersuchten Genvariationen IL-10-12.806TC, IL-10-11.777GA, IL-10-11.668GA sowie IL-10+4.259AG jeweils heterozygot ist.

Proben, die zu internen Kontrollzwecken sowohl sequenziert als auch mittels SNaPshot genotypisiert worden waren, wiesen bei beiden Verfahren jeweils identische Genotypen auf.

\subsection{Genvariationsanalysen des Zytokins IL-10}

\subsection{1 Überblick über die durchgeführten Genvariationsanalysen}

Im Rahmen dieser Dissertation wurden Genvariationen im Promotorbereich des IL-10Gens analysiert. Hierfür wurde eine Kohorte von 594 Patienten mit diffus großzelligem B-Zell-Lymphom untersucht. Die Analyse wurde auf 135 gesunde Kontrollprobanden ausgeweitet, um auf diese Art und Weise Allelfrequenzen bei Erkrankten und gesunden Probanden vergleichen zu können; dies erfolgte jedoch nicht im Rahmen einer klassischen Fall-Kontroll-Studie.

Beide Kohorten wurden neben den distalen Genvariationen IL-10 $12.806 \mathrm{TC}, \mathrm{IL}-10_{-11.777 \mathrm{GA}}$ sowie IL-10-11.668GA auch hinsichtlich der Genvariation IL-10+4.259AG im Bereich der 3'UTR näher betrachtet.

Die Genotypisierung der Patienten wurde von Angela Lenz (MTA) unterstützt.

\subsubsection{Analyse von IL-10-Genvariationen bei DLBCL-Patienten}

Um ggf. einen Zusammenhang zwischen bestimmten IL-10-Genotypen sowie dem Gesamtüberleben und der ereignisfreien Überlebensrate von Patienten mit DLBCL herstellen zu können, wurde eine Kohorte von 594 Patienten analysiert. In Tabelle 7 sind die Namen der SNPs, refSNP Ids, die mittels SNaPshot ermittelte Verteilung der Genotypen innerhalb des Patientenkollektivs sowie das jeweilige Hardy-Weinberg- 
Gleichgewicht (Abk. HWG) aufgeführt. Bei diesem Patientenkollektiv befanden sich sämtliche analysierten Genvariationen im Gleichgewicht nach Hardy-Weinberg und konnten somit für weitere Untersuchungen eingesetzt werden.

Tabelle 7: Analysierte Genvariationen bei 594 DLBCL-Patienten, Verteilung der Genotypen sowie Hardy-Weinberg-Gleichgewicht. n. d.: engl. no data.

\begin{tabular}{ccccc}
\hline SNP & refSNP ID & Genotyp & Anzahl der Patienten & HWG $\left(\chi^{2}\right)$ \\
\hline IL-10-12.806TC & rs17015865 & CC & $377(63,5 \%)$ & 0,688 \\
& & CT & $192(32,3 \%)$ & \\
IL-10-11.777GA & rs4072227 & TT & $22(3,7 \%)$ & 0,8511 \\
& & n. d. & $3(0,5 \%)$ & \\
& AA & $513(86,4 \%)$ & 0,0909 \\
IL-10-11.668GA & AG & $74(12,4 \%)$ & \\
& rs4072226 & GG & $3(0,5 \%)$ & \\
& & n. d. & $4(0,7 \%)$ & \\
& AA & $92(15,5 \%)$ & 0,0599 \\
IL-10+4.259AG & AG 3024498 & GG & $307(51,7 \%)$ & \\
& & n. d. & $192(32,3 \%)$ & \\
& AA & AG & $346(58,2 \%)$ & \\
& & GG & $222(37,4 \%)$ & \\
& & n. d. & $22(3,7 \%)$ & \\
& & & $4(0,7 \%)$ & \\
& & &
\end{tabular}

Einfluss der IL-10-Genvariationen auf das Gesamtüberleben sowie ereignisfreie Überleben der DLBCL-Patienten

Die Analyse von IL-10-Genvariationen bei DLBCL-Patienten erfolgte in einer Kooperation mit dem IMISE der Universität Leipzig, welches auf sämtliche klinischen Daten aller DSHNHL-Studien Zugriff hat.

Durchgeführt wurde neben einer univariaten Analyse (log-rank Test, Tabelle 8) eine multivariate, auf IPI-Faktoren adjustierte Untersuchung (Cox-Regressionsmodell, Tabelle 9) der Genvariationen - jeweils hinsichtlich des Gesamtüberlebens und ereignisfreien Überlebens von 594 an einem DLBCL erkrankten Patienten. 
Tabelle 8: Univariate Analyse der IL-10-Genvariationen bezüglich des Gesamtüberlebens und ereignisfreien Überlebens von DLBCL-Patienten. OS: engl. overall survival. EFS: engl. event-free survival.

\begin{tabular}{lcc}
\hline IL-10-12.806TC & OS (p-Wert) & EFS (p-Wert) \\
\hline Trend & 0,989 & 0,466 \\
IL-10-12.806TT VS. IL-10-12.806CT & 0,256 & 0,883 \\
IL-10-12.806TT Vs. IL-10-12.806CC & 0,449 & 0,759 \\
IL-10-12.806CT vs. IL-10-12.806CC & 0,584 & 0,484 \\
IL-10-12.806TT/CT VS. IL-10-12.806CC & 0,753 & 0,459 \\
IL-10-12.806TT Vs. IL-10-12.806CT/CC & 0,366 & 0,795
\end{tabular}

\begin{tabular}{lcc}
\hline IL-10-11.777GA & OS (p-Wert) & EFS (p-Wert) \\
\hline IL-10-11.777AG VS. IL-10-11.777AA & 0,878 & 0,171 \\
IL-10-11.777GG/AG VS. IL-10-11.777AA & 0,854 & 0,136
\end{tabular}

\begin{tabular}{lcc}
\hline IL-10-11.668GA & OS (p-Wert) & EFS (p-Wert) \\
\hline Trend & 0,355 & 0,811 \\
IL-10-11.668AA vs. IL-10-11.668AG & 0,484 & 0,205 \\
IL-10-11.668AA vs. IL-10-11.668GG & 0,548 & 0,875 \\
IL-10-11.668AG Vs. IL-10-11.668GG & 0,118 & 0,188 \\
IL-10-11.668AA/AG Vs. IL-10-11.668GG & 0,146 & 0,306 \\
IL-10-11.668AA Vs. IL-10-11.668AG/GG & 0,869 & 0,378
\end{tabular}

\begin{tabular}{|c|c|c|}
\hline IL-10 $+4.259 A G$ & OS (p-Wert) & EFS (p-Wert) \\
\hline Trend & 0,705 & 0,399 \\
\hline IL-10 $+4.259 \mathrm{GG}$ vs. IL-10 $+4.259 \mathrm{AG}$ & 0,568 & 0,459 \\
\hline IL-10+4.259GG vs. IL-10+4.259AA & 0,581 & 0,418 \\
\hline IL-10 +4.259 AG vs. IL- $10_{+4.259 A A}$ & 0,922 & 0,609 \\
\hline IL-10+4.259GG/AG vs. IL-10 $+4.259 \mathrm{AA}$ & 0,825 & 0,503 \\
\hline IL-10 $+4.259 \mathrm{GG}$ Vs. IL-10 $+4.259 \mathrm{AG} / \mathrm{AA}$ & 0,571 & 0,429 \\
\hline
\end{tabular}

Die univariate Analyse der oben aufgeführten Genvariationen zeigte keine signifkanten Unterschiede bezüglich des Gesamtüberlebens und ereignisfreien Überlebens der DLBCL-Patienten, was ggf. auf die niedrige Frequenz der Minor-Allele zurückzuführen sein könnte. Da lediglich 0,5\% des Patientenkollektivs als homozygote Merkmalsträger

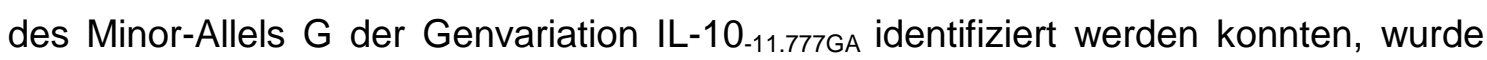
diese bei der univariaten Analyse nicht gesondert betrachtet.

Tabelle 9: Multivariate Analyse der IL-10-Genvariationen bezüglich des Gesamtüberlebens und ereignisfreien Überlebens von DLBCL-Patienten. RR: Relatives Risiko. KI: Konfidenzintervall. 


\begin{tabular}{|c|c|c|c|c|c|c|}
\hline \multirow{2}{*}{$\begin{array}{l}\text { IL-10-12.806TC } \\
\text { IPI-Faktoren }\end{array}$} & \multicolumn{3}{|c|}{ os } & \multicolumn{3}{|c|}{ EFS } \\
\hline & $\mathbf{R R}$ & $95 \% \mathrm{KI}$ & p-Wert & $\mathbf{R R}$ & $95 \% \mathrm{KI}$ & $p$-Wert \\
\hline Serum-LDH oberhalb des & 1,61 & $(1,13 ; 2,30)$ & 0,008 & 1,37 & $(1,00 ; 1,88)$ & 0,052 \\
\hline \multicolumn{7}{|l|}{ Referenzwertes } \\
\hline Alter > 60 Jahre & 2,55 & $(1,71 ; 3,81)$ & $<0,001$ & 1,75 & $(1,28 ; 2,39)$ & $<0,001$ \\
\hline ECOG Performance-Status $>1$ & 2,42 & $(1,69 ; 3,47)$ & $<0,001$ & 2,01 & $(1,45 ; 2,79)$ & $<0,001$ \\
\hline Ann Arbor Klassifikation > II & 1,61 & $(1,17 ; 2,22)$ & 0,004 & 1,63 & $(1,24 ; 2,13)$ & $<0,001$ \\
\hline > 1 extranodale Manifestation & 1,21 & $(0,85 ; 1,73)$ & 0,298 & 1,25 & $(0,92 ; 1,70)$ & 0,147 \\
\hline IL-10-12.806Cc VS. IL-10-12.806TT & 1,13 & $(0,55 ; 2,34)$ & 0,736 & 0,97 & $(0,50 ; 1,91)$ & 0,938 \\
\hline IL-10-12.806CC VS. IL-10-12.806TC & 0,96 & $(0,70 ; 1,32)$ & 0,809 & 1,12 & $(0,86 ; 1,46)$ & 0,389 \\
\hline
\end{tabular}

\begin{tabular}{lcccccr}
\hline IL-10-11.777GA & \multicolumn{3}{c}{ OS } & & & \multicolumn{2}{c}{ EFS } \\
\hline IPI-Faktoren & $\mathbf{R R}$ & $\mathbf{9 5} \% \mathbf{K I}$ & $\mathbf{p - W e r t}$ & $\mathbf{R R}$ & $\mathbf{9 5} \% \mathbf{K I}$ & $\mathbf{p}$-Wert \\
\hline $\begin{array}{l}\text { Serum-LDH oberhalb des } \\
\text { Referenzwertes }\end{array}$ & 1,64 & $(1,15 ; 2,34)$ & 0,006 & 1,39 & $(1,01 ; 1,90)$ & 0,067 \\
Alter > 60 Jahre & & & & & & \\
ECOG Performance-Status > 1 & 2,62 & $(1,75 ; 3,91)$ & $<0,001$ & 1,80 & $(1,32 ; 2,46)$ & $<0,001$ \\
Ann Arbor Klassifikation > II & 2,54 & $(1,78 ; 3,62)$ & $<0,001$ & 2,12 & $(1,54 ; 2,92)$ & $<0,001$ \\
$>$ 1 extranodale Manifestation & 1,63 & $(1,19 ; 2,25)$ & 0,003 & 1,66 & $(1,27 ; 2,17)$ & $<0,001$ \\
IL-10-11.777AA vs. IL-10-11.777GA & 1,29 & $(0,91 ; 1,84)$ & 0,151 & 1,34 & $(0,99 ; 1,81)$ & 0,057 \\
& 0,79 & $(0,50 ; 1,25)$ & 0,309 & 0,68 & $(0,45 ; 1,03)$ & 0,067
\end{tabular}

\begin{tabular}{lcccccc}
\hline IL-10-11.668GA & \multicolumn{7}{c}{ OS } & & & EFS \\
\hline IPI-Faktoren & RR & $\mathbf{9 5} \%$ KI & p-Wert & RR & $95 \%$ KI & p-Wert \\
\hline $\begin{array}{l}\text { Serum-LDH oberhalb des } \\
\text { Referenzwertes }\end{array}$ & 1,60 & $(1,12 ; 2,29)$ & 0,010 & 1,38 & $(1,00 ; 1,90)$ & 0,047 \\
Alter > 60 Jahre & & & & & & \\
ECOG Performance-Status > 1 & 2,55 & $(1,71 ; 3,80)$ & $<0,001$ & 1,71 & $(1,25 ; 2,34)$ & $<0,001$ \\
Ann Arbor Klassifikation > II & 2,42 & $(1,69 ; 3,48)$ & $<0,001$ & 2,03 & $(1,46 ; 2,81)$ & $<0,001$ \\
$>1$ extranodale Manifestation & 1,61 & $(1,17 ; 2,22)$ & 0,004 & 1,61 & $(1,23 ; 2,11)$ & $<0,001$ \\
IL-10-11.668GG vs. IL-10-11.668AA & 1,21 & $(0,85 ; 1,73)$ & 0,291 & 1,26 & $(0,93 ; 1,70)$ & 0,143 \\
IL-10-11.668GG Vs. IL-10-11.668GA & 0,86 & $(0,55 ; 1,33)$ & 0,498 & 1,02 & $(0,71 ; 1,47)$ & 0,899 \\
& 0,83 & $(0,60 ; 1,14)$ & 0,243 & 0,88 & $(0,67 ; 1,15)$ & 0,342
\end{tabular}

\begin{tabular}{|c|c|c|c|c|c|c|}
\hline \multirow{2}{*}{$\begin{array}{l}\text { IL-10+4.259AG } \\
\text { IPI-Faktoren }\end{array}$} & \multicolumn{3}{|c|}{ os } & \multicolumn{3}{|c|}{ EFS } \\
\hline & $\mathbf{R R}$ & $95 \% \mathrm{KI}$ & p-Wert & $\mathbf{R R}$ & $95 \% \mathrm{KI}$ & p-Wert \\
\hline Serum-LDH oberhalb des & 1,61 & $(1,13 ; 2,30)$ & 0,08 & 1,38 & $(1,00 ; 1,89)$ & 0,049 \\
\hline \multicolumn{7}{|l|}{ Referenzwertes } \\
\hline Alter $>60$ Jahre & 2,56 & $(1,72 ; 3,82)$ & $<0,001$ & 1,72 & $(1,26 ; 2,35)$ & $<0,001$ \\
\hline ECOG Performance-Status $>1$ & 2,41 & $(1,68 ; 3,45)$ & $<0,001$ & 2,02 & $(1,46 ; 2,81)$ & $<0,001$ \\
\hline Ann Arbor Klassifikation > II & 1,60 & $(1,16 ; 2,21)$ & 0,004 & 1,62 & $(1,24 ; 2,12)$ & $<0,001$ \\
\hline$>1$ extranodale Manifestation & 1,21 & $(0,85 ; 1,72)$ & 0,298 & 1,24 & $(0,92 ; 1,69)$ & 0,161 \\
\hline IL- $10_{+4.259 A A}$ vs. IL-10+4.259GG & 1,07 & $(0,52 ; 2,19)$ & 0,863 & 1,10 & $(0,59 ; 2,03)$ & 0,770 \\
\hline IL-10+4.259AA Vs. IL-10+4.259AG & 1,04 & $(0,77 ; 1,41)$ & 0,810 & 1,07 & $(0,82 ; 1,38)$ & 0,628 \\
\hline
\end{tabular}




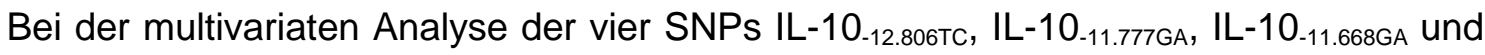
IL-10 $0_{+4.259 A G}$ wurden homozygote Merkmalsträger des Major-Allels mit homozyten Merkmalsträgern des Minor-Allels bzw. heterozygoten Merkmalsträgern, bei der Genvariation IL-10-11.777GA aufgrund einer zu geringen Fallzahl an homozygoten Merkmalsträgern des Minor-Allels $G$ hingegen lediglich homozygote Merkmalsträger des Major-Allels mit heterozygoten Merkmalsträgern verglichen. Die multivariate Analyse zeigte keine signifikanten Unterschiede hinsichtlich des Gesamtüberlebens sowie ereignisfreien Überlebens von DLBCL-Patienten. Bezüglich des ereignisfreien Überlebens lässt sich jedoch die Tendenz erkennen, dass homozygote Merkmalsträger des Major-Allels A der Genvariation IL-10 $11.777 \mathrm{GA}$ gegenüber heterozygoten Merkmalsträgern im Vorteil sein könnten; laut p-Wert $(=0,067)$ besitzt dies dieselbe Aussagekraft wie der etablierte IPI-Faktor Serum-LDH. Von den 594 hier analysierten DLBCL-Patienten wurden $87 \%$ als homozygote Merkmalsträger des Major-Allels identifiziert.

Folglich konnten die im Rahmen dieser Dissertation analysierten Genvariationen nicht als bisher unentdeckte Risikofaktoren für einen schlechten klinischen Verlauf von DLBCL-Patienten identifiziert werden, weshalb deren Stratifizierung in Therapiegruppen weiterhin gemäß IPI erfolgen muss. Auf eine Darstellung beider Analysen nach Kaplan-Meier wird aufgrund der fehlenden Signifikanz verzichtet.

\subsubsection{Analyse von IL-10-Genvariationen bei gesunden Kontrollprobanden}

Um Informationen über die Häufigkeiten der verschiedenen Genotypen in der Allgemeinbevölkerung zu erhalten, wurde die Analyse von IL-10-Genvariationen auf 135 gesunde Kontrollprobanden ausgeweitet. Von diesen Proben entfielen 23 auf LCLZellen des internationalen HapMap-Projektes, 28 auf LCL-Zellen, welche aus mononukleären Zellen des peripheren Blutes gesunder Spender gewonnen sowie 84 auf DNA-Proben, die aus Buffy coats isoliert worden waren. In Tabelle 10 sind die Namen der SNPs, refSNP IDs, die mittels SNaPshot ermittelte Verteilung der Genotypen des Kollektivs sowie die jeweiligen p-Werte des Hardy-WeinbergGleichgewichts aufgeführt.

Tabelle 10: Analysierte Genvariationen bei 135 gesunden Kontrollprobanden sowie Verteilung der Genotypen

$\begin{array}{lllll}\text { SNP } & \text { refSNP ID } & \text { Genotyp } & \text { Anzahl der Kontrollprobanden }\end{array}$




\begin{tabular}{|c|c|c|c|c|}
\hline \multirow[t]{3}{*}{ IL-10-12.806TC } & rs17015865 & $\mathrm{CC}$ & 66 (48,9 \%) & 0,675 \\
\hline & & CT & $59(43,7 \%)$ & \\
\hline & & TT & $10(7,4 \%)$ & \\
\hline \multirow[t]{3}{*}{ IL-10-11.777GA } & rs4072227 & $A A$ & $113(83,7 \%)$ & 0,599 \\
\hline & & $A G$ & $22(16,3 \%)$ & \\
\hline & & GG & $0(0 \%)$ & \\
\hline \multirow[t]{3}{*}{ IL-10-11.668GA } & rs4072226 & $A A$ & 25 (18,5 \%) & 0,734 \\
\hline & & $A G$ & $69(51,1 \%)$ & \\
\hline & & GG & $41(30,4 \%)$ & \\
\hline \multirow[t]{3}{*}{ IL- $10_{+4.259 A G}$} & rs3024498 & $A A$ & 65 (48,1 \%) & 0,417 \\
\hline & & $A G$ & $54(40,0 \%)$ & \\
\hline & & GG & $16(11,9 \%)$ & \\
\hline
\end{tabular}

\subsubsection{Vergleich der Genotypenverteilung bei DLBCL-Patienten und gesunden Kontrollprobanden}

Tabelle 11 führt die Genotypenverteilung bei den analysierten DLBCL-Patienten sowie gesunden Kontrollprobanden auf; die Bewertung erfolgte mithilfe des exakten Tests nach Fisher. Mittels zweiseitiger Analyse konnte nachgewiesen werden, dass die Genotypen der Genvariationen IL-10 $12.806 \mathrm{TC}$, IL-10 -11.777GA $_{\text {und IL-10 }}$-11.668GA in beiden Kohorten homogen verteilt sind. Bei den Patienten mit dem SNP IL-10 ${ }_{+4.259 A G}$ fiel hingegen ein signifikant höherer Anteil an Trägern des Genotyps AA auf, womit dieser ggf. für eine Erkrankung an einem DLBCL prädisponieren könnte.

Tabelle 11: Genotypenverteilung bei 594 DLBCL-Patienten und 135 gesunden Kontrollprobanden

\begin{tabular}{lccc}
\hline \multicolumn{1}{c}{ Genotyp } & Anzahl der Patienten & Anzahl der Kontrollprobanden & p-Wert \\
\hline IL-10-12.806TC & $377(63,5 \%)$ & $66(48,9 \%)$ & 0,07 \\
CC & $192(32,3 \%)$ & $59(43,7 \%)$ & \\
CT & $22(3,7 \%)$ & $10(7,4 \%)$ & \\
TT & $3(0,5 \%)$ & - & 0,502 \\
n. d. & & $113(83,7 \%)$ & \\
IL-10-11..777GA & $513(86,4 \%)$ & $22(16,3 \%)$ & \\
AA & $74(12,4 \%)$ & $0(0 \%)$ & \\
AG & $3(0,5 \%)$ & - & 0,813 \\
GG & $4(0,7 \%)$ & $25(18,5 \%)$ & \\
n. d. & & $69(51,1 \%)$ & \\
IL-10-11.668GA & $92(15,5 \%)$ & $41(30,4 \%)$ & \\
AA & $307(51,7 \%)$ & - & 0,02 \\
AG & $192(32,3 \%)$ & & \\
GG & $3(0,5 \%)$ & $65(48,1 \%)$ & \\
n. d. & $346(58,2 \%)$ & & \\
IL-10+4.259AG & & & \\
AA & &
\end{tabular}




$\begin{array}{lcc}\text { AG } & 222(37,4 \%) & 54(40,0 \%) \\ G G & 22(3,7 \%) & 16(11,9 \%) \\ \text { n. d. } & 4(0,7 \%) & -\end{array}$

\subsection{Analyse der IL-10-Genexpression}

Verschiedene Arbeitsgruppen haben die Hypothese aufgestellt, dass ein Zusammenhang zwischen SNPs des IL-10-Gens und der IL-10-Expressionshöhe besteht. Mittels ELISA sollte überprüft werden, ob interindividuelle Unterschiede bei der IL-10-Produktion tatsächlich existieren; hierfür wurde die Sekretionshöhe von IL-10 in Zellkultur-Überständen von LCL-Zellen bestimmt. Zwecks Analyse der IL-10Transkriptmenge wurden zwei unterschiedliche Methoden angewendet. Zunächst erfolgte die Diskriminierung und Quantifizierung unterschiedlicher Transkriptmengen mittels Durchführung von Real-Time PCR-Analysen. Weiterhin wurde eine Analyse von Restriktionsfragmentlängenpolymorphismen auf RNA-Ebene vorgenommen. Untersucht wurde jeweils die Genvariation IL-10 $0_{+4.259 \text { AG. }}$

\subsubsection{Nachweis interindividueller Unterschiede bei der IL-10-Sekretion mittels ELISA}

Zwecks Bestimmung der IL-10-Sekretionshöhe wurden die Überstände zuvor kultivierter Zellen mittels ELISA untersucht. Die Analyse der Überstände von zehn zuvor von der Arbeitsgruppe gewonnenen LCL-Zellen sowie neun LCL-Zellen des internationalen HapMap-Projektes zeigte signifikante Unterschiede in der Höhe der Sekretion von IL-10. Tabelle 12 und 13 geben die Resultate der Analyse wider; die Konzentrationen der z. T. verdünnt gemessenen Proben wurden zwecks Vergleichbarkeit mit den unverdünnt gemessenen Proben wieder mit dem Faktor 10 multipliziert. Sämtliche Werte für die optische Dichte befanden sich in einem linearen Messbereich und konnten folglich mittels Erstellung einer Standardkurve ausgewertet werden.

Tabelle 12: IL-10-Sekretion von LCL-Zellen der eigenen Arbeitsgruppe. Zellüberstände wurden mittels ELISA hinsichtlich ihrer IL-10-Sekretion untersucht, welche in $[\mathrm{pg} / \mathrm{ml}]$ angegeben wird. Weiterhin sind die dazugehörigen Genotypen der Genvariation IL-10+4.259AG aufgeführt.

\begin{tabular}{ccc}
\hline LCL & Genotyp & IL-10-Sekretion in [pg/ml] \\
\hline $7 / 3$ & GG & 1.090 \\
$9 / 1$ & AA & 240 \\
$31 / 1$ & AA & 210 \\
$49 / 1$ & AA & 470 \\
$59 / 3$ & GG & 60 \\
$60 / 2$ & AA & 400
\end{tabular}




$\begin{array}{ccc}102 / 2 & A A & 870 \\ 103 / 1 & A G & 1.360 \\ 103 / 2 & A G & 670 \\ 103 / 4 & A G & 320\end{array}$

Tabelle 13: IL-10-Sekretion von LCL-Zellen des internationalen HapMap-Projektes. Zellüberstände wurden mittels ELISA hinsichtlich ihrer IL-10-Sekretion untersucht, welche in $[\mathrm{pg} / \mathrm{ml}]$ angegeben wird. Weiterhin sind die dazugehörigen Genotypen des SNPs IL-10+4.259AG aufgeführt.

\begin{tabular}{ccc}
\hline LCL & Genotyp & IL-10-Sekretion in $[\mathrm{pg} / \mathbf{m l}]$ \\
\hline 12 & AG & 17 \\
13 & AG & 47 \\
14 & AG & 27 \\
15 & AG & 5 \\
21 & AA & 0 \\
22 & AA & 21 \\
23 & GG & 108 \\
24 & AA & 141 \\
30 & AG & 7
\end{tabular}

Die analysierten LCL-Zellen lassen sich anhand ihrer IL-10-Sekretion in Gruppen mit niedriger (<100 pg/ml), mittelhoher (zwischen 100 und $500 \mathrm{pg} / \mathrm{ml}$ ) und hoher (> 500 $\mathrm{pg} / \mathrm{ml}$ ) Sekretion einteilen. Werte unter $5 \mathrm{pg} / \mathrm{ml}$ sind unterhalb der Nachweisgrenze und wurden als „0“ gewertet. Anhand der vorliegenden Ergebnisse lässt sich keine eindeutige Assoziation zwischen Genotyp und IL-10-Sekretionshöhe nachweisen.

\subsubsection{Nachweis interindividueller Unterschiede der IL-10-Transkriptmenge mittels Real-Time PCR}

Mittels Real-Time PCR-Analysen konnten interindividuelle Unterschiede bezüglich der Transkriptmenge von IL-10 nachgewiesen werden. Untersucht wurden insgesamt 25 LCL-Zellen des internationalen HapMap-Projektes. Hierfür wurde zunächst RNA isoliert und diese nachfolgend zu cDNA umgeschrieben. Die Ergebnisse werden in Tabelle 14 aufgeführt.

Tabelle 14: Bestimmung der IL-10-Transkriptmenge mitttels Real-Time PCR. Hierfür wurde zu CDNA umgeschriebene RNA von 25 LCL-Zellen des internationalen HapMap-Projektes eingesetzt. Weiterhin sind die dazugehörigen Genotypen der Genvariation IL-10+4.259AG aufgeführt. 


\begin{tabular}{llc}
\hline 1 & GG & 13 \\
2 & GG & 19,59 \\
3 & AA & 16,04 \\
4 & AA & 15,95 \\
5 & AA & 15,65 \\
12 & AG & 15,38 \\
13 & AG & 15,76 \\
14 & AG & 15,62 \\
15 & AG & 14,28 \\
16 & GG & 12,7 \\
20 & AA & 16,91 \\
21 & AA & 23,54 \\
22 & AA & 14,53 \\
23 & GG & 14,77 \\
24 & AA & 15,68 \\
30 & AG & 16,05 \\
31 & AG & 17,8 \\
32 & AG & 13,76 \\
33 & AG & 19,2 \\
34 & AA & 21,6 \\
40 & AA & 17.01 \\
41 & AA & 15,41 \\
50 & AG & 15,22 \\
54 & AA & 14,87 \\
60 & GG & 19,82 \\
& &
\end{tabular}

Im Gegensatz zu den ELISA-Analysen war keine Tendenz zu niedriger, mittelhoher bzw. hoher Expression von IL-10 zu erkennen.

\subsubsection{Bestimmung der IL-10-Transkriptmenge mittels Analyse von Restriktionsfragmentlängenpolymorphismen}

Um die IL-10-Transkriptmenge mithilfe einer Analyse von Restriktionsfragmentlängenpolymorphismen bestimmen zu können, wurden die - nach Durchführung einer PCR mit fluoreszenzmarkierten Primern - amplifizierten Fragmente einem Restriktionsendonuklease-Verdau unterworfen. Hierbei kamen sowohl DNA- als auch zu cDNA-umgeschriebene RNA-Fragmente zum Einsatz. In einem späteren Schritt wurden bei heterozygoten Trägern nach Analyse im 3130 Genetic Analyzer die Flächen unterhalb der Peaks berechnet; durch die Untersuchung von zu cDNA umgeschriebener RNA sollte folglich überprüft werden, welches Allel bevorzugt transkribiert wird. 
Das amplifizierte DNA-Fragment wies eine Größe von 416 bp auf. Homozygote Träger des Allels A konnten nach abgeschlossenem Restriktionsendonuklease-Verdau durch nur ein vorliegendes Fragment von 416 bp identifiziert werden. Homozygote Träger des Allels G wiesen zwei kleinere Fragmente von 132 sowie 284 bp auf. Bei heterozygoten Trägern waren Fragmente von 132, 284 sowie 416 bp Größe zu finden. Neben Sequenzierung und SNaPshot-Analyse handelt es sich bei diesem Verfahren folglich um eine weitere Methode der Genotypisierung.

Abbildung 7 zeigt schematisch die Position der Genvariation IL-10 ${ }_{+4.259 \mathrm{AG}}$ im Bereich des IL-10-Gens sowie die Aufspaltungsmotive des amplifizierten DNA-Fragments nach Restriktionsendonuklease-Verdau mit Fnu4HI.

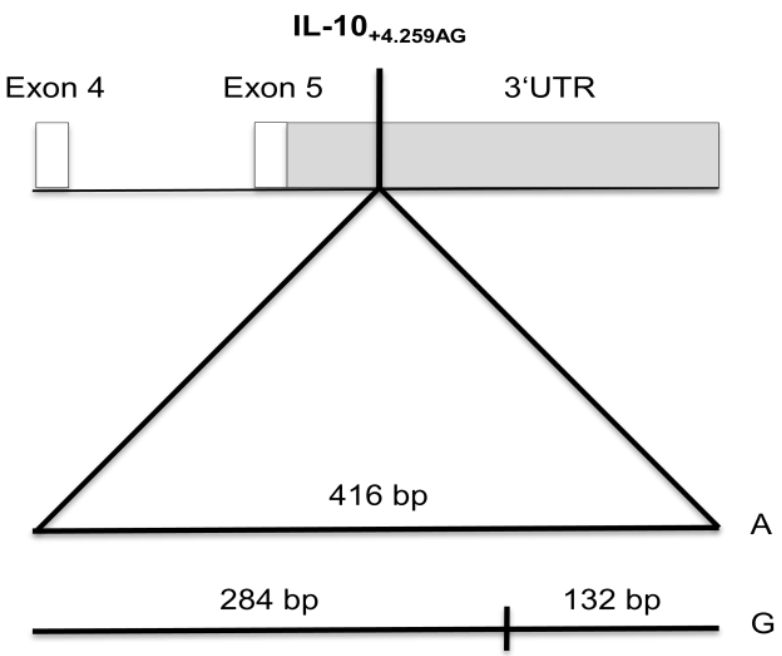

Abbildung 7: Schematische Darstellung der Postition der Genvariation IL-10+4.259AG sowie der Aufspaltungsmotive nach Restriktionsendonuklease-Verdau mit Fnu4HI. Bei homozygoten Trägern des Allels A wurde ein Fragment von 416 bp nachgewiesen, bei homozygoten Trägern des Allesl G zwei Fragmente von 132 und 284 bp, bei heterozygoten Trägern drei Fragmente von 132, 284 und 416 bp.

Abbildung 8 illustriert beispielhaft die Aufspaltungsmotive von fünf Proben nach Restriktionsendonuklease-Verdau mit Fnu4HI. Beim Vergleich der Fragmente der Proben 60/2 und Gö301 fällt auf, dass sich diese in ihrer Dicke deutlich unterscheiden, obwohl für die PCR identische Mengen an genomischer DNA eingesetzt wurden. 
60/2 102/2 Gö299 Gö300 Gö301

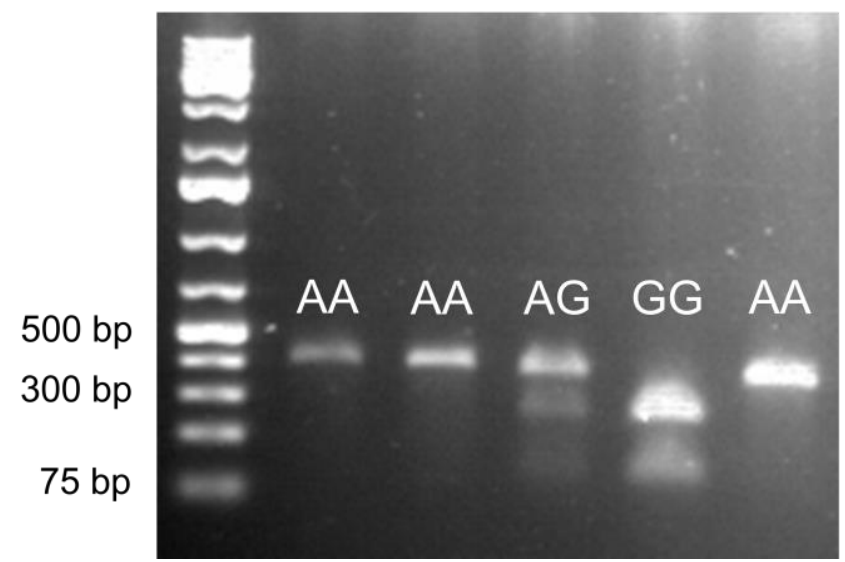

Abbildung 8: Restriktionsendonuklease-Verdau mit Fnu4HI. Dargestellt sind amplifizierte DNAFragemente gesunder Spender (60/2,102/2, Gö299, Gö300 und Gö301) nach RestriktionsendonukleaseVerdau mit Fnu4HI, welche auf ein 1,3\%iges Agarose-Gel aufgetragen wurden. Die Genotypen unterscheiden sich in der Anzahl der sichtbaren Banden. Homozygote Träger des Allels A zeichnen sich durch nur ein Fragment von 416 bp Größe aus, während bei homozygoten Trägern des Allels $\mathrm{G}$ zwei Banden von 132 und 284 bp Größe zu sehen sind. Bei heterozygoten Trägern findet man drei Spaltprodukte (132, 284 und 416 bp).

Der Restriktionsendonuklease-Verdau von zu cDNA umgeschriebener RNA zeigte die gleichen Aufspaltungsmotive wie auf DNA-Ebene (Genotyp AA: 416 bp; Genotyp AG: 132, 284 und 416 bp; Genotyp GG: 132 und 284 bp).

Im nächsten Schritt wurden die DNA- und RNA-Spaltprodukte mithilfe des 3130 Genetic Analyzers näher untersucht, wobei identische Genotypen wie bei der zuvor durchgeführten Gelektrophorese ermittelt werden konnten. Homozygote Träger des Allels A wiesen ein Peak bei 416 bp auf, homozygote Träger des Allels G insgesamt zwei Peaks bei jeweils 132 und 284 bp, heterozygote Träger dementsprechend drei Peaks bei 132, 284 und 416 bp. Grüne Peaks entsprechen den Spaltprodukten von DNA, welche zuvor unter Verwendung eines mit dem fluoreszierenden Farbstoff Hex markierten Primers amplifiziert worden war, blaue Peaks den Spaltprodukten von zu cDNA umgeschriebener RNA, für deren Vervielfältigung ein mit dem Fluoreszenzfarbstoff Fam markierter Primer zum Einsatz gekommen war.

Abbildung 9 illustriert die Analyse von Restriktionsfragmentlängenpolymorphismen mithilfe des 3130 Genetic Analyzers. Aufgeführt wird jeweils ein Beispiel für einen homozygoten Träger des Allels A (HapMap-LCL 4), einen homozygoten Träger des Allels G (HapMap-LCL 1) sowie einen heterozygoten Träger (HapMap-LCL 15). 


\section{(a)}

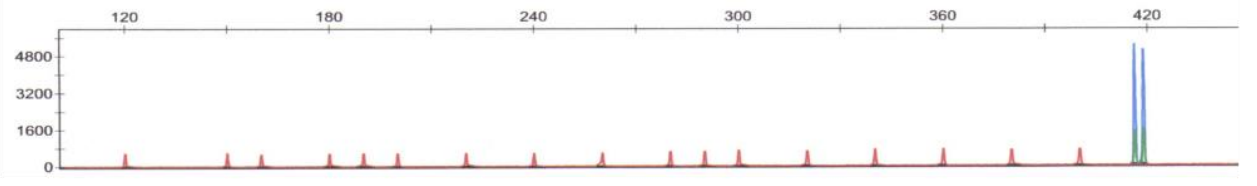

(b)

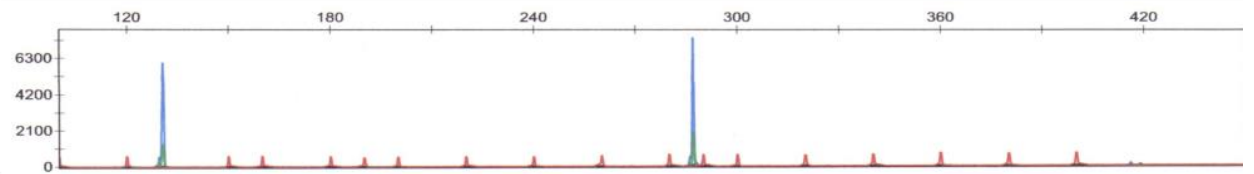

(c)

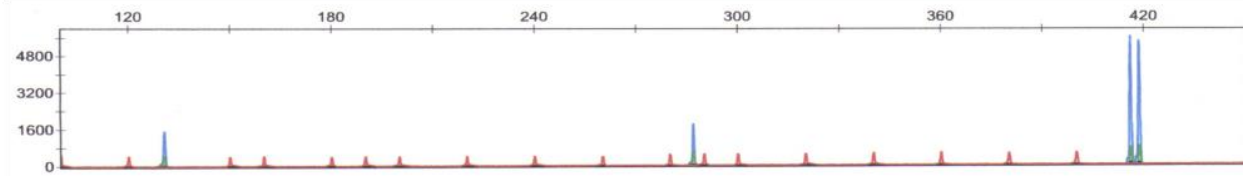

Abbildung 9: Elektropherogramm der Analyse von Restriktionsfragmentlängenpolymorphismen. (a) HapMap-LCL 4 mit einem Peak bei 416 bp entsprechend dem Genotypen AA. (b) Hap-Map-LCL 1 mit insgesamt zwei Peaks bei jeweils 132 und 284 bp entsprechend dem Genotypen GG. (c) Hap-Map-LCL 15 mit insgesamt drei Peaks bei jeweils 132, 284 und 416 bp entsprechend dem Genotypen AG. Spaltprodukte von DNA stellen sich in grün dar, Spaltprodukte von zu cDNA umgeschriebener RNA in blau. Doppelpeaks bei 416 bp wurden als PCR-Artefakt gewertet. Auf der x-Achse lässt sich die Größe des Fragmentes ablesen, auf der y-Achse die Fluoreszenzintensität.

Die auf diese Art und Weise ermittelten Genotypen stimmten mit den Ergebnissen der SNaPshot-Analysen überein. Somit konnte ausgeschlossen werden, dass der mittels Analyse von Restriktionsfragmentlängenpolymorphismen erhaltene Genotyp AA nicht lediglich auf einem unvollständigen Restriktionsendonuklease-Verdau beruhte.

\section{Bestimmung der IL-10-Transkriptmenge}

Desweiteren war die Bestimmung der Allel-spezifischen IL-10-Transkriptmenge geplant, indem bei heterozygoten Trägern nach Analyse der Spaltprodukte im 3130 Genetic Analyzer die Flächen unterhalb der Peaks für das Allel A (Peak bei 416 bp) bzw. G (Peaks bei 132 und 284 bp) berechnet und miteinander verglichen wurden. Dadurch sollte auf RNA-Ebene ermittelt werden, welches der beiden Allele bevorzugt transkribiert wurde. Untersucht wurden zunächst sieben der insgesamt 25 in dieser Dissertation bearbeiteten HapMap-LCL-Zellen, welche den Genotyp IL-10 $0_{+4.259 \mathrm{AG}}$ aufwiesen. Da auf DNA-Ebene ein AG-Verhältnis von $1: 1$ erwartet, dieses hingegen zwischen 1,3:1 und 2,6: 1 bestimmt wurde, erschien das Vorhandensein eines methodischen Problems sehr wahrscheinlich, weshalb auf die Darstellung der Ergebnisse der AG-Verhältnisse auf RNA-Ebene verzichtet wird. Weitere Analysen wurden vorerst nicht durchgeführt. 


\section{Diskussion}

Ziel dieser Dissertation war es, herauszufinden, ob bestimmte IL-10-Genvariationen bisher unentdeckte Risikofaktoren für einen schlechten klinischen Verlauf von DLBCLPatienten darstellen könnten. Die Identifizierung klinisch relevanter und praktisch anwendbarer prognostischer Faktoren soll langfristig zu einer Optimierung der bereits bestehenden Therapiemöglichkeiten führen.

Die Ergebnisse einiger bisher durchgeführter Studien lassen vermuten, dass neben dem Risiko, an einem Non-Hodgkin-Lymphom zu erkranken auch der klinische Verlauf im Falle einer Erkrankung in einem gewissen Maß durch das Zytokin IL-10 beeinflusst werden könnten (Breen et al. 2003; Cunningham et al. 2003; Lech-Maranda et al. 2004); hierbei scheinen insbesondere distale Promotorpolymorphismen eine hohe biologische Signifikanz aufzuweisen, da diese vermutlich zu einer vermehrten Expression von IL-10 führen (Gibson et al. 2001). Da Ergebnisse der eigenen Arbeitsgruppe vermuten lassen, dass der Genotyp IL-10-7.400DelDel bei Patienten mit einem Non-Hodgkin-Lymphom mit einem signifikant kürzeren kumulativen Gesamtüberleben assoziiert sein könnte, dieser laut bisherigen Analysen jedoch eher selten auftritt, wurden in der vorliegenden Dissertation weitere distale IL-10Genvariationen betrachtet, von denen man sich eine höhere klinische Relevanz versprach (Kube et al. 2008; Mörmann et al. 2004).

Obwohl Non-Hodgkin-Lymphome überwiegend B-lymphozytären Ursprungs sind und IL-10 beträchtlich in deren Pathophysiologie involviert ist, beschäftigte sich der Großteil sämtlicher bisher durchgeführten Untersuchungen mit T-Zell-Non-HodgkinLymphomen. Zwecks Analyse einer möglichen Assoziation von Gesamtüberleben und ereignisfreiem Überleben wurde eine große, repräsentative Kohorte von 594 DLBCLPatienten aus dem Gesamtkollektiv der NHL-B1-/B2-Studien ausgewählt. Anhand dieser wurde untersucht, ob sich Therapieerfolge bei Patienten im Alter von 18 bis 60 Jahren mit guter Prognose (normwertige Serum-LDH) durch häufigere Gaben von CHOP sowie die zusätzliche Applikation von Etoposid optimieren lassen. Während nach Therapie mit CHOEP mehr Patienten eine Vollremission erreichten konnten sowie während des Beobachtungszeitraums von fünf Jahren seltener Rezidive erlitten, führte die Reduktion der Therapieintervalle von drei auf zwei Wochen zu einem verbesserten Gesamtüberleben (Pfreundschuh et al. 2004 a und b).

Die multivariate Analyse der vier Genvariationen IL-10 ${ }_{-12.806 \mathrm{TC}}$, IL-10 ${ }_{-11.777 \mathrm{GA}}$, IL-10 $11.668 \mathrm{GA}$ und IL-10 ${ }_{+4.259 A G}$ zeigte keine signifikanten Unterschiede hinsichtlich des ereignisfreien Überlebens sowie des Gesamtüberlebens der untersuchten DLBCL-Patienten; 
verglichen wurden jeweils homozygote Träger des Major-Allels mit homozygoten Trägern des Minor-Allels bzw. heterozygoten Merkmalsträgern. Folglich muss vermutet werden, dass die soeben genannten Genvariationen keinen Einfluss auf den Krankheitsverlauf von DLBCL-Patienten haben und somit nicht dazu geeignet sind, letztere in Therapiegruppen zu stratifizieren. Zukünftige Studien sollten demnach die Analyse weiterer Genvariationen zum Inhalt haben, um langfristig eine dem genetischen Risiko entsprechend adaptierte, individualisierte Therapie anbieten zu können.

Die Arbeitsgruppe um Blay beobachtete bereits vor über zwanzig Jahren, dass IL-10 im Serum von Non-Hodgkin-Lymphom-Patienten sowohl in akuten als auch in intermediären oder späten Stadien detektiert werden konnte. Demgegenüber steht die Tatsache, dass der Nachweis bei Patienten, die sich in Teil- oder Vollremission befinden, nur selten, bei gesunden Kontrollprobanden hingegen überhaupt nicht gelang (Blay et al. 1993). Daraufhin wurde die Hypothese abgeleitet, dass hohe IL-10Serumkonzentrationen mit einer schlechten Prognose korrelieren könnten; als ursächlich werden verschiedene Genvariationen diskutiert, welche laut Arbeitsgruppe um Mörmann zu einer unterschiedlich ausgeprägten In-vitro-Produktion von IL-10 führen (Mörmann et al. 2004). Die Arbeitsgruppen um Lech-Maranda und Gupta fanden im Rahmen neuerer Studien Hinweise dafür, dass erhöhte IL-10Serumkonzentrationen bei DLBCL-Patienten mit einem ungünstigen Krankheitsverlauf assoziiert sein könnten (Gupta et al. 2012; Lech-Maranda et al. 2010). Weiterhin wurde ein Zusammenhang zwischen hohem IL-10-Nachweis und höheren IPI-Scores beobachtet (Gupta et al. 2012). Erhöhte IL-10-Serumkonzentrationen könnten jedoch auch lediglich Resultat einer Entzündungsreaktion sein. Es kann jedoch nicht ausgeschlossen werden, dass durch große Tumormassen (bulky disease), welche als prognostisch ungünstig eingeschätzt werden, aufgrund der größeren Anzahl maligner Zellen mehr IL-10 produziert wird (Mocellin et al. 2005).

Rituximab, welches NHL-Patienten in Kombination mit dem CHOP- bzw. CHOEPSchema appliziert wird, führt in der B-Zelllinie 2F7 infolge einer Herabregulierung von IL-10 zu einer verminderten Bildung des anti-apoptotischen Proteins Bcl-2, was letztendlich eine erhöhte Chemosensitivität maligne transformierter B-Zellen zur Folge hat (Alas et al. 2001). Die Wirksamkeit dieses monoklonalen Antikörpers könnte also u. a. auf den konsekutiv niedrigeren IL-10-Serumkonzentrationen beruhen. Dieser Zusammenhang wurde bisher allerdings noch nicht im Rahmen von Studien untersucht. 
Andere Studien hingegen konnten keine Assoziation zwischen hohen IL-10Serumkonzentrationen und einer größeren Wahrscheinlichkeit für das Auftreten eines Rezidivs bzw. einer kürzeren Gesamtüberlebensdauer finden (Berglund et al. 2005; Cortes et al. 1995; Ozdemir et al. 2004). Während die Arbeitsgruppen um Cortes und Ozdemir lediglich kleine Patientenkollektive $(n \sim 50)$ untersuchten und bei Ozdemir weiterhin ein mit über $70 \%$ deutlich höherer Prozentsatz der Patienten - verglichen mit der in der vorliegenden Dissertation untersuchten Kohorte - eine komplette Remission erreichte, war die Altersverteilung der Studie von Berglund und Kollegen eher untypisch für DLBCL-Patienten; die Repräsentativität der Ergebnisse darf folglich angezweifelt werden.

Bisher wurden keine Studien veröffentlicht, welche eine Assoziation zwischen hohen IL-10-Serumkonzentrationen und einer günstigen Prognose nachweisen konnten.

In der vorliegenden Dissertation wurden die bei DLBCL-Patienten analysierten Genvariationen nicht hinsichtlich ihrer IL-10-Expressionshöhe analysiert. Im Rahmen weiterer umfangreicher Studien sollte folglich geprüft werden, inwieweit erhöhte IL-10Serumwerte vor Therapiebeginn tatsächlich mit einer ungünstigen Prognose der Tumorpatienten korrelieren, um daraus im Verlauf eine Optimierung der bisherigen Therapieoptionen ableiten zu können. Idealerweise sollten die Patienten parallel auf ggf. vorliegende Genvariationen untersucht werden, um zukünftig verlässlichere Aussagen über den bereits vermuteten Zusammenhang tätigen zu können. Simultan sollte selbstverständlich die Untersuchung von Kontrollgruppen erfolgen.

Bei der Diskussion um die Bedeutung der IL-10-Expressionshöhe in Bezug auf den klinischen Verlauf von NHL-Patienten könnte die Frage aufkommen, warum weiterhin nach ggf. zugrundeliegenden Genvariationen gesucht wird und nicht einfach die Serumkonzentrationen bei Patienten bestimmt werden. Da sich IL-10 im Serum im Gegensatz zu DNA sehr instabil verhält (van der Linden et al. 1998), erschien die Analyse letzterer als deutlich verlässlicher und reproduzierbarer. Vor dem Hintergrund der Ergebnisse dieser Dissertation ist eine qualifizierte Abnahme von Serum vor Therapie-Beginn mit anschließender optimaler Lagerung der Genotypisierung möglicherweise dennoch vorzuziehen.

IL-10 ist als autokriner Wachstumsfaktor für humane (sowohl gesunde als auch neoplastisch transformierte) B-Lymphozyten in die Pathophysiologie von Non-HodgkinLymphomen involviert (Benjamin et al. 1994; Blay et al. 1993); der genaue Wirkmechanismus ist bisher allerdings nur unzureichend bekannt. Dies könnte auf der pleiotropen biologischen Aktivität des Zytokins sowie der Vielzahl an bisher eingesetzten Tumormodellen beruhen. IL-10 inhibiert die Bildung proinflammatorischer 
Zytokine wie bspw. IL-6 und TNF- $\alpha$. Da chronische Entzündungszustände die Entstehung und/oder Progression eines Tumors begünstigen können, hätte IL-10 damit eine völlig konträre Wirkung (Lin und Karin 2007). Weiterhin hemmt IL-10 die Angiogenese im Mikromilieu von Tumoren, was ebenfalls eine Regression zur Folge haben könnte (Cervenak et al. 2000).

Da IL-10 mittels Hemmung von regulatorischen T-Zellen zu einer Immunsuppression führt (Moore et al. 2001), können Tumorzellen vom Immunsystem nicht als solche erkannt werden, womit deren Elimination ausbleibt (Mocellin et al. 2005). Folglich könnte die Entwicklung von IL-10-Antikörpern, welche die immunsupprimierende Wirkung des Zytokins aufheben, von klinischer Relevanz sein. Andererseits werden immunstimulierende Eigenschaften von IL-10 diskutiert, wobei die zugrundeliegenden molekularen Mechanismen noch weitestgehend unbekannt sind (Lin und Karin 2007; Mocellin et al. 2005). Zusammenfassend konnte der tatsächliche Einfluss von IL-10 auf das Immunsystem bisher nicht eindeutig geklärt werden. 


\section{Zusammenfassung}

Obwohl Non-Hodgkin-Lymphome aufgrund der gegenwärtigen Therapiestrategien grundsätzlich heilbar sind, kann nicht immer eine komplette Remission erreicht werden. Außerdem sind zahlreiche Patienten von einer ausgeprägten Therapie-assoziierten Toxizität betroffen. Bei der Suche nach neuen klinisch relevanten und praktisch anwendbaren prognostischen Faktoren werden zunehmend Genvariationen bei Zytokinen in Betracht gezogen, welche als ursächlich für eine Erkrankung diskutiert sowie mit dem klinischen Verlauf in Zusammenhang gebracht werden. Der Hauptaspekt der vorliegenden Dissertation bestand deshalb in der Analyse von drei distalen single nucleotide polymorphisms (IL-10 ${ }_{-12.806 \mathrm{TC}}$ IL-10 ${ }_{-11.777 \mathrm{GA}}$ und IL-10-11.668GA $)$ sowie einer Genvariation im Bereich der 3'UTR des IL-10-Gens (IL-10 ${ }_{+4.259 A G)}$ bei 594 Patienten mit diffus großzelligem B-Zell-Lymphom. Desweiteren erfolgte eine Analyse der IL-10-Genexpression, da ein Zusammenhang zwischen bestimmten IL-10Genvariationen sowie der IL-10-Expressionshöhe vermutet wird.

Im Rahmen der Genotypisierungen konnte das bereits bekannte Verfahren der SNaPshot-Analyse erfolgreich zu einem Multiplex Assay weiterentwickelt werden. Neben einer univariaten Analyse erfolgte eine multivariate, auf IPI-Faktoren adjustierte Untersuchung der Genvariationen. Hierbei wurden jedoch keine signifikanten Unterschiede bezüglich des Gesamtüberlebens sowie ereignisfreien Überlebens der Patienten beobachtet. Auffällig war jedoch die Tendenz, dass DLBCL-Patienten mit dem Genotyp AA des SNPs IL-10-11.777GA gegenüber heterozygoten Merkmalsträgern einen Vorteil hinsichtlich des ereignisfreien Überlebens zu haben scheinen. Desweiteren könnte der Genotyp AA der Genvariation IL-10 ${ }_{+4.259 A G}$ ggf. für eine Erkrankung an einem DLBCL prädisponieren, da bei den untersuchten Patienten (verglichen mit gesunden Kontrollprobanden) ein signifikant höherer Anteil dieser Merkmalsträger identifiziert werden konnte. Die Durchführung weiterer Untersuchungen erscheint folglich sinnvoll.

Der Nachweis interindividueller Unterschiede bezüglich der IL-10-Transkriptmenge gelang hingegen nur teilweise, weshalb auch hier weitere Analysen durchgeführt werden sollten. 


\section{$7 \quad$ Anhang}

Anhang A Ergebnisse der Sequenzierungsanalysen. Eingesetzt wurde DNA von 24 zuvor von Mitarbeitern der Arbeitsgruppe gewonnenen LCL-Zellen (Bezeichnung bspw. 7/3) sowie 30 bereits vorliegende DNA gesunder Kontrollprobanden (Bezeichnung: ,Gö’ plus Ziffernfolge, z. B. Gö35).

\begin{tabular}{|c|c|c|c|}
\hline Probe & IL-10 & IL-10-11.777GA & IL-10-11.668GA \\
\hline $7 / 3$ & TT & $\mathrm{AA}$ & $\mathrm{AA}$ \\
\hline $8 / 2$ & $\mathrm{CC}$ & $A A$ & GG \\
\hline $8 / 4$ & $\mathrm{CC}$ & AA & GG \\
\hline $9 / 1$ & $\mathrm{CC}$ & AA & $A G$ \\
\hline $13 / 1$ & $\mathrm{CC}$ & $\mathrm{AA}$ & GG \\
\hline $13 / 3$ & СT & AA & $\mathrm{AA}$ \\
\hline $15 / 3$ & $\mathrm{CC}$ & $A A$ & GG \\
\hline $16 / 3$ & $\mathrm{CT}$ & $A A$ & $\mathrm{AA}$ \\
\hline $23 / 1$ & CT & AA & $\mathrm{AA}$ \\
\hline $23 / 2$ & CT & AA & $\mathrm{AA}$ \\
\hline $31 / 1$ & $\mathrm{CC}$ & AA & $A G$ \\
\hline $33 / 2$ & CT & AA & $A G$ \\
\hline $34 / 1$ & TT & AA & AA \\
\hline $44 / 2$ & TT & $\mathrm{AA}$ & $\mathrm{AA}$ \\
\hline $49 / 1$ & $\mathrm{CC}$ & $A A$ & GG \\
\hline $58 / 1$ & $\mathrm{CC}$ & AA & $A G$ \\
\hline $58 / 3$ & CT & $A G$ & $A G$ \\
\hline $59 / 3$ & TT & AA & $\mathrm{AA}$ \\
\hline $60 / 2$ & $\mathrm{CC}$ & $A G$ & GG \\
\hline $102 / 2$ & $\mathrm{CC}$ & AA & GG \\
\hline $103 / 1$ & $\mathrm{CC}$ & $A G$ & $A G$ \\
\hline $103 / 2$ & $\mathrm{CC}$ & AA & GG \\
\hline $103 / 3$ & CT & AA & GG \\
\hline $103 / 4$ & $\mathrm{CT}$ & $\mathrm{AA}$ & $A G$ \\
\hline Gö35 & СT & $A G$ & $A G$ \\
\hline Gö36 & CT & $A A$ & $A G$ \\
\hline Gö37 & CT & $\mathrm{AA}$ & $A G$ \\
\hline Gö40 & $\mathrm{CC}$ & $A A$ & GG \\
\hline Gö41 & $\mathrm{CC}$ & AA & GG \\
\hline Gö42 & CT & AA & $A G$ \\
\hline Gö48 & $\mathrm{CC}$ & $A G$ & GG \\
\hline Gö49 & $\mathrm{CT}$ & AA & $A G$ \\
\hline Gö50 & CT & AA & $A G$ \\
\hline Gö51 & $\mathrm{CC}$ & AA & $G G$ \\
\hline Gö52 & $\mathrm{CC}$ & $A A$ & GG \\
\hline Gö53 & TT & AA & AA \\
\hline Gö54 & CT & AA & $\mathrm{AA}$ \\
\hline Gö55 & $\mathrm{CT}$ & AA & $A G$ \\
\hline Gö56 & CT & $A G$ & $A G$ \\
\hline Gö57 & $\mathrm{CC}$ & $A G$ & GG \\
\hline Gö58 & CT & $A G$ & $A G$ \\
\hline Gö59 & CT & $A A$ & $\mathrm{AA}$ \\
\hline
\end{tabular}




\begin{tabular}{llll}
\hline Gö60 & CC & AG \\
Gö61 & CC & AA & AG \\
Gö62 & CC & AA & AG \\
Gö63 & CT & AA & AA \\
Gö306 & CC & AA & GG \\
Gö307 & CC & AG & GG \\
Gö308 & CC & AG & GG \\
Gö309 & CT & AA & AG \\
Gö310 & CC & AA & GG \\
Gö311 & AA & AA \\
Gö312 & CT & AA & AA \\
Gö313 & CC & AA & AG
\end{tabular}

Anhang B Ergebnisse der Multiplex Assays bei DLBCL-Patienten. Analysiert wurde eine Kohorte von 594 Patienten, welche als repräsentativ für alle an einem DLBCL erkrankten Personen innerhalb der NHLB1-/B2-Studien betrachtet werden kann.

\begin{tabular}{|c|c|c|c|c|}
\hline Studien-Nr. & IL-10 & IL-10 $11.777 \mathrm{GA}$ & IL-10-11.668GA & IL-10 $+4.259 \mathrm{AG}$ \\
\hline 3 & $\mathrm{CC}$ & AA & GG & AA \\
\hline 4 & $\mathrm{CC}$ & AA & GG & AA \\
\hline 6 & $\mathrm{CC}$ & AA & $A G$ & AA \\
\hline 15 & $\mathrm{CC}$ & AA & GG & AA \\
\hline 22 & CT & AA & AA & $A G$ \\
\hline 24 & CT & AA & AA & $A G$ \\
\hline 25 & $\mathrm{CC}$ & AA & GG & $\mathrm{AA}$ \\
\hline 29 & CT & $\mathrm{AA}$ & $A G$ & $A G$ \\
\hline 34 & CT & $A A$ & $A G$ & $\mathrm{AA}$ \\
\hline 36 & $\mathrm{CC}$ & $A A$ & $A G$ & $\mathrm{AA}$ \\
\hline 37 & $\mathrm{CC}$ & GG & GG & $A G$ \\
\hline 38 & $\mathrm{CT}$ & AA & $A G$ & $A G$ \\
\hline 42 & $\mathrm{CC}$ & AA & $\mathrm{AA}$ & AA \\
\hline 44 & $\mathrm{CC}$ & $A A$ & $A G$ & $A G$ \\
\hline 45 & $\mathrm{CC}$ & AA & $A G$ & AA \\
\hline 48 & $\mathrm{CC}$ & $\mathrm{AA}$ & $A G$ & AA \\
\hline 55 & $\mathrm{CT}$ & $A G$ & $A G$ & $A G$ \\
\hline 56 & $\mathrm{CT}$ & $A G$ & $A G$ & $A G$ \\
\hline 64 & $\mathrm{CC}$ & $A G$ & GG & $A A$ \\
\hline 67 & $\mathrm{CC}$ & $A A$ & $A G$ & $A A$ \\
\hline 69 & $\mathrm{CC}$ & AA & $A G$ & $A G$ \\
\hline 78 & $\mathrm{CC}$ & AA & $A G$ & $A G$ \\
\hline 81 & $\mathrm{CC}$ & AA & GG & AA \\
\hline 86 & $\mathrm{CC}$ & AA & GG & AA \\
\hline 90 & CT & AA & AA & $A G$ \\
\hline 91 & $\mathrm{CC}$ & $\mathrm{AA}$ & $A G$ & $\mathrm{AA}$ \\
\hline 94 & $\mathrm{CC}$ & $A G$ & $\mathrm{GG}$ & $\mathrm{AA}$ \\
\hline 96 & $\mathrm{CT}$ & $\mathrm{AA}$ & $A G$ & $A G$ \\
\hline 98 & $\mathrm{CT}$ & AA & $A G$ & $A G$ \\
\hline 99 & $\mathrm{CC}$ & AA & $A G$ & $\mathrm{AA}$ \\
\hline 100 & $\mathrm{CC}$ & AA & $\mathrm{GG}$ & AA \\
\hline 106 & $\mathrm{CT}$ & $\mathrm{AA}$ & $A G$ & $A G$ \\
\hline 110 & $\mathrm{CC}$ & AA & $\mathrm{GG}$ & AA \\
\hline
\end{tabular}


7 Anhang

\begin{tabular}{|c|c|c|c|c|}
\hline 113 & $\mathrm{CC}$ & $\mathrm{AA}$ & $\mathrm{GG}$ & $A A$ \\
\hline 114 & $\mathrm{CC}$ & AA & $\mathrm{AA}$ & $A A$ \\
\hline 117 & $\mathrm{CC}$ & $A G$ & $\mathrm{GG}$ & $A A$ \\
\hline 118 & CT & AA & $\mathrm{AA}$ & $A A$ \\
\hline 131 & TT & $\mathrm{AA}$ & $\mathrm{AA}$ & GG \\
\hline 142 & CT & AA & $\mathrm{AA}$ & $A G$ \\
\hline 154 & $\mathrm{CT}$ & $\mathrm{AA}$ & $A G$ & $A G$ \\
\hline 162 & $\mathrm{CC}$ & AA & $\mathrm{GG}$ & $A A$ \\
\hline 165 & $\mathrm{CC}$ & $\mathrm{AA}$ & $A G$ & $A A$ \\
\hline 166 & $\mathrm{CC}$ & AA & $\mathrm{GG}$ & $A A$ \\
\hline 171 & $\mathrm{CC}$ & AA & $A G$ & $A A$ \\
\hline 172 & $\mathrm{CC}$ & $\mathrm{AA}$ & $\mathrm{GG}$ & $A A$ \\
\hline 181 & $\mathrm{CC}$ & $\mathrm{AA}$ & $\mathrm{GG}$ & $A A$ \\
\hline 184 & $\mathrm{CC}$ & $\mathrm{AA}$ & $\mathrm{GG}$ & $A A$ \\
\hline 187 & $\mathrm{CC}$ & $\mathrm{AA}$ & $A G$ & $A G$ \\
\hline 189 & $\mathrm{CC}$ & $\mathrm{AA}$ & $A G$ & $A A$ \\
\hline 191 & $\mathrm{CT}$ & $\mathrm{AA}$ & $A G$ & $A G$ \\
\hline 193 & $\mathrm{CC}$ & AA & $\mathrm{GG}$ & $A A$ \\
\hline 194 & $\mathrm{CC}$ & AA & $A G$ & $A A$ \\
\hline 195 & $\mathrm{CC}$ & $\mathrm{AA}$ & $A G$ & $\mathrm{AA}$ \\
\hline 196 & $\mathrm{CT}$ & $\mathrm{AA}$ & $\mathrm{GG}$ & $\mathrm{AA}$ \\
\hline 202 & $\mathrm{CC}$ & $\mathrm{AA}$ & $A G$ & $A A$ \\
\hline 207 & $\mathrm{CC}$ & $A A$ & GG & $A A$ \\
\hline 208 & $\mathrm{CC}$ & $A A$ & $A G$ & $A A$ \\
\hline 214 & $\mathrm{CC}$ & $A A$ & $A G$ & $A A$ \\
\hline 224 & $\mathrm{CT}$ & $\mathrm{AA}$ & $A G$ & $A G$ \\
\hline 227 & $\mathrm{CC}$ & AA & $A G$ & $A A$ \\
\hline 228 & $\mathrm{CC}$ & $\mathrm{AA}$ & $A G$ & $\mathrm{AA}$ \\
\hline 230 & $\mathrm{CC}$ & $\mathrm{AA}$ & $A G$ & $A G$ \\
\hline 234 & $\mathrm{CC}$ & $\mathrm{AA}$ & $G G$ & $\mathrm{AA}$ \\
\hline 235 & $\mathrm{CC}$ & $\mathrm{AA}$ & $A G$ & $A A$ \\
\hline 236 & $\mathrm{CT}$ & $\mathrm{AA}$ & $A G$ & $A G$ \\
\hline 237 & $\mathrm{CC}$ & $\mathrm{AA}$ & $A G$ & $A A$ \\
\hline 240 & $\mathrm{CC}$ & $\mathrm{AA}$ & $A G$ & $A A$ \\
\hline 243 & $\mathrm{CT}$ & $\mathrm{AA}$ & $\mathrm{AA}$ & $A G$ \\
\hline 244 & $\mathrm{CC}$ & $\mathrm{AA}$ & $\mathrm{AA}$ & $\mathrm{AA}$ \\
\hline 245 & $\mathrm{CT}$ & $\mathrm{AA}$ & $A G$ & $A G$ \\
\hline 249 & $\mathrm{CC}$ & AA & $A G$ & $A A$ \\
\hline 255 & $\mathrm{CC}$ & $A G$ & $\mathrm{GG}$ & $A A$ \\
\hline 259 & $\mathrm{CC}$ & $\mathrm{AA}$ & $A G$ & $A A$ \\
\hline 262 & $\mathrm{CC}$ & $\mathrm{AA}$ & $\mathrm{AA}$ & GG \\
\hline 265 & $\mathrm{CC}$ & $\mathrm{AA}$ & $\mathrm{GG}$ & $A A$ \\
\hline 267 & $\mathrm{CC}$ & $\mathrm{AA}$ & $A G$ & $A A$ \\
\hline 268 & $\mathrm{CC}$ & AA & $A A$ & AA \\
\hline 269 & $\mathrm{CC}$ & $\mathrm{AA}$ & $\mathrm{AA}$ & $A A$ \\
\hline 270 & $\mathrm{CC}$ & AA & $A G$ & $A A$ \\
\hline 275 & $\mathrm{CT}$ & $A A$ & $A G$ & $A G$ \\
\hline 277 & $\mathrm{CC}$ & $A G$ & $\mathrm{GG}$ & $A A$ \\
\hline 279 & $\mathrm{CC}$ & $\mathrm{AA}$ & $A G$ & $A A$ \\
\hline 280 & $\mathrm{CC}$ & $\mathrm{AA}$ & $A G$ & $A A$ \\
\hline 284 & $\mathrm{CC}$ & $A A$ & $A G$ & $A A$ \\
\hline
\end{tabular}


7 Anhang

\begin{tabular}{|c|c|c|c|c|}
\hline 285 & CT & $\mathrm{AA}$ & $\mathrm{AA}$ & GG \\
\hline 290 & $\mathrm{CC}$ & AA & $\mathrm{GG}$ & $A G$ \\
\hline 292 & $\mathrm{CC}$ & $\mathrm{AA}$ & $\mathrm{GG}$ & $A A$ \\
\hline 293 & $\mathrm{CC}$ & $A G$ & $\mathrm{GG}$ & $A A$ \\
\hline 295 & CT & $\mathrm{AA}$ & $A G$ & $A G$ \\
\hline 298 & CT & AA & $A G$ & $A G$ \\
\hline 306 & $\mathrm{CC}$ & $A G$ & $\mathrm{GG}$ & $A A$ \\
\hline 307 & CT & $A A$ & $A G$ & $A G$ \\
\hline 313 & $\mathrm{CC}$ & $\mathrm{AA}$ & $\mathrm{GG}$ & $A G$ \\
\hline 317 & CT & AA & $A G$ & $A G$ \\
\hline 319 & CT & AA & $A G$ & $A G$ \\
\hline 320 & $\mathrm{CC}$ & $\mathrm{AA}$ & $\mathrm{AA}$ & $A G$ \\
\hline 321 & CT & $\mathrm{AA}$ & $A G$ & $A G$ \\
\hline 326 & CT & $\mathrm{AA}$ & $A G$ & $A G$ \\
\hline 332 & $\mathrm{CC}$ & $\mathrm{AA}$ & $A G$ & $A A$ \\
\hline 334 & $\mathrm{CT}$ & $\mathrm{AA}$ & $A G$ & $A G$ \\
\hline 337 & $\mathrm{CC}$ & $\mathrm{AA}$ & $\mathrm{GG}$ & $A A$ \\
\hline 339 & $\mathrm{CC}$ & $\mathrm{AA}$ & $A G$ & $\mathrm{AA}$ \\
\hline 340 & $\mathrm{CC}$ & $\mathrm{AA}$ & $A G$ & $A A$ \\
\hline 345 & $\mathrm{CC}$ & $\mathrm{AA}$ & $A G$ & $A A$ \\
\hline 349 & CT & $A G$ & $A G$ & $A G$ \\
\hline 353 & $\mathrm{CT}$ & $\mathrm{AA}$ & $A G$ & $A G$ \\
\hline 359 & $\mathrm{CC}$ & $A A$ & $A G$ & $A A$ \\
\hline 368 & $\mathrm{CC}$ & $A A$ & GG & $A A$ \\
\hline 370 & $\mathrm{TT}$ & $\mathrm{AA}$ & $\mathrm{AA}$ & GG \\
\hline 380 & $\mathrm{CT}$ & $\mathrm{AA}$ & $\mathrm{AA}$ & $A G$ \\
\hline 384 & $\mathrm{CC}$ & $\mathrm{AA}$ & $\mathrm{GG}$ & $\mathrm{AA}$ \\
\hline 385 & $\mathrm{CC}$ & AA & $\mathrm{GG}$ & $A A$ \\
\hline 387 & $\mathrm{CC}$ & $A G$ & GG & $A A$ \\
\hline 396 & $\mathrm{CC}$ & $\mathrm{AA}$ & $A G$ & $A A$ \\
\hline 398 & $\mathrm{CC}$ & $\mathrm{AA}$ & GG & $A A$ \\
\hline 400 & $\mathrm{CT}$ & $A A$ & $A A$ & $A G$ \\
\hline 401 & $\mathrm{CC}$ & $A G$ & $\mathrm{GG}$ & $A A$ \\
\hline 406 & $\mathrm{CC}$ & $\mathrm{AA}$ & $\mathrm{GG}$ & $A A$ \\
\hline 409 & $\mathrm{CC}$ & $\mathrm{AA}$ & $A G$ & $A G$ \\
\hline 411 & $\mathrm{CC}$ & $\mathrm{AA}$ & $\mathrm{GG}$ & $\mathrm{AA}$ \\
\hline 412 & $\mathrm{TT}$ & $\mathrm{AA}$ & $\mathrm{AA}$ & $\mathrm{GG}$ \\
\hline 417 & $\mathrm{CC}$ & AA & $\mathrm{AA}$ & $A A$ \\
\hline 432 & $\mathrm{CC}$ & $\mathrm{AA}$ & $\mathrm{AA}$ & $A A$ \\
\hline 433 & CT & $\mathrm{AA}$ & $A G$ & $A G$ \\
\hline 436 & $\mathrm{CC}$ & $\mathrm{AA}$ & GG & $A A$ \\
\hline 442 & $\mathrm{CT}$ & $A A$ & $A G$ & $A G$ \\
\hline 449 & $\mathrm{CC}$ & $A A$ & $\mathrm{GG}$ & $A G$ \\
\hline 452 & $\mathrm{CC}$ & $\mathrm{AA}$ & $\mathrm{GG}$ & $\mathrm{AA}$ \\
\hline 455 & $\mathrm{CT}$ & $\mathrm{AA}$ & $A G$ & $A G$ \\
\hline 457 & $\mathrm{CC}$ & $\mathrm{AA}$ & $\mathrm{GG}$ & $\mathrm{AA}$ \\
\hline 470 & $\mathrm{CC}$ & $A G$ & $\mathrm{GG}$ & $A A$ \\
\hline 473 & $\mathrm{CC}$ & $A G$ & $\mathrm{GG}$ & $A A$ \\
\hline 474 & $\mathrm{CC}$ & $\mathrm{AA}$ & $\mathrm{GG}$ & $A A$ \\
\hline 479 & $\mathrm{TT}$ & $\mathrm{AA}$ & $\mathrm{AA}$ & GG \\
\hline 484 & $\mathrm{CC}$ & AA & $\mathrm{GG}$ & $\mathrm{AA}$ \\
\hline
\end{tabular}


7 Anhang

\begin{tabular}{|c|c|c|c|c|}
\hline 486 & $\mathrm{CC}$ & $A A$ & $G G$ & $A G$ \\
\hline 487 & CT & $A A$ & $A G$ & $A G$ \\
\hline 489 & CT & $A G$ & $A G$ & $A G$ \\
\hline 490 & $\mathrm{CC}$ & $A G$ & GG & $A A$ \\
\hline 491 & $\mathrm{CC}$ & $A A$ & $A G$ & $\mathrm{AA}$ \\
\hline 495 & CT & $A A$ & $A G$ & $A G$ \\
\hline 498 & $\mathrm{CC}$ & $A A$ & $A G$ & $A A$ \\
\hline 503 & $\mathrm{CT}$ & $A G$ & $A G$ & $A G$ \\
\hline 504 & $\mathrm{CT}$ & $A A$ & $A A$ & $A G$ \\
\hline 508 & $\mathrm{CT}$ & $\mathrm{AA}$ & $A G$ & $A A$ \\
\hline 514 & CT & $A A$ & $A G$ & $A G$ \\
\hline 515 & $\mathrm{CC}$ & $A G$ & $G G$ & $A A$ \\
\hline 523 & $\mathrm{CT}$ & $A A$ & $A G$ & $A G$ \\
\hline 524 & $\mathrm{CT}$ & $A A$ & $A G$ & $A G$ \\
\hline 527 & $\mathrm{CT}$ & $\mathrm{AA}$ & $A G$ & $A G$ \\
\hline 535 & $\mathrm{CC}$ & $\mathrm{AA}$ & $\mathrm{GG}$ & $\mathrm{AA}$ \\
\hline 536 & $\mathrm{CC}$ & $\mathrm{AA}$ & $A A$ & $\mathrm{GG}$ \\
\hline 537 & CT & $\mathrm{AA}$ & $A A$ & $A G$ \\
\hline 538 & $\mathrm{CC}$ & $A A$ & $G G$ & $A G$ \\
\hline 539 & $\mathrm{CC}$ & $A A$ & $A G$ & $A A$ \\
\hline 547 & $\mathrm{CC}$ & $A A$ & GG & $A A$ \\
\hline 548 & $\mathrm{CT}$ & $A A$ & $A G$ & $A G$ \\
\hline 549 & $\mathrm{CC}$ & $A A$ & $A G$ & $A A$ \\
\hline 551 & $\mathrm{CC}$ & $A A$ & $\mathrm{GG}$ & $A A$ \\
\hline 553 & $\mathrm{CC}$ & $\mathrm{AA}$ & $\mathrm{GG}$ & $A A$ \\
\hline 556 & $\mathrm{CT}$ & $\mathrm{AA}$ & $A G$ & $A G$ \\
\hline 563 & CT & $\mathrm{AA}$ & $A G$ & $A G$ \\
\hline 568 & CT & $A A$ & $A A$ & $A G$ \\
\hline 569 & CT & $A A$ & $A A$ & $A G$ \\
\hline 571 & $\mathrm{CT}$ & $A A$ & $A G$ & $A G$ \\
\hline 572 & $\mathrm{CC}$ & $A A$ & $A G$ & $A A$ \\
\hline 573 & CT & $A A$ & $A G$ & $A G$ \\
\hline 578 & $\mathrm{CC}$ & $\mathrm{AA}$ & $\mathrm{GG}$ & $A A$ \\
\hline 579 & $\mathrm{CC}$ & $\mathrm{AA}$ & $A G$ & $\mathrm{AA}$ \\
\hline 594 & $\mathrm{CC}$ & $\mathrm{AA}$ & $A G$ & $A A$ \\
\hline 609 & CT & $\mathrm{AA}$ & $A G$ & $A G$ \\
\hline 611 & CT & $\mathrm{AA}$ & AA & $A G$ \\
\hline 614 & $\mathrm{CT}$ & $A A$ & $A G$ & $A G$ \\
\hline 624 & $\mathrm{CC}$ & $A G$ & $G G$ & $A A$ \\
\hline 625 & n. d. & n. d. & n. d. & n. d. \\
\hline 626 & $\mathrm{CC}$ & $\mathrm{AA}$ & $A G$ & $A A$ \\
\hline 628 & $\mathrm{CC}$ & $A G$ & $\mathrm{GG}$ & $A A$ \\
\hline 634 & CT & $A A$ & $A G$ & $A G$ \\
\hline 638 & CT & $\mathrm{AA}$ & $A G$ & $A G$ \\
\hline 639 & $\mathrm{CT}$ & $\mathrm{AA}$ & $A G$ & $\mathrm{AA}$ \\
\hline 640 & CT & $\mathrm{AA}$ & AA & $\mathrm{GG}$ \\
\hline 641 & $\mathrm{CC}$ & $A G$ & $A G$ & $A A$ \\
\hline 644 & $\mathrm{CC}$ & $A A$ & $G G$ & $A A$ \\
\hline 652 & $\mathrm{CC}$ & $A A$ & $G G$ & $A A$ \\
\hline 654 & $\mathrm{CC}$ & $A A$ & GG & $A A$ \\
\hline 656 & CT & $\mathrm{AA}$ & $A G$ & $A G$ \\
\hline
\end{tabular}


7 Anhang

\begin{tabular}{|c|c|c|c|c|}
\hline 657 & CT & $\mathrm{AA}$ & $A G$ & $A G$ \\
\hline 666 & CT & $\mathrm{AA}$ & $\mathrm{GG}$ & AA \\
\hline 670 & $\mathrm{CC}$ & $A G$ & $A G$ & $\mathrm{AA}$ \\
\hline 671 & $\mathrm{CC}$ & $\mathrm{AA}$ & $A G$ & n. d. \\
\hline 675 & CT & $\mathrm{AA}$ & $A G$ & $A G$ \\
\hline 681 & $\mathrm{CC}$ & $A G$ & $\mathrm{GG}$ & AA \\
\hline 684 & CT & $A A$ & $A G$ & $A G$ \\
\hline 686 & $\mathrm{CC}$ & $\mathrm{AA}$ & $A A$ & $A G$ \\
\hline 688 & $\mathrm{CC}$ & $A G$ & $A G$ & $\mathrm{AA}$ \\
\hline 692 & $\mathrm{CC}$ & AA & $\mathrm{GG}$ & AA \\
\hline 695 & $\mathrm{CC}$ & $\mathrm{AA}$ & $\mathrm{GG}$ & AA \\
\hline 699 & $\mathrm{CC}$ & $\mathrm{AA}$ & $A G$ & $A G$ \\
\hline 703 & $\mathrm{CT}$ & $\mathrm{AA}$ & $A G$ & $A G$ \\
\hline 707 & $\mathrm{TT}$ & $\mathrm{AA}$ & $A A$ & GG \\
\hline 710 & $\mathrm{CC}$ & $\mathrm{AA}$ & $\mathrm{GG}$ & AA \\
\hline 720 & $\mathrm{CT}$ & $\mathrm{AA}$ & $A G$ & $A G$ \\
\hline 725 & $\mathrm{CC}$ & $\mathrm{AA}$ & $\mathrm{GG}$ & AA \\
\hline 726 & $\mathrm{CC}$ & $\mathrm{AA}$ & $\mathrm{GG}$ & AA \\
\hline 727 & CT & AA & $A G$ & $A G$ \\
\hline 729 & CT & $\mathrm{AA}$ & $A G$ & $A G$ \\
\hline 731 & $\mathrm{CC}$ & $\mathrm{AA}$ & $A G$ & $\mathrm{AA}$ \\
\hline 732 & $\mathrm{CC}$ & $A A$ & $A A$ & $A A$ \\
\hline 733 & $\mathrm{CC}$ & $\mathrm{AA}$ & $A G$ & $A A$ \\
\hline 735 & $\mathrm{CC}$ & $\mathrm{AA}$ & $\mathrm{GG}$ & $A A$ \\
\hline 738 & $\mathrm{CC}$ & $\mathrm{AA}$ & $A G$ & $A A$ \\
\hline 739 & $\mathrm{CC}$ & $\mathrm{AA}$ & $A G$ & AA \\
\hline 740 & CT & AA & $A G$ & $A G$ \\
\hline 744 & $\mathrm{CT}$ & $\mathrm{AA}$ & $A A$ & $A G$ \\
\hline 749 & $\mathrm{CC}$ & $\mathrm{AA}$ & $\mathrm{GG}$ & AA \\
\hline 750 & $\mathrm{CC}$ & $\mathrm{AA}$ & $A A$ & AA \\
\hline 753 & $\mathrm{CC}$ & $A A$ & $A G$ & AA \\
\hline 754 & $\mathrm{CT}$ & $\mathrm{AA}$ & $A G$ & AA \\
\hline 755 & $\mathrm{CC}$ & $\mathrm{AA}$ & $A G$ & $A A$ \\
\hline 756 & $\mathrm{CC}$ & $\mathrm{AA}$ & $\mathrm{GG}$ & AA \\
\hline 764 & $\mathrm{CC}$ & AA & $A G$ & AA \\
\hline 765 & $\mathrm{CC}$ & AA & $A G$ & AA \\
\hline 767 & $\mathrm{CC}$ & AA & $\mathrm{GG}$ & AA \\
\hline 768 & $\mathrm{TT}$ & AA & $A A$ & $A G$ \\
\hline 772 & CT & $\mathrm{AA}$ & $A G$ & $A G$ \\
\hline 776 & $\mathrm{CT}$ & $\mathrm{AA}$ & $A G$ & $A G$ \\
\hline 782 & $\mathrm{CT}$ & $\mathrm{AA}$ & $A G$ & $A G$ \\
\hline 784 & $\mathrm{CT}$ & $\mathrm{AA}$ & $A G$ & $A G$ \\
\hline 789 & $\mathrm{CT}$ & $\mathrm{AA}$ & $A G$ & $A G$ \\
\hline 790 & CT & AA & $A A$ & $A G$ \\
\hline 791 & $\mathrm{CC}$ & AA & $A G$ & AA \\
\hline 792 & $\mathrm{CT}$ & $A G$ & $A G$ & $A G$ \\
\hline 799 & $\mathrm{CC}$ & $A G$ & $A G$ & $A A$ \\
\hline 800 & $\mathrm{CC}$ & $\mathrm{AA}$ & $A A$ & AA \\
\hline 802 & $\mathrm{CC}$ & $\mathrm{AA}$ & $A G$ & $\mathrm{AA}$ \\
\hline 804 & $\mathrm{CT}$ & $\mathrm{AA}$ & $A G$ & $A G$ \\
\hline 808 & $\mathrm{CC}$ & $A G$ & $A G$ & AA \\
\hline
\end{tabular}


7 Anhang

\begin{tabular}{|c|c|c|c|c|}
\hline 809 & $\mathrm{CC}$ & $\mathrm{AA}$ & GG & $A A$ \\
\hline 810 & CT & AA & $A G$ & $A G$ \\
\hline 811 & $\mathrm{CC}$ & $A G$ & $\mathrm{GG}$ & $A A$ \\
\hline 814 & CT & AA & $A A$ & $A A$ \\
\hline 818 & CT & $\mathrm{AA}$ & $A G$ & $A G$ \\
\hline 819 & $\mathrm{CC}$ & AA & $\mathrm{GG}$ & $A A$ \\
\hline 822 & $\mathrm{CC}$ & $\mathrm{AA}$ & $A G$ & $A A$ \\
\hline 825 & CT & AA & $A A$ & $A G$ \\
\hline 826 & $\mathrm{CC}$ & $\mathrm{AA}$ & GG & $A A$ \\
\hline 827 & $\mathrm{CC}$ & AA & $\mathrm{GG}$ & $A A$ \\
\hline 829 & $\mathrm{CC}$ & AA & $\mathrm{GG}$ & $A A$ \\
\hline 834 & $\mathrm{CC}$ & GG & $\mathrm{GG}$ & $A A$ \\
\hline 836 & $\mathrm{CC}$ & $\mathrm{AA}$ & $\mathrm{GG}$ & $A G$ \\
\hline 838 & CT & $\mathrm{AA}$ & $A G$ & $A G$ \\
\hline 839 & $\mathrm{CC}$ & $A G$ & $\mathrm{GG}$ & $A A$ \\
\hline 842 & $\mathrm{CT}$ & $\mathrm{AA}$ & $A G$ & $A G$ \\
\hline 848 & CT & AA & $A G$ & $A G$ \\
\hline 850 & CT & AA & $A G$ & $A G$ \\
\hline 853 & $\mathrm{TT}$ & $\mathrm{AA}$ & $A A$ & $A G$ \\
\hline 854 & $\mathrm{CT}$ & $\mathrm{AA}$ & $A G$ & $A G$ \\
\hline 855 & $\mathrm{CC}$ & $\mathrm{AA}$ & $\mathrm{GG}$ & $A A$ \\
\hline 856 & $\mathrm{CC}$ & $\mathrm{AA}$ & GG & $A A$ \\
\hline 857 & $\mathrm{CC}$ & $\mathrm{AA}$ & $\mathrm{GG}$ & $A A$ \\
\hline 862 & $\mathrm{CC}$ & AA & $A G$ & $A A$ \\
\hline 863 & $\mathrm{CC}$ & $\mathrm{AA}$ & $A G$ & $\mathrm{AA}$ \\
\hline 865 & $\mathrm{CC}$ & AA & $A G$ & $\mathrm{AA}$ \\
\hline 869 & $\mathrm{CC}$ & $\mathrm{AA}$ & $A G$ & $A A$ \\
\hline 870 & $\mathrm{CC}$ & $A G$ & GG & $\mathrm{AA}$ \\
\hline 872 & $\mathrm{CC}$ & $A G$ & GG & $\mathrm{AA}$ \\
\hline 881 & $\mathrm{CC}$ & $\mathrm{AA}$ & $A G$ & $A A$ \\
\hline 882 & $\mathrm{CC}$ & $\mathrm{AA}$ & $\mathrm{GG}$ & $A A$ \\
\hline 885 & $\mathrm{CC}$ & $\mathrm{AA}$ & $A G$ & $A A$ \\
\hline 888 & $\mathrm{CT}$ & $\mathrm{AA}$ & $A G$ & $A G$ \\
\hline 889 & $\mathrm{CC}$ & AA & $A G$ & $A G$ \\
\hline 892 & TT & AA & $A A$ & $\mathrm{GG}$ \\
\hline 894 & CT & AA & $A A$ & $A G$ \\
\hline 897 & CT & AA & $A G$ & $A G$ \\
\hline 898 & $\mathrm{CC}$ & $\mathrm{AA}$ & $A G$ & $A G$ \\
\hline 899 & $\mathrm{CT}$ & $\mathrm{AA}$ & $A G$ & $\mathrm{AA}$ \\
\hline 901 & $\mathrm{CT}$ & $\mathrm{AA}$ & $A G$ & $A G$ \\
\hline 905 & CT & AA & $A G$ & $A G$ \\
\hline 906 & $\mathrm{CC}$ & $\mathrm{AA}$ & $A G$ & $A G$ \\
\hline 909 & $\mathrm{CC}$ & $\mathrm{AA}$ & $A G$ & $\mathrm{AA}$ \\
\hline 910 & $\mathrm{CC}$ & $\mathrm{AA}$ & GG & $A A$ \\
\hline 912 & $\mathrm{CC}$ & AA & $A G$ & $A G$ \\
\hline 914 & $\mathrm{CC}$ & AA & $A A$ & $A A$ \\
\hline 915 & $\mathrm{CC}$ & $\mathrm{AA}$ & GG & $\mathrm{AA}$ \\
\hline 917 & $\mathrm{CT}$ & $A G$ & $A G$ & $A G$ \\
\hline 919 & TT & $\mathrm{AA}$ & $A A$ & $A G$ \\
\hline 923 & $\mathrm{CC}$ & $A G$ & $A G$ & $A G$ \\
\hline 929 & $\mathrm{CC}$ & $\mathrm{AA}$ & $A G$ & $A A$ \\
\hline
\end{tabular}


7 Anhang

\begin{tabular}{|c|c|c|c|c|}
\hline 932 & CT & $A A$ & $A G$ & $A G$ \\
\hline 935 & CC & $A A$ & $\mathrm{GG}$ & $\mathrm{AA}$ \\
\hline 936 & CT & $A A$ & $A G$ & $A G$ \\
\hline 937 & CT & $A A$ & $A A$ & $A G$ \\
\hline 940 & CC & $A A$ & $A G$ & AA \\
\hline 944 & CC & $A A$ & $A G$ & AA \\
\hline 950 & CC & $A A$ & $A A$ & $\mathrm{AA}$ \\
\hline 952 & CT & $A A$ & $A G$ & $A G$ \\
\hline 953 & CT & $A A$ & $A G$ & AA \\
\hline 962 & CC & $A A$ & GG & AA \\
\hline 963 & CC & $A G$ & GG & AA \\
\hline 967 & $\mathrm{CC}$ & $A A$ & GG & $\mathrm{AA}$ \\
\hline 968 & $\mathrm{CC}$ & $A A$ & $A A$ & $A A$ \\
\hline 969 & CC & $A A$ & GG & $A A$ \\
\hline 970 & CC & $A A$ & GG & $A A$ \\
\hline 971 & CC & $A A$ & GG & $A A$ \\
\hline 973 & CC & $A A$ & $\mathrm{GG}$ & $A A$ \\
\hline 974 & CC & $A A$ & GG & $A A$ \\
\hline 976 & CT & $A A$ & $A A$ & $A G$ \\
\hline 977 & $\mathrm{CC}$ & $A A$ & $A G$ & $A A$ \\
\hline 978 & $\mathrm{CC}$ & $A A$ & GG & $A A$ \\
\hline 980 & СT & $A A$ & $A A$ & $A G$ \\
\hline 982 & $\mathrm{CT}$ & $A A$ & $A G$ & $A G$ \\
\hline 983 & $\mathrm{CC}$ & $A A$ & $A G$ & $A A$ \\
\hline 984 & n. d. & n. d. & n. d. & n. d. \\
\hline 985 & $\mathrm{CC}$ & $A A$ & $\mathrm{GG}$ & $A A$ \\
\hline 986 & $\mathrm{CC}$ & $A G$ & $A G$ & AA \\
\hline 987 & $\mathrm{CC}$ & $A A$ & $A G$ & AA \\
\hline 988 & CT & $A A$ & $A G$ & $A G$ \\
\hline 991 & CT & $A A$ & $A G$ & $A G$ \\
\hline 992 & СТ & $A A$ & $A G$ & $A G$ \\
\hline 994 & CC & $A A$ & $A A$ & $A A$ \\
\hline 996 & TT & $A A$ & $A A$ & GG \\
\hline 998 & CT & $A A$ & $A G$ & $A G$ \\
\hline 999 & CC & $A A$ & GG & AA \\
\hline 1000 & CT & $A A$ & $A G$ & $A G$ \\
\hline 1006 & CC & $A G$ & GG & AA \\
\hline 1007 & $\mathrm{CC}$ & $A A$ & GG & AA \\
\hline 1010 & $\mathrm{CC}$ & $A G$ & $A G$ & $A G$ \\
\hline 1011 & CT & $A A$ & $A G$ & $A G$ \\
\hline 1012 & CC & $A A$ & $A G$ & AA \\
\hline 1013 & CC & $A A$ & $A A$ & AA \\
\hline 1022 & CT & $A A$ & $A A$ & $A G$ \\
\hline 1024 & $\mathrm{CC}$ & $A A$ & $A G$ & $A G$ \\
\hline 1025 & CC & $A A$ & $A G$ & AA \\
\hline 1029 & CC & $A A$ & GG & AA \\
\hline 1030 & $\mathrm{CC}$ & $A A$ & GG & AA \\
\hline 1031 & $\mathrm{CC}$ & $A A$ & GG & AA \\
\hline 1033 & СT & $A A$ & $A G$ & $A G$ \\
\hline 1038 & CC & $A A$ & $A G$ & $A A$ \\
\hline 1042 & $\mathrm{CC}$ & $A A$ & $A G$ & AA \\
\hline
\end{tabular}


7 Anhang

\begin{tabular}{|c|c|c|c|c|}
\hline 1046 & CT & $\mathrm{AA}$ & $A G$ & $A A$ \\
\hline 1047 & $\mathrm{CC}$ & $A G$ & $\mathrm{GG}$ & $A A$ \\
\hline 1048 & CT & $A G$ & $A G$ & $A G$ \\
\hline 1049 & $\mathrm{CC}$ & $\mathrm{AA}$ & $\mathrm{AA}$ & $A A$ \\
\hline 1053 & $\mathrm{CC}$ & $\mathrm{AA}$ & $\mathrm{GG}$ & $A A$ \\
\hline 1054 & CT & $\mathrm{AA}$ & $A G$ & $A G$ \\
\hline 1055 & $\mathrm{CC}$ & $\mathrm{AA}$ & $A G$ & $A G$ \\
\hline 1062 & $\mathrm{CC}$ & $\mathrm{AA}$ & $\mathrm{GG}$ & $A A$ \\
\hline 1065 & CT & $\mathrm{AA}$ & $A G$ & $A G$ \\
\hline 1070 & CT & AA & $A G$ & $A G$ \\
\hline 1072 & $\mathrm{CC}$ & $\mathrm{AA}$ & $A G$ & $A A$ \\
\hline 1075 & $\mathrm{CC}$ & $A G$ & $\mathrm{GG}$ & $A A$ \\
\hline 1076 & $\mathrm{CC}$ & $\mathrm{AA}$ & $\mathrm{GG}$ & $A A$ \\
\hline 1080 & CT & $\mathrm{AA}$ & $A G$ & $A G$ \\
\hline 1081 & $\mathrm{CC}$ & $\mathrm{AA}$ & $A G$ & $A A$ \\
\hline 1086 & $\mathrm{CC}$ & $\mathrm{AA}$ & $\mathrm{GG}$ & $A A$ \\
\hline 1087 & $\mathrm{CC}$ & $\mathrm{AA}$ & $A G$ & $A A$ \\
\hline 1089 & $\mathrm{CC}$ & AA & $A G$ & $A G$ \\
\hline 1090 & $\mathrm{CC}$ & $\mathrm{AA}$ & $\mathrm{GG}$ & $A A$ \\
\hline 1091 & $\mathrm{CC}$ & $A G$ & $A G$ & $A A$ \\
\hline 1092 & $\mathrm{CC}$ & $\mathrm{AA}$ & $A G$ & $A G$ \\
\hline 1096 & $\mathrm{CT}$ & $\mathrm{AA}$ & $A G$ & $A G$ \\
\hline 1100 & $\mathrm{CC}$ & $\mathrm{AA}$ & $A G$ & $A A$ \\
\hline 1101 & $\mathrm{CC}$ & $\mathrm{AA}$ & GG & $A A$ \\
\hline 1102 & $\mathrm{CC}$ & $\mathrm{AA}$ & GG & $A G$ \\
\hline 1106 & $\mathrm{CC}$ & $\mathrm{AA}$ & $A G$ & $\mathrm{AA}$ \\
\hline 1107 & $\mathrm{CC}$ & AA & $A G$ & $A G$ \\
\hline 1108 & $\mathrm{CC}$ & $\mathrm{AA}$ & $\mathrm{GG}$ & $A A$ \\
\hline 1112 & $\mathrm{CC}$ & $\mathrm{AA}$ & $A G$ & $\mathrm{AA}$ \\
\hline 1113 & $\mathrm{CT}$ & $A G$ & $A G$ & $A G$ \\
\hline 1116 & $\mathrm{CC}$ & $\mathrm{AA}$ & $A G$ & $A A$ \\
\hline 1117 & $\mathrm{CC}$ & $\mathrm{AA}$ & $A G$ & $A A$ \\
\hline 1120 & $\mathrm{CT}$ & $A G$ & $A G$ & $A G$ \\
\hline 1126 & $\mathrm{CC}$ & $A A$ & $\mathrm{GG}$ & $A A$ \\
\hline 1128 & $\mathrm{CC}$ & AA & $A G$ & $\mathrm{AA}$ \\
\hline 1135 & $\mathrm{CT}$ & AA & $A G$ & $A G$ \\
\hline 1136 & $\mathrm{CC}$ & AA & $\mathrm{GG}$ & $\mathrm{AA}$ \\
\hline 1139 & CT & $\mathrm{AA}$ & $A G$ & $A G$ \\
\hline 1144 & $\mathrm{CC}$ & AA & $\mathrm{GG}$ & $A A$ \\
\hline 1145 & $\mathrm{CT}$ & $\mathrm{AA}$ & $\mathrm{AA}$ & $A G$ \\
\hline 1146 & $\mathrm{CC}$ & $A G$ & GG & $A A$ \\
\hline 1147 & $\mathrm{CC}$ & $\mathrm{AA}$ & $A G$ & $A A$ \\
\hline 1148 & $\mathrm{CC}$ & $A G$ & $\mathrm{GG}$ & $A A$ \\
\hline 1158 & $\mathrm{CC}$ & $\mathrm{AA}$ & $A G$ & AA \\
\hline 1160 & CT & $\mathrm{AA}$ & $\mathrm{AA}$ & $A G$ \\
\hline 1165 & $\mathrm{CC}$ & AA & $A G$ & $A A$ \\
\hline 1166 & $\mathrm{CC}$ & $\mathrm{AA}$ & $A G$ & $A A$ \\
\hline 1167 & $\mathrm{CC}$ & $A G$ & $\mathrm{GG}$ & $A A$ \\
\hline 1170 & $\mathrm{CT}$ & $\mathrm{AA}$ & $\mathrm{AA}$ & $A G$ \\
\hline 1175 & $\mathrm{CT}$ & $\mathrm{AA}$ & $A G$ & $A G$ \\
\hline 1176 & $\mathrm{CC}$ & $A G$ & $\mathrm{GG}$ & $A A$ \\
\hline
\end{tabular}


7 Anhang

\begin{tabular}{|c|c|c|c|c|}
\hline 1180 & $\mathrm{CC}$ & $A A$ & $\mathrm{AA}$ & $A G$ \\
\hline 1181 & $\mathrm{CT}$ & $A A$ & $A G$ & $A G$ \\
\hline 1184 & $\mathrm{CT}$ & $A A$ & $A G$ & AA \\
\hline 1188 & $\mathrm{CT}$ & $A A$ & $A G$ & $A G$ \\
\hline 1189 & $\mathrm{CC}$ & $A A$ & $A G$ & $A G$ \\
\hline 1194 & $\mathrm{CC}$ & $A A$ & $\mathrm{GG}$ & AA \\
\hline 1195 & CC & $A G$ & $\mathrm{GG}$ & AA \\
\hline 1199 & $\mathrm{CC}$ & $A A$ & $\mathrm{GG}$ & AA \\
\hline 1203 & $\mathrm{CT}$ & $A A$ & $\mathrm{AA}$ & GG \\
\hline 1207 & $\mathrm{CC}$ & $A A$ & $A G$ & AA \\
\hline 1216 & $\mathrm{CC}$ & $A A$ & $A G$ & AA \\
\hline 1217 & $\mathrm{CC}$ & $A A$ & GG & AA \\
\hline 1220 & $\mathrm{CT}$ & $A A$ & $A G$ & $A G$ \\
\hline 1221 & CC & $A A$ & GG & $A A$ \\
\hline 1223 & CC & $A G$ & $A G$ & $A A$ \\
\hline 1225 & CT & $A A$ & $A G$ & $A G$ \\
\hline 1227 & CC & $A A$ & $A G$ & AA \\
\hline 1233 & $\mathrm{CC}$ & $A A$ & $\mathrm{GG}$ & AA \\
\hline 1235 & $\mathrm{CC}$ & $A A$ & $A G$ & $A A$ \\
\hline 1238 & $\mathrm{CC}$ & $A A$ & $A G$ & $A A$ \\
\hline 1241 & $\mathrm{CC}$ & $A A$ & $G G$ & $A A$ \\
\hline 1244 & $\mathrm{CC}$ & $A A$ & $A G$ & $A A$ \\
\hline 1248 & CC & $A A$ & $A G$ & $A G$ \\
\hline 1249 & CC & $A A$ & $A G$ & AA \\
\hline 1252 & CT & $A A$ & $A G$ & $A G$ \\
\hline 1256 & CT & $A A$ & $A G$ & $A G$ \\
\hline 1258 & CC & $A A$ & $G G$ & $A A$ \\
\hline 1259 & $\mathrm{CC}$ & $A A$ & $A G$ & $A A$ \\
\hline 1262 & $\mathrm{CC}$ & $A A$ & $A G$ & $A A$ \\
\hline 1264 & $\mathrm{CC}$ & $A G$ & $G G$ & $A A$ \\
\hline 1266 & CT & $A A$ & $A G$ & $A G$ \\
\hline 1267 & TT & $A A$ & $\mathrm{AA}$ & GG \\
\hline 1268 & CC & $A G$ & $\mathrm{GG}$ & $A A$ \\
\hline 1269 & CT & $A A$ & $A G$ & $A A$ \\
\hline 1277 & $\mathrm{CC}$ & $A G$ & $\mathrm{GG}$ & AA \\
\hline 1279 & $\mathrm{CC}$ & $A A$ & $\mathrm{GG}$ & AA \\
\hline 1283 & n. d. & n. d. & n. d. & n. d. \\
\hline 1284 & $\mathrm{CC}$ & $A A$ & $G G$ & AA \\
\hline 1286 & $\mathrm{CC}$ & $A A$ & $G G$ & $A A$ \\
\hline 1287 & $\mathrm{CC}$ & $A A$ & $A G$ & $A A$ \\
\hline 1294 & $\mathrm{CT}$ & $A A$ & $A G$ & $A G$ \\
\hline 1298 & CC & $A A$ & $\mathrm{GG}$ & AA \\
\hline 1301 & CT & $A A$ & $A G$ & AA \\
\hline 1302 & $\mathrm{CC}$ & $A A$ & $A G$ & $A A$ \\
\hline 1303 & $\mathrm{CT}$ & $A A$ & $A G$ & $A G$ \\
\hline 1304 & $\mathrm{CT}$ & $A A$ & $A G$ & $A G$ \\
\hline 1305 & $\mathrm{CT}$ & $A A$ & $\mathrm{AA}$ & $A G$ \\
\hline 1310 & $\mathrm{CC}$ & $A G$ & $A G$ & $A G$ \\
\hline 1314 & CC & $A A$ & $G G$ & $A A$ \\
\hline 1315 & $\mathrm{TT}$ & $A A$ & $A A$ & $A A$ \\
\hline 1318 & $\mathrm{CC}$ & $A A$ & $G G$ & $A G$ \\
\hline
\end{tabular}


7 Anhang

\begin{tabular}{|c|c|c|c|c|}
\hline 1319 & TT & $A A$ & $\mathrm{AA}$ & $A G$ \\
\hline 1320 & CT & $A A$ & AA & $A G$ \\
\hline 1322 & $\mathrm{CC}$ & $A A$ & $\mathrm{GG}$ & $A A$ \\
\hline 1332 & $\mathrm{CC}$ & $A G$ & $\mathrm{GG}$ & $\mathrm{AA}$ \\
\hline 1333 & TT & $A A$ & $\mathrm{AA}$ & $\mathrm{GG}$ \\
\hline 1340 & $\mathrm{CC}$ & $A A$ & GG & $\mathrm{AA}$ \\
\hline 1341 & CT & $A A$ & $A G$ & $A G$ \\
\hline 1344 & $\mathrm{CC}$ & $A A$ & $A G$ & $\mathrm{AA}$ \\
\hline 1345 & $\mathrm{CC}$ & $A A$ & GG & $A A$ \\
\hline 1346 & CT & $A A$ & $\mathrm{AA}$ & $A G$ \\
\hline 1348 & $\mathrm{CC}$ & $A A$ & $A G$ & $A G$ \\
\hline 1350 & $\mathrm{CC}$ & $A A$ & $A G$ & $A G$ \\
\hline 1353 & CT & $A A$ & $A G$ & $A G$ \\
\hline 1356 & $\mathrm{CC}$ & $A A$ & $A G$ & $\mathrm{AA}$ \\
\hline 1357 & $\mathrm{CC}$ & $A G$ & GG & $A G$ \\
\hline 1359 & $\mathrm{CC}$ & $\mathrm{GG}$ & $\mathrm{GG}$ & $A A$ \\
\hline 1360 & $\mathrm{CC}$ & $A G$ & $\mathrm{GG}$ & $A G$ \\
\hline 1361 & $\mathrm{CC}$ & $A A$ & $\mathrm{GG}$ & $\mathrm{AA}$ \\
\hline 1362 & $\mathrm{CT}$ & $A A$ & $A G$ & $A G$ \\
\hline 1364 & $\mathrm{CC}$ & $A G$ & $G G$ & $A G$ \\
\hline 1370 & $\mathrm{CC}$ & $A G$ & $G G$ & $\mathrm{AA}$ \\
\hline 1375 & $\mathrm{TT}$ & $A A$ & $\mathrm{AA}$ & $A G$ \\
\hline 1376 & $\mathrm{CC}$ & $A A$ & GG & $A A$ \\
\hline 1382 & $\mathrm{CC}$ & $A A$ & $A G$ & $\mathrm{AA}$ \\
\hline 1388 & $\mathrm{CC}$ & $A A$ & $A G$ & $A G$ \\
\hline 1389 & $\mathrm{CC}$ & $A A$ & $\mathrm{GG}$ & $A A$ \\
\hline 1391 & CT & $A A$ & $\mathrm{AA}$ & $\mathrm{AA}$ \\
\hline 1395 & $\mathrm{CT}$ & $A A$ & $\mathrm{AA}$ & $A G$ \\
\hline 1396 & $\mathrm{CT}$ & $A A$ & $A G$ & $A G$ \\
\hline 1399 & $\mathrm{CC}$ & $A A$ & $\mathrm{GG}$ & $\mathrm{AA}$ \\
\hline 1402 & $\mathrm{CC}$ & $A G$ & $A G$ & $\mathrm{AA}$ \\
\hline 1403 & $\mathrm{CC}$ & $A G$ & $A G$ & $A A$ \\
\hline 1404 & $\mathrm{CC}$ & $A A$ & $A G$ & $A A$ \\
\hline 1405 & $\mathrm{CC}$ & AA & $A G$ & $A A$ \\
\hline 1407 & $\mathrm{CC}$ & n. d. & $A G$ & $\mathrm{AA}$ \\
\hline 1408 & $\mathrm{CC}$ & $A A$ & $\mathrm{GG}$ & $\mathrm{AA}$ \\
\hline 1409 & CT & $A A$ & $A G$ & $A A$ \\
\hline 1415 & $\mathrm{CC}$ & $A G$ & $\mathrm{GG}$ & $\mathrm{AA}$ \\
\hline 1418 & $\mathrm{CT}$ & $A A$ & $A G$ & $A G$ \\
\hline 1420 & $\mathrm{CT}$ & $A A$ & $\mathrm{AA}$ & $\mathrm{AA}$ \\
\hline 1423 & CT & $A A$ & $A G$ & $A G$ \\
\hline 1427 & $\mathrm{CT}$ & $A A$ & $A G$ & $A G$ \\
\hline 1428 & $\mathrm{CC}$ & $A A$ & $A G$ & $\mathrm{AA}$ \\
\hline 1432 & $\mathrm{CT}$ & $A A$ & $A G$ & $A G$ \\
\hline 1433 & CT & $A A$ & $A G$ & $A G$ \\
\hline 1434 & $\mathrm{CC}$ & $A A$ & $A G$ & $\mathrm{AA}$ \\
\hline 1435 & $\mathrm{CC}$ & $A G$ & $A G$ & $\mathrm{AA}$ \\
\hline 1436 & $\mathrm{CC}$ & $A A$ & $G G$ & $\mathrm{AA}$ \\
\hline 1437 & $\mathrm{CC}$ & $A G$ & $A G$ & $A A$ \\
\hline 1440 & $\mathrm{TT}$ & $A A$ & $\mathrm{AA}$ & GG \\
\hline 1441 & $\mathrm{CT}$ & $A A$ & $\mathrm{AA}$ & $\mathrm{GG}$ \\
\hline
\end{tabular}


7 Anhang

\begin{tabular}{|c|c|c|c|c|}
\hline 1445 & CT & $\mathrm{AA}$ & $A G$ & $A G$ \\
\hline 1453 & $\mathrm{CC}$ & $A G$ & $\mathrm{GG}$ & $A A$ \\
\hline 1455 & $\mathrm{CC}$ & $\mathrm{AA}$ & $\mathrm{GG}$ & $A A$ \\
\hline 1458 & $\mathrm{CC}$ & AA & $A G$ & $A A$ \\
\hline 1460 & $\mathrm{CC}$ & $\mathrm{AA}$ & GG & $A A$ \\
\hline 1461 & CT & AA & $A G$ & $A G$ \\
\hline 1463 & $\mathrm{CC}$ & $\mathrm{AA}$ & $\mathrm{AA}$ & $A A$ \\
\hline 1466 & $\mathrm{CC}$ & AA & $\mathrm{GG}$ & $A A$ \\
\hline 1468 & $\mathrm{CC}$ & AA & $A G$ & $\mathrm{AA}$ \\
\hline 1469 & CT & $\mathrm{AA}$ & $A G$ & $A G$ \\
\hline 1470 & $\mathrm{CC}$ & AA & $A G$ & $A A$ \\
\hline 1474 & CT & $\mathrm{AA}$ & $A A$ & $A G$ \\
\hline 1476 & $\mathrm{CC}$ & $\mathrm{AA}$ & $\mathrm{GG}$ & $A A$ \\
\hline 1477 & CT & $\mathrm{AA}$ & $A G$ & $A G$ \\
\hline 1484 & $\mathrm{CT}$ & $\mathrm{AA}$ & $A A$ & $A G$ \\
\hline 1485 & $\mathrm{CC}$ & $\mathrm{AA}$ & GG & $\mathrm{AA}$ \\
\hline 1487 & $\mathrm{CC}$ & AA & $A G$ & AA \\
\hline 1488 & $\mathrm{CC}$ & AA & $A G$ & $A G$ \\
\hline 1489 & $\mathrm{CT}$ & $\mathrm{AA}$ & $A G$ & $A G$ \\
\hline 1491 & $\mathrm{CC}$ & $\mathrm{AA}$ & $A G$ & $\mathrm{AA}$ \\
\hline 1492 & $\mathrm{CT}$ & $\mathrm{AA}$ & $A A$ & $\mathrm{AA}$ \\
\hline 1498 & $\mathrm{CC}$ & $\mathrm{AA}$ & $A G$ & $A G$ \\
\hline 1499 & $\mathrm{CC}$ & $\mathrm{AA}$ & $\mathrm{GG}$ & $A A$ \\
\hline 1500 & $\mathrm{CC}$ & $A G$ & $\mathrm{GG}$ & $\mathrm{AA}$ \\
\hline 1503 & $\mathrm{CC}$ & $\mathrm{AA}$ & $\mathrm{AA}$ & $\mathrm{AA}$ \\
\hline 1504 & CT & AA & $A G$ & $A G$ \\
\hline 1507 & $\mathrm{CC}$ & $\mathrm{AA}$ & GG & $A A$ \\
\hline 1510 & $\mathrm{CC}$ & $\mathrm{AA}$ & GG & $\mathrm{AA}$ \\
\hline 1511 & $\mathrm{CT}$ & $\mathrm{AA}$ & $A G$ & $A G$ \\
\hline 1516 & TT & $\mathrm{AA}$ & $A A$ & $\mathrm{GG}$ \\
\hline 1518 & $\mathrm{CC}$ & $\mathrm{AA}$ & $A G$ & $A G$ \\
\hline 1520 & $\mathrm{CC}$ & $\mathrm{AA}$ & $A G$ & $A A$ \\
\hline 1521 & $\mathrm{CT}$ & $\mathrm{AA}$ & $A A$ & $A G$ \\
\hline 1522 & TT & AA & $\mathrm{AA}$ & $\mathrm{GG}$ \\
\hline 1524 & $\mathrm{CC}$ & AA & $A A$ & $A G$ \\
\hline 1527 & $\mathrm{CC}$ & AA & $\mathrm{GG}$ & $A A$ \\
\hline 1536 & CT & $\mathrm{AA}$ & $A G$ & $A G$ \\
\hline 1540 & $\mathrm{CC}$ & $A G$ & GG & $\mathrm{AA}$ \\
\hline 1541 & $\mathrm{CC}$ & $\mathrm{AA}$ & GG & $\mathrm{AA}$ \\
\hline 1544 & $\mathrm{CC}$ & $\mathrm{AA}$ & GG & AA \\
\hline 1548 & $\mathrm{CC}$ & $A G$ & GG & $\mathrm{AA}$ \\
\hline 1549 & CT & $\mathrm{AA}$ & $A G$ & $A G$ \\
\hline 1550 & $\mathrm{CC}$ & $A G$ & $\mathrm{GG}$ & $\mathrm{AA}$ \\
\hline 1553 & $\mathrm{CC}$ & $\mathrm{AA}$ & $A G$ & $A G$ \\
\hline 1554 & $\mathrm{CC}$ & AA & $A G$ & AA \\
\hline 1555 & $\mathrm{CC}$ & $\mathrm{AA}$ & $A G$ & $A G$ \\
\hline 1557 & $\mathrm{CC}$ & $\mathrm{AA}$ & $A G$ & $\mathrm{AA}$ \\
\hline 1558 & $\mathrm{CC}$ & $\mathrm{AA}$ & $\mathrm{GG}$ & $A G$ \\
\hline 1561 & CT & $\mathrm{AA}$ & $A A$ & $A G$ \\
\hline 1563 & $\mathrm{CC}$ & $\mathrm{AA}$ & $\mathrm{GG}$ & $A A$ \\
\hline 1565 & $\mathrm{CT}$ & $A A$ & $A G$ & $A G$ \\
\hline
\end{tabular}


7 Anhang

\begin{tabular}{|c|c|c|c|c|}
\hline 1569 & $\mathrm{CC}$ & $\mathrm{AA}$ & $A G$ & $A G$ \\
\hline 1571 & CT & AA & $A G$ & $A G$ \\
\hline 1573 & $\mathrm{CC}$ & $\mathrm{AA}$ & $\mathrm{GG}$ & $A A$ \\
\hline 1576 & $\mathrm{CC}$ & AA & $\mathrm{GG}$ & $\mathrm{AA}$ \\
\hline 1577 & CT & $\mathrm{AA}$ & $A A$ & $A G$ \\
\hline 1582 & $\mathrm{CC}$ & AA & $A A$ & $A G$ \\
\hline 1587 & $\mathrm{TT}$ & $\mathrm{AA}$ & $\mathrm{AA}$ & $\mathrm{GG}$ \\
\hline 1588 & CT & AA & $A G$ & $A G$ \\
\hline 1595 & CT & $\mathrm{AA}$ & $A G$ & $A G$ \\
\hline 1600 & CT & AA & $A A$ & $A G$ \\
\hline 1601 & CT & AA & $A G$ & $\mathrm{AA}$ \\
\hline 1602 & $\mathrm{CC}$ & $\mathrm{AA}$ & $A A$ & $\mathrm{AA}$ \\
\hline 1605 & $\mathrm{CC}$ & $\mathrm{AA}$ & $A G$ & $A A$ \\
\hline 1606 & $\mathrm{CC}$ & $\mathrm{AA}$ & $\mathrm{GG}$ & $\mathrm{AA}$ \\
\hline 1608 & $\mathrm{CT}$ & $\mathrm{AA}$ & $A G$ & $A A$ \\
\hline 1611 & CT & AA & $A A$ & $A A$ \\
\hline 1613 & $\mathrm{CC}$ & AA & $A G$ & $A A$ \\
\hline 1615 & $\mathrm{CC}$ & AA & $A G$ & $\mathrm{AA}$ \\
\hline 1617 & $\mathrm{CT}$ & $\mathrm{AA}$ & $A G$ & $A G$ \\
\hline 1618 & $\mathrm{CC}$ & $\mathrm{AA}$ & $A G$ & $A G$ \\
\hline 1619 & $\mathrm{CT}$ & $\mathrm{AA}$ & $A G$ & $A G$ \\
\hline 1621 & $\mathrm{CC}$ & $\mathrm{AA}$ & GG & $\mathrm{AA}$ \\
\hline 1630 & $\mathrm{CC}$ & $\mathrm{AA}$ & $\mathrm{GG}$ & $A A$ \\
\hline 1631 & $\mathrm{CC}$ & $\mathrm{AA}$ & $A G$ & $A G$ \\
\hline 1633 & $\mathrm{CC}$ & $\mathrm{AA}$ & $\mathrm{AA}$ & $A G$ \\
\hline 1634 & $\mathrm{CC}$ & AA & $\mathrm{GG}$ & $A A$ \\
\hline 1637 & CT & $\mathrm{AA}$ & $A G$ & $A G$ \\
\hline 1638 & $\mathrm{CC}$ & $A G$ & GG & $\mathrm{AA}$ \\
\hline 1640 & $\mathrm{CC}$ & $\mathrm{AA}$ & GG & $\mathrm{AA}$ \\
\hline 1643 & CT & $\mathrm{AA}$ & $A G$ & $A G$ \\
\hline 1646 & $\mathrm{CC}$ & $A G$ & $\mathrm{GG}$ & $\mathrm{AA}$ \\
\hline 1647 & $\mathrm{CC}$ & $A G$ & $\mathrm{GG}$ & $A A$ \\
\hline 1658 & $\mathrm{CT}$ & $\mathrm{AA}$ & $A G$ & $A G$ \\
\hline 1660 & CT & AA & $A G$ & $A A$ \\
\hline 1664 & CT & AA & $A G$ & $\mathrm{AA}$ \\
\hline 1666 & $\mathrm{CC}$ & $A G$ & $A G$ & $\mathrm{AA}$ \\
\hline 1668 & $\mathrm{CC}$ & $\mathrm{AA}$ & GG & $\mathrm{AA}$ \\
\hline 1671 & $\mathrm{CC}$ & $\mathrm{AA}$ & GG & $\mathrm{AA}$ \\
\hline 1674 & $\mathrm{CC}$ & $\mathrm{AA}$ & $A G$ & $\mathrm{AA}$ \\
\hline 1675 & $\mathrm{CC}$ & $\mathrm{AA}$ & $A G$ & $\mathrm{AA}$ \\
\hline 1678 & $\mathrm{CC}$ & AA & GG & $\mathrm{AA}$ \\
\hline 1684 & $\mathrm{CC}$ & $\mathrm{AA}$ & $\mathrm{GG}$ & $A G$ \\
\hline 1685 & $\mathrm{CC}$ & $\mathrm{AA}$ & GG & $\mathrm{AA}$ \\
\hline 1686 & CT & AA & $A G$ & $A G$ \\
\hline 1688 & $\mathrm{CC}$ & AA & $\mathrm{GG}$ & $A A$ \\
\hline 1689 & $\mathrm{CC}$ & AA & $\mathrm{GG}$ & $\mathrm{AA}$ \\
\hline 1690 & $\mathrm{CC}$ & $A G$ & GG & $\mathrm{AA}$ \\
\hline 1694 & $\mathrm{TT}$ & $\mathrm{AA}$ & $A A$ & $G G$ \\
\hline 1695 & TT & $A G$ & $A A$ & $G G$ \\
\hline 1697 & $\mathrm{TT}$ & $\mathrm{AA}$ & $A A$ & GG \\
\hline 1699 & $\mathrm{CT}$ & $A A$ & $A G$ & $A G$ \\
\hline
\end{tabular}


Anhang $\boldsymbol{C}$ Ergebnisse der Multiplex Assays bei gesunden Kontrollprobanden. Von den 135 Proben entfielen 23 auf LCL-Zellen des internationalen HapMap-Projektes (Bezeichnung 1 bis 60), 24 auf LCLZellen, welche aus mononukleären Zellen des peripheren Blutes gesunder Spender gewonnen (Bezeichnung bspw. 7/3) sowie 84 auf DNA-Proben, die aus Buffy coats isoliert worden waren (Bezeichnung: ,Gö’ plus Ziffernfolge, z. B. Gö35).

\begin{tabular}{|c|c|c|c|c|}
\hline Probe & IL-10-12.806TC & IL-10-11.777GA & IL-10-11.668GA & IL-10 $+4.259 \mathrm{AG}$ \\
\hline 1 & TT & AA & AA & GG \\
\hline 2 & TT & AA & AA & GG \\
\hline 3 & $\mathrm{CC}$ & AA & AA & AA \\
\hline 4 & $\mathrm{CC}$ & AA & GG & AA \\
\hline 5 & $\mathrm{CC}$ & AA & $A G$ & $\mathrm{AA}$ \\
\hline 12 & $\mathrm{CC}$ & $A A$ & $A G$ & $A G$ \\
\hline 13 & CT & AA & $A G$ & $A G$ \\
\hline 14 & CT & AA & $A G$ & $A G$ \\
\hline 15 & CT & $A G$ & $A G$ & $A G$ \\
\hline 16 & TT & $A A$ & $A A$ & GG \\
\hline 21 & $\mathrm{CC}$ & $A A$ & $A G$ & $\mathrm{AA}$ \\
\hline 22 & $\mathrm{CC}$ & AA & GG & AA \\
\hline 23 & CT & AA & $A G$ & GG \\
\hline 24 & $\mathrm{CC}$ & AA & $A G$ & $\mathrm{AA}$ \\
\hline 30 & CT & AA & $A G$ & $A G$ \\
\hline 31 & CT & AA & $A G$ & $A G$ \\
\hline 32 & $\mathrm{CC}$ & $A G$ & $A G$ & $A G$ \\
\hline 34 & $\mathrm{CC}$ & AA & $A G$ & $A A$ \\
\hline 40 & $\mathrm{CC}$ & AA & GG & AA \\
\hline 41 & $\mathrm{CC}$ & AA & GG & AA \\
\hline 50 & CT & AA & $A G$ & $A G$ \\
\hline 54 & $\mathrm{CC}$ & AA & GG & $\mathrm{AA}$ \\
\hline 60 & CT & AA & $A G$ & $\mathrm{GG}$ \\
\hline $7 / 3$ & TT & AA & AA & GG \\
\hline $8 / 2$ & $\mathrm{CC}$ & AA & GG & AA \\
\hline $8 / 4$ & $\mathrm{CC}$ & AA & GG & AA \\
\hline $9 / 1$ & $\mathrm{CC}$ & AA & $A G$ & AA \\
\hline $13 / 1$ & $\mathrm{CC}$ & AA & GG & $\mathrm{AA}$ \\
\hline $13 / 3$ & CT & $A A$ & $A A$ & $A G$ \\
\hline $15 / 3$ & $\mathrm{CC}$ & AA & GG & AA \\
\hline $16 / 3$ & CT & AA & AA & GG \\
\hline $23 / 1$ & CT & AA & $A A$ & $A G$ \\
\hline $23 / 2$ & CT & AA & AA & $A G$ \\
\hline $31 / 1$ & $\mathrm{CC}$ & AA & $A G$ & AA \\
\hline $33 / 2$ & $\mathrm{CT}$ & AA & $A G$ & $A G$ \\
\hline $34 / 1$ & TT & AA & AA & $\mathrm{GG}$ \\
\hline $44 / 2$ & TT & AA & AA & GG \\
\hline $49 / 1$ & $\mathrm{CC}$ & AA & GG & AA \\
\hline $58 / 1$ & $\mathrm{CC}$ & AA & $A G$ & AA \\
\hline $58 / 3$ & CT & $A G$ & $A G$ & $A G$ \\
\hline $59 / 3$ & TT & AA & AA & $\mathrm{GG}$ \\
\hline $60 / 2$ & $\mathrm{CC}$ & $A G$ & GG & AA \\
\hline $102 / 2$ & $\mathrm{CC}$ & AA & GG & AA \\
\hline $103 / 1$ & $\mathrm{CC}$ & $A G$ & $A G$ & $A G$ \\
\hline
\end{tabular}


7 Anhang

\begin{tabular}{|c|c|c|c|c|}
\hline $103 / 2$ & $\mathrm{CC}$ & $\mathrm{AA}$ & GG & $A G$ \\
\hline $103 / 3$ & $\mathrm{CT}$ & AA & GG & $A A$ \\
\hline $103 / 4$ & $\mathrm{CT}$ & AA & $A G$ & $A G$ \\
\hline Gö35 & CT & $A G$ & $A G$ & $A G$ \\
\hline Gö36 & CT & $\mathrm{AA}$ & $A G$ & $A G$ \\
\hline Gö37 & CT & AA & $A G$ & $A G$ \\
\hline Gö40 & $\mathrm{CC}$ & $\mathrm{AA}$ & GG & $A G$ \\
\hline Gö41 & $\mathrm{CC}$ & AA & GG & $A A$ \\
\hline Gö42 & CT & $\mathrm{AA}$ & $A G$ & $A G$ \\
\hline Gö48 & $\mathrm{CC}$ & $A G$ & GG & $A A$ \\
\hline Gö49 & CT & AA & $A G$ & GG \\
\hline Gö50 & $\mathrm{CT}$ & $A A$ & $A G$ & $A G$ \\
\hline Gö51 & $\mathrm{CC}$ & $\mathrm{AA}$ & GG & $A A$ \\
\hline Gö52 & $\mathrm{CC}$ & $A A$ & GG & $A A$ \\
\hline Gö53 & $\mathrm{TT}$ & $\mathrm{AA}$ & $A A$ & GG \\
\hline Gö54 & $\mathrm{CT}$ & $\mathrm{AA}$ & $A A$ & $A G$ \\
\hline Gö55 & $\mathrm{CT}$ & $\mathrm{AA}$ & $A G$ & $A G$ \\
\hline Gö56 & CT & $A G$ & $A G$ & $A G$ \\
\hline Gö57 & $\mathrm{CC}$ & $A G$ & GG & $A A$ \\
\hline Gö58 & $\mathrm{CT}$ & $A G$ & $A G$ & $A G$ \\
\hline Gö59 & $\mathrm{CT}$ & $\mathrm{AA}$ & $\mathrm{AA}$ & $A G$ \\
\hline Gö60 & $\mathrm{CC}$ & $A G$ & $A G$ & $A A$ \\
\hline Gö61 & $\mathrm{CC}$ & $\mathrm{AA}$ & $A G$ & $A A$ \\
\hline Gö62 & $\mathrm{CC}$ & $A A$ & $A G$ & $A A$ \\
\hline Gö63 & $\mathrm{CT}$ & $\mathrm{AA}$ & $\mathrm{AA}$ & $A A$ \\
\hline Gö65 & CT & AA & $A G$ & $A A$ \\
\hline Gö66 & $\mathrm{CC}$ & AA & GG & $A A$ \\
\hline Gö67 & $\mathrm{CC}$ & AA & GG & $A A$ \\
\hline Gö68 & $\mathrm{CC}$ & $\mathrm{AA}$ & $A G$ & $A G$ \\
\hline Gö69 & $\mathrm{CT}$ & $\mathrm{AA}$ & $\mathrm{AA}$ & $A G$ \\
\hline Gö70 & $\mathrm{CT}$ & $A A$ & $\mathrm{AA}$ & $A G$ \\
\hline Gö71 & $\mathrm{CC}$ & $\mathrm{AA}$ & $A G$ & $A A$ \\
\hline Gö72 & $\mathrm{CT}$ & $\mathrm{AA}$ & $A G$ & $A G$ \\
\hline Gö73 & $\mathrm{CT}$ & $\mathrm{AA}$ & $A G$ & $A G$ \\
\hline Gö74 & $\mathrm{CC}$ & $\mathrm{AA}$ & $\mathrm{GG}$ & $A A$ \\
\hline Gö75 & $\mathrm{CC}$ & $\mathrm{AA}$ & $\mathrm{GG}$ & $A A$ \\
\hline Gö76 & $\mathrm{CC}$ & $A G$ & $A G$ & $A A$ \\
\hline Gö78 & CT & AA & $A G$ & $A G$ \\
\hline Gö79 & $\mathrm{CC}$ & $\mathrm{AA}$ & GG & $A A$ \\
\hline Gö80 & $\mathrm{CT}$ & $A A$ & $A G$ & $A G$ \\
\hline Gö81 & $\mathrm{CC}$ & $A G$ & GG & $A A$ \\
\hline Gö82 & $\mathrm{CT}$ & $A G$ & $A G$ & $A G$ \\
\hline Gö83 & $\mathrm{CT}$ & $\mathrm{AA}$ & $A G$ & $A G$ \\
\hline Gö84 & $\mathrm{CC}$ & $\mathrm{AA}$ & $A G$ & $A A$ \\
\hline Gö85 & $\mathrm{TT}$ & $\mathrm{AA}$ & $A A$ & GG \\
\hline Gö86 & $\mathrm{CT}$ & $A A$ & $A G$ & $A G$ \\
\hline Gö87 & CT & AA & $A G$ & $A G$ \\
\hline Gö90 & CT & $\mathrm{AA}$ & $\mathrm{GG}$ & $A G$ \\
\hline Gö91 & $\mathrm{CC}$ & $A G$ & GG & $A A$ \\
\hline Gö92 & $\mathrm{CC}$ & $A G$ & $G G$ & $A A$ \\
\hline Gö93 & $\mathrm{CC}$ & $A G$ & $A G$ & $A A$ \\
\hline
\end{tabular}


7 Anhang

\begin{tabular}{|c|c|c|c|c|}
\hline Gö96 & $\mathrm{CC}$ & $\mathrm{AA}$ & $A G$ & $A A$ \\
\hline Gö97 & $\mathrm{CC}$ & AA & $A G$ & $A A$ \\
\hline Gö99 & $\mathrm{CT}$ & $\mathrm{AA}$ & $A G$ & $A A$ \\
\hline Gö100 & $\mathrm{CT}$ & $A G$ & $A G$ & $A G$ \\
\hline Gö101 & $\mathrm{CT}$ & $\mathrm{AA}$ & $A A$ & $A G$ \\
\hline Gö103 & $\mathrm{CC}$ & $A G$ & GG & $A A$ \\
\hline Gö104 & $\mathrm{CT}$ & $\mathrm{AA}$ & $A A$ & GG \\
\hline Gö106 & $\mathrm{CC}$ & $A A$ & $\mathrm{GG}$ & $A G$ \\
\hline Gö107 & $\mathrm{CT}$ & $\mathrm{AA}$ & $A G$ & $A G$ \\
\hline Gö108 & $\mathrm{CC}$ & $A A$ & $\mathrm{GG}$ & $A A$ \\
\hline Gö110 & $\mathrm{CC}$ & $\mathrm{AA}$ & $A G$ & $A A$ \\
\hline Gö112 & $\mathrm{CT}$ & $A A$ & $A G$ & $A G$ \\
\hline Gö113 & $\mathrm{CC}$ & $\mathrm{AA}$ & $\mathrm{GG}$ & $A A$ \\
\hline Gö121 & $\mathrm{CC}$ & $A A$ & $A G$ & $A A$ \\
\hline Gö122 & $\mathrm{CC}$ & $\mathrm{AA}$ & $A G$ & $A A$ \\
\hline Gö127 & $\mathrm{CT}$ & $\mathrm{AA}$ & $A G$ & $A G$ \\
\hline Gö128 & $\mathrm{TT}$ & $\mathrm{AA}$ & $A A$ & $\mathrm{GG}$ \\
\hline Gö130 & $\mathrm{CC}$ & $\mathrm{AA}$ & $\mathrm{GG}$ & $A A$ \\
\hline Gö131 & $\mathrm{CT}$ & AA & $A G$ & $A A$ \\
\hline Gö132 & $\mathrm{CC}$ & $\mathrm{AA}$ & $\mathrm{GG}$ & $A A$ \\
\hline Gö133 & $\mathrm{CT}$ & $\mathrm{AA}$ & $A G$ & $A G$ \\
\hline Gö135 & $\mathrm{CT}$ & $A A$ & $A A$ & $A G$ \\
\hline Gö136 & $\mathrm{CC}$ & $\mathrm{AA}$ & $A G$ & $A A$ \\
\hline Gö137 & $\mathrm{CT}$ & $\mathrm{AA}$ & $A G$ & $A G$ \\
\hline Gö139 & $\mathrm{CT}$ & $\mathrm{AA}$ & $A G$ & GG \\
\hline Gö142 & $\mathrm{CC}$ & $\mathrm{AA}$ & $A G$ & $A A$ \\
\hline Gö143 & $\mathrm{CC}$ & $\mathrm{AA}$ & $A G$ & $A A$ \\
\hline Gö223 & $\mathrm{CC}$ & $A G$ & GG & AA \\
\hline Gö306 & $\mathrm{CC}$ & AA & GG & $A A$ \\
\hline Gö307 & $\mathrm{CC}$ & $A G$ & $\mathrm{GG}$ & $A A$ \\
\hline Gö308 & $\mathrm{CC}$ & $A G$ & $\mathrm{GG}$ & $A A$ \\
\hline Gö309 & $\mathrm{CT}$ & $\mathrm{AA}$ & $A G$ & $A G$ \\
\hline Gö310 & $\mathrm{CC}$ & $A A$ & GG & $A A$ \\
\hline Gö311 & $\mathrm{CT}$ & $\mathrm{AA}$ & $A A$ & $A G$ \\
\hline Gö312 & $\mathrm{CT}$ & $\mathrm{AA}$ & $\mathrm{AA}$ & $A A$ \\
\hline Gö313 & $\mathrm{CC}$ & $\mathrm{AA}$ & $A G$ & $A A$ \\
\hline
\end{tabular}




\section{$8 \quad$ Literaturverzeichnis}

Alas S, Emmanouilides C, Bonavida B (2001): Inhibition of interleukin 10 by rituximab results in down-regulation of bcl-2 and sensitization of B-cell non-Hodgkin's lymphoma to apoptosis. Clin Cancer Res $\underline{7}(3), 709-23$

Alexander DD, Mink PJ, Adami HO, Chang ET, Cole P, Mandel JS, Trichopoulos D (2007): The non-Hodgkin lymphomas: a review of the epidemiologic literature. Int J Cancer 120 Suppl $\underline{12}, 1-39$

Beatty PR, Krams SM, Martinez OM (1997): Involvement of IL-10 in the autonomous growth of EBV-transformed B cell lines. J Immunol 158(9), 4045-51

Bellan C, Lazzi S, De Falco G, Nyongo A, Giordano A, Leoncini L (2003): Burkitt's lymphoma: new insights into molecular pathogenesis. J Clin Pathol $\underline{56}(3), 188-92$

Benjamin D, Park CD, Sharma V (1994): Human B cell interleukin 10. Leuk Lymphoma 12(3-4), 205-10

Berglund M, Thunberg U, Roos G, Rosenquist R, Enblad G (2005): The interleukin-10 gene promoter polymorphism (-1082) does not correlate with clinical outcome in diffuse large Bcell lymphoma. Blood 105(12), 4894-5

Blay JY, Burdin N, Rousset F, Lenoir G, Biron P, Philip T, Banchereau J, Favrot MC (1993): Serum interleukin-10 in non-Hodgkin's Iymphoma: a prognostic factor. Blood $\underline{82}(7), 2169-$ 74

Bräuninger A, Schmitz R, Bechtel D, Renné C, Hansmann ML, Küppers R (2006): Molecular biology of Hodgkin's and Reed/Sternberg cells in Hodgkin's lymphoma. Int $\mathrm{J}$ Cancer $\underline{118}(8), 1853-61$

Breen EC, Boscardin WJ, Detels R, Jacobson LP, Smith MW, O'Brien SJ, Chmiel JS, Rinaldo CR, Lai S, Martínez-Maza O (2003): Non-Hodgkin's B cell lymphoma in persons with acquired immunodeficiency syndrome is associated with increased serum levels of IL10, or the IL10 promotor -592 C/C genotype. Clin Immunol 109(2), 119-29

Cavet J, Middleton PG, Segall M, Noreen H, Davies SM, Dickinson AM (1999): Recipient tumor necrosis factor-alpha and interleukin-10 gene polymorphisms associate with early mortality 
and acute graft-versus-host disease severity in HLA-matched sibling bone marrow transplant. Blood 94(11), 3941-6

Cervenak L, Morbidelli L, Donati D, Donnini S, Kambayashi T, Wilson JL, Axelson H, CastañosVelez E, Ljunggren HG, Malefyt RD et al. (2000): Abolished angiogenicity and tumorigenicity of Burkitt lymphoma by interleukin-10. Blood $\underline{96}(7), 2568-73$

Cortes JE, Talpaz M, Cabanillas F, Seymour JF, Kurzrock R (1995): Serum levels of interleukin10 in patients with diffuse large cell lymphoma: lack of correlation with prognosis. Blood 85(9), 2516-20

Cunningham LM, Chapman C, Dunstan R, Bell MC, Joske DJ (2003): Polymorphisms in the interleukin 10 gene promoter are associated with susceptibility to aggressive nonHodgkin's lymphoma. Leuk Lymphoma $\underline{44(2), ~ 251-5}$

D'Alfonso S, Rampi M, Bocchio D, Colombo G, Scorza-Smeraldi R, Momigliano-Richardi P (2000): Systemic lupus erythematosus candidate genes in the Italian population: evidence for a significant association with interleukin-10. Arthritis Rheum $\underline{43}(1), 120-8$

de Waal MR, Abrams J, Bennett B, Figdor CG, de Vries JE (1991): Interleukin 10 (IL-10) inhibits cytokine synthesis by human monocytes: an autoregulatory role of IL-10 produced by monocytes. J Exp Med 174(5), 1209-20

Eskdale J, Wordsworth P, Bowman S, Field M, Gallagher G (1997): Association between polymorphisms at the human IL-10 locus and systemic lupus erythematosus. Tissue Antigens $\underline{49}(6), 635-9$

Eskdale J, Gallagher G, Verweij CL, Keijsers V, Westendorp RG, Huizinga TW (1998): Interleukin 10 secretion in relation to human IL-10 locus haplotypes. Proc Natl Acad Sci U S A $\underline{95}(16), 9465-70$

Fischbach W (1998): Current aspects of pathogenesis, diagnosis and therapy of primary MALT stomach lymphomas. Z Gastroenterol $\underline{36}(4), 307-12$

Gibson AW, Edberg JC, Wu J, Westendorp RG, Huizinga TW, Kimberly RP (2001): Novel single nucleotide polymorphisms in the distal IL-10 promoter affect IL-10 production and enhance the risk of systemic lupus erythematosus. J Immunol $\underline{166}(6), 3915-22$ 
Grulich AE, Vajdic CM (2005): The epidemiology of non-Hodgkin lymphoma. Pathology $\underline{37}(6)$, 409-19

Gupta M, Han JJ, Stenson M, Maurer M, Wellik L, Hu G, Ziesmer S, Dogan A, Witzig TE (2012): Elevated serum IL-10 levels in diffuse large B-cell lymphoma: a mechanism of aberrant JAK2 activation. Blood 119(12), 2844-53

Hajeer AH, Lazarus M, Turner D, Mageed RA, Vencovsky J, Sinnott P, Hutchinson IV, Ollier WE (1998): IL-10 gene promoter polymorphisms in rheumatoid arthritis. Scand J Rheumatol $\underline{27}(2), 142-5$

Hanahan D, Weinberg RA (2000): The hallmarks of cancer. Cell $\underline{100(1), 57-70}$

Hill AV (2001): The genomics and genetics of human infectious disease susceptibility. Annu Rev Genomicx Hum Genet 2, 373-400

Hofmann SR, Ettinger R, Zhou YJ, Gadina M, Lipsky P, Siegel R, Candotti F, O'Shea JJ (2002): Cytokines and their role in lymphoid development, differentiation and homeostasis. Curr Opin Allergy Clin Immunol 2 (6), 495-506

Hollegaard MV, Bidwell JL (2006): Cytokine gene polymorphism in human disease: on-line databases, Supplement 3. Genes Immun $\underline{7}(4)$, 269-76

Holloway AF, Rao S, Shannon MF (2002): Regulation of cytokine gene transcription in the immune system. Mol Immunol $\underline{38}(8), 567-80$

Howell WM, Calder PC, Grimble RF (2002): Gene polymorphisms, inflammatory diseases and cancer. Proc Nutr Soc $\underline{61}(4), 447-56$

Howell WM, Rose-Zerilli MJ (2006): Cytokine gene polymorphisms, cancer susceptibility and prognosis. Fam Cancer $\underline{5}(2), 143-9$

Husmann G, Kaatsch P, Katalinic A, Bertz J, Haberland J, Kraywinkel K, Wolf U: Krebs in Deutschland 2005/2006. Häufigkeiten und Trends. 7. Ausgabe; Robert Koch-Institut (Hrsg.) und die Gesellschaft der epidemiologischen Krebsregister in Deutschland e.V. (Hrsg.), Berlin 2010 
Jaffe ES, Harris NL, Stein H, Vardiman JW: World Health Organization Classification of Tumours. Pathology \& Genetics. Tumours of Haematopoietic and Lymphoid Tissues. IARC Press, Lyon 2001

Kube D, Rieth H, Eskdale J, Kremsner PG, Gallagher G (2001): Structural characterisation of the distal 5' flanking region of the human interleukin-10 gene. Genes Immun 2(4), 181-90

Kube D, Hua TD, von Bonin F, Schoof N, Zeynalova S, Klöss M, Gocht D, Potthoff B, Tzvetkov M, Brockmöller $J$ et al. (2008): Effect of interleukin-10 gene polymorphisms on clinical outcome of patients with aggressive non-Hodgkin's lymphoma: an exploratory study. Clin Cancer Res 14(12), 3777-84

Kurreeman FA, Schonkeren JJ, Heijmans BT, Toes RE, Huizinga TW (2004): Transcription of the IL10 gene reveals allele-specific regulation at the mRNA level. Hum Mol Genet 13(16), $1755-62$

Kurtzhals JA, Adabayeri V, Goka BQ, Akanmori BD, Oliver-Commey JO, Nkrumah FK, Behr C, Hviid L (1998): Low plasma concentrations of interleukin 10 in severe malarial anaemia compared with cerebral and uncomplicated malaria. Lancet $\underline{351}(9118), 1768-72$

Lacki JK, Samborski W, Mackiewicz SH (1997): Interleukin-10 and interleukin-6 in lupus erythematosus and rheumatoid arthritis, correlations with acute phase proteins. Clin Rheumatol $\underline{16}(3), 275-8$

Lalani I, Bhol K, Ahmed AR (1997): Interleukin-10: biology, role in inflammation and autoimmunity. Ann Allergy Asthma Immunol 79(6), 469-83

Lech-Maranda E, Baseggio L, Bienvenu J, Charlot C, Berger F, Rigal D, Warzocha K, Coiffier B, Salles G (2004): Interleukin-10 gene promoter polymorphisms influence the clinical outcome of diffuse large B-cell lymphoma. Blood 103(9), 3529-34

Lech-Maranda E, Bienvenu J, Michallet AS, Houot R, Robak T, Coiffier B, Salles G (2006): Elevated IL-10 plasma levels correlate with poor prognosis in diffuse large B-cell lymphoma. Eur Cytokine Netw 17(1), 60-6

Lech-Maranda E, Bienvenu J, Broussais-Guillaumot F, Warzocha K, Michallet AS, Robak T, Coiffier B, Salles G (2010): Plasma TNF-alpha and IL-10 level-based prognostic model predicts outcome of patients with diffuse large B-Cell lymphoma in different risk groups defined by the International Prognostic Index. Arch Immunol Ther Exp $\underline{58(2), ~ 131-41 ~}$ 
Lin WW, Karin M (2007): A cytokine-mediated link between innate immunity, inflammation, and cancer. J Clin Invest 117(5), 1175-83

Mocellin S, Marincola FM, Young HA (2005): Interleukin-10 and the immune response against cancer: a counterpoint. J Leukoc Biol $\underline{78}(5), 1043-51$

Mörmann M, Rieth H, Hua TD, Assohou C, Roupelieva M, Hu SL, Kremsner PG, Luty AJ, Kube D (2004): Mosaics of gene variations in the Interleukin-10 gene promoter affect interleukin10 production depending on the stimulation used. Genes Immun $\underline{5}(4), 246-55$

Moore KW, O'Garra A, de Waal Malefyt R, Vieira P, Mosmann TR (1993): Interleukin-10. Annu Rev Immunol 11, 165-90

Moore KW, de Waal Malefyt R, Coffman RL, O'Garra A (2001): Interleukin-10 and the interleukin-10 receptor. Annu Rev Immunol 19, 683-765

Pfreundschuh M, Trümper L, Kloess M, Schmits R, Feller AC, Rudolph C, Reiser M, Hossfeld DK, Metzner B, Hasenclever D et al. (2004 a): Two-weekly or 3-weekly CHOP chemotherapy with or without etoposide for the treatment of young patients with goodprognosis (normal LDH) aggressive lymphomas: results of the NHL-B1 trial of the DSHNHL. Blood 104(3), 626-33

Pfreundschuh M, Trümper L, Kloess M, Schmits R, Feller AC, Rübe C, Rudolph C, Reiser M, Hossfeld DK, Eimermacher $\mathrm{H}$ et al. (2004 b): Two-weekly or 3-weekly CHOP chemotherapy with or without etoposide for the treatment of elderly patients with aggressive lymphomas: results of the NHL-B2 trial of the DSHNHL. Blood 104(3), 634-41

Preiß J, Dornoff W, Hagmann FG, Schmieder A: Taschenbuch Onkologie 2008/09. Interdisziplinäre Empfehlungen zur Therapie. 14. Auflage; W. Zuckschwerdt Verlag GmbH, Germering/München 2008

Reuss E, Fimmers R, Kruger A, Becker C, Rittner C, Höhler T (2002): Differential regulation of interleukin-10 production by genetic and environmental factors - a twin study. Genes Immun $\underline{3}(7), 407-13$

Rieth H, Mörmann M, Luty AJ, Assohou-Luty CA, Roupelieva M, Kremsner PG, Kube D (2004): A three base pair gene variation within the distal 5'-flanking region of the interleukin-10 (IL10) gene is related to the in vitro IL-10 production capacity of lipopolysaccharide-stimulated peripheral blood mononuclear cells. Eur Cytokine Netw 15(2), 153-8 
Tagore A, Gonsalkorale WM, Pravica V, Hajeer AH, McMahon R, Whorwell PJ, Sinnott PJ, Hutchinson IV (1999): Interleukin-10 (IL-10) genotypes in inflammatory bowel disease. Tissue Antigens $\underline{54}(4), 386-90$

Turner DM, Williams DM, Sankaran D, Lazarus M, Sinnott PJ, Hutchinson IV (1997): An investigation of polymorphism in the interleukin-10 gene promoter. Eur $\mathrm{J}$ Immunogenet $\underline{24}(1), 1-8$

van der Linden MW, Huizinga TW, Stoeken DJ, Sturk A, Westendorp RG (1998): Determination of tumour necrosis factor-alpha and interleukin-10 production in a whole blood stimulation system: assessment of laboratory error and individual variation. J Immunol Methods 218(12), 63-71

Westendorp RG, Langermans JA, Huizinga TW, Elouali AH, Verweij CL, Boomsma DI, Vandenbroucke JP (1997): Genetic influence on cytokine production and fatal meningococcal disease. Lancet $\underline{349}(9046), 170-3$

Internetquelle

http://www.ncbi.nlm.nih.gov/snp; Zugriff am 24.11.2015 


\section{Danksagung}

Herzlichen Dank an

- Prof. Dr. med. Lorenz Trümper für die Möglichkeit, in seiner Abteilung promovieren zu können.

- meinen Doktorvater Prof. Dr. rer. nat. Dieter Kube für die Betreuung dieser Dissertation.

- Dr. rer. nat. Christina Stadler für ihre Hilfsbereitschaft und Geduld bei jeder Fragestellung.

- Frederike von Bonin, Angela Lenz und Maike Schaffrinski für die Unterstützung bei einer Vielzahl von Versuchen.

- PD Dr. rer. nat. habil. Mladen Tzvetkov (Institut für Klinische Pharmakologie der Universitätsmedizin Göttingen) für die Bereitstellung der HapMap-LCLs.

- Dr. rer. med. Markus Kreuz (Institut für Medizinische Informatik, Statistik und Epidemiologie der Medizinischen Fakultät der Universität Leipzig) für die Berechnung der statistischen Überlebenszeitanalysen. 